University of Nebraska - Lincoln

DigitalCommons@University of Nebraska - Lincoln

Architectural Engineering -- Dissertations and

Student Research

Architectural Engineering and Construction,

Durham School of

8-2012

\title{
Effects of Short Noise Bursts on Human Performance and Perception
}

Christopher Ainley

University of Nebraska - Lincoln, cainley@unomaha.edu

Follow this and additional works at: https://digitalcommons.unl.edu/archengdiss

Part of the Architectural Engineering Commons

Ainley, Christopher, "Effects of Short Noise Bursts on Human Performance and Perception" (2012).

Architectural Engineering -- Dissertations and Student Research. 22.

https://digitalcommons.unl.edu/archengdiss/22

This Article is brought to you for free and open access by the Architectural Engineering and Construction, Durham School of at DigitalCommons@University of Nebraska - Lincoln. It has been accepted for inclusion in Architectural Engineering -- Dissertations and Student Research by an authorized administrator of DigitalCommons@University of Nebraska - Lincoln. 


\title{
EFFECTS OF SHORT NOISE BURSTS ON HUMAN PERFORMANCE AND PERCEPTION
}

\author{
by
}

\author{
Christopher A. Ainley
}

\begin{abstract}
A THESIS
Presented to the Faculty of

The Graduate College at the University of Nebraska

In Partial Fulfillment of Requirements

For the Degree of Master of Science

Major: Architectural Engineering

Under the Supervision of Professor Lily M. Wang

Lincoln, Nebraska
\end{abstract}

August, 2012 


\title{
EFFECTS OF SHORT NOISE BURSTS ON HUMAN \\ PERFORMANCE AND PERCEPTION
}

\author{
Christopher A. Ainley, M.S. \\ University of Nebraska, 2012
}

Adviser: Lily M. Wang

The goal of this research project is to better quantify human reactions to short bursts of noise, to complement research at NASA Langley Research Center on evaluating human response inside buildings to low-level sonic booms. The project involved exposing participants over 30minute sessions to a number of $250 \mathrm{~ms}$ broadband noise bursts of certain levels, presented in a controlled yet randomized fashion throughout the session, and gathering responses on human perception and performance on an arithmetic task dealing with short-term memory. While previous research has demonstrated effects of noise bursts of varying amplitudes on other types of tasks that study cognitive processing including attention and at louder levels on this arithmetic task (i.e. $100 \mathrm{~dB}$ peak), more information is needed to indicate at what level and to what degree such noise bursts may impact human performance and perception.

Twenty-seven test subjects were tested over multiple 30-minute test sessions, with four different levels of the noise bursts. The noise bursts ranged from peak A-weighted sound pressure levels ( $\left.\mathrm{L}_{\mathrm{Apk}}\right)$ of 47 to $77 \mathrm{dBA}$ presented over an ambient background noise level of 37 dB L $L_{\text {eq }}$ measured over 2 minutes, or RC-29 $(\mathrm{H})$.

Few significant relationships were found in relation to task performance, although there are still some general trends including an increase in incorrect answers for impulse-presented test 
questions as the noise burst level increases. Results show significant relationships, $\mathrm{p}<0.05$, between each noise condition and subjective perception qualities. All noise metrics studied were highly correlated with each other, $\mathrm{p}<0.01$, and therefore all correlated well with subjective perception. Based on subjective perception ratings, noise burst levels with $\mathrm{L}_{\mathrm{Apk}}$ around $67 \mathrm{dBA}$ and higher may not be considered acceptable in an otherwise ambient background noise level condition, in this case RC-29(H). 


\section{APPROVAL/SIGNATURE PAGE}

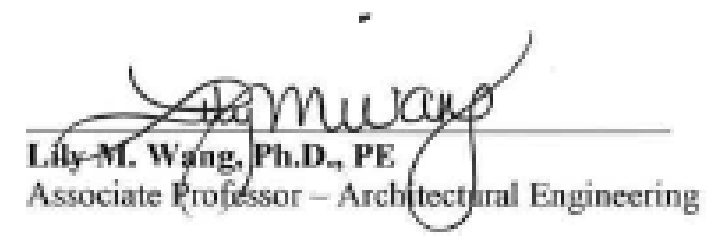

$$
\frac{4 \text { ov. 26, 2012 }}{\text { Date }}
$$

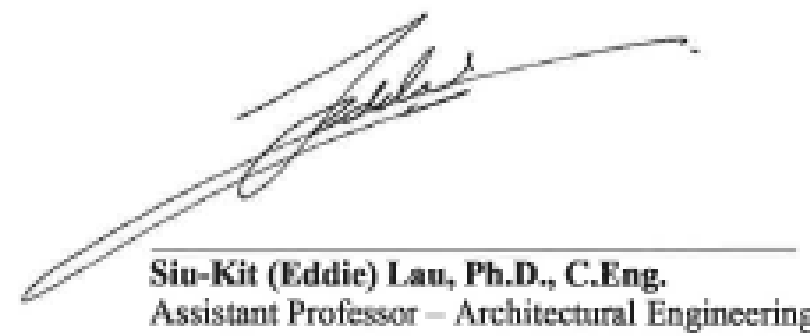

$$
\frac{\text { Ang } 13,2012}{\text { Date }}
$$

Assistant Professor - Architectural Engineering

$$
\frac{8-13-12}{\text { Date }}
$$

Steven From, Ph.D.

Professor - Matbematics 


\section{Acknowledgements}

This project has been a fantastic experience. I have greatly enjoyed the challenge and opportunity to work on a project such as this. I first must thank the NASA Nebraska Space Grant Consortium who funded this study. This work would not have been done without their assistance and for that I am grateful.

I am thankful for my friends both near and far for their continued support. I would not be who I am without my family who have shaped me into the man I am today. All of my fellow classmates here at the University of Nebraska have helped me to stay focused, keep my sanity, and get my mind off of work when necessary. In particular, I must thank my colleagues who had a hand in assisting with this research in one form or another. This includes Matt Blevins, Andrew Hathaway, John Lloyd, Ellen Peng, and Adam Steinbach. They all put in many hours with this study and I am extremely grateful for their help. I would not have been able to do this without everyone.

I also want to make sure and thank Paul Sim for his assistance with creating the JavaScript program used for the arithmetic test in this study. I especially thank him for being able to make quick changes and fixes when needed on the fly. I also want to thank Dr. Jonathan Rathsam from the NASA Langley Research Center for taking the time and effort to assist me with a number of questions.

I must also thank my advisory committee for their guidance through this process. Dr. SiuKit (Eddie) Lau and Dr. Steven From were both extremely helpful and welcoming during this process. Of course, I have to thank Dr. Lily Wang who was my advisor but was also a great teacher, listener, guidance counselor, and friend. This study would not be what it is without her and I must thank her immensely for all of the time she committed. 


\section{Table of Contents}

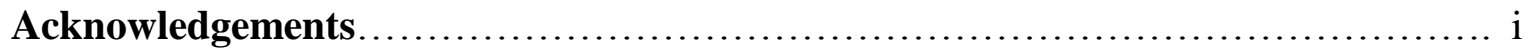

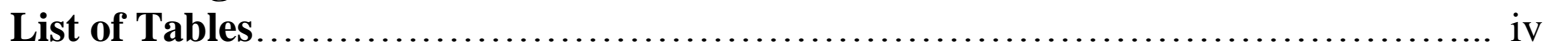

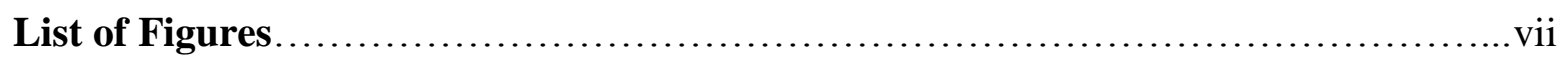

Chapter 1: Introduction..................................................... 1

1.1. Introduction to Work...................................................

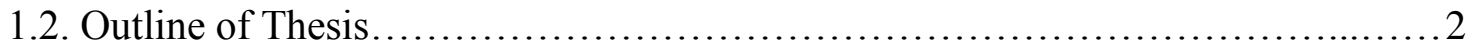

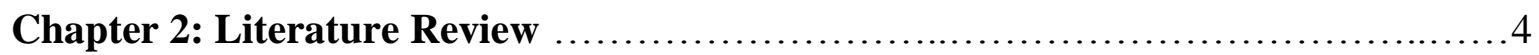

2.1 Types of Noise........................................................ 4

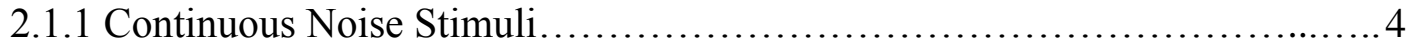

2.1.2 Low Frequency Noise Stimuli...................................... 5

2.1.3 Noise Burst Stimuli................................................6 6

2.1.4 Sonic Boom Stimuli.................................................. 9

2.2 Task Performance under Different Noise Conditions............................. 10

2.3 Subjective Perception under Different Noise Conditions....................... 14

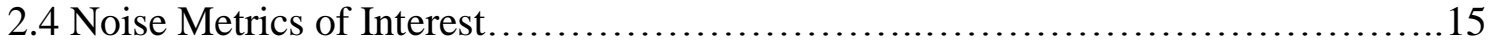

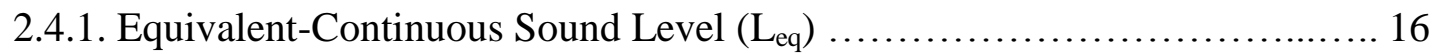

2.4.2. Sound Exposure Level (ASEL/CSEL) ................................... 16

2.4.3. Perceived Level (PL) ............................................. 17

2.4.4. Perceived Noise Level (PNL) ....................................... 19

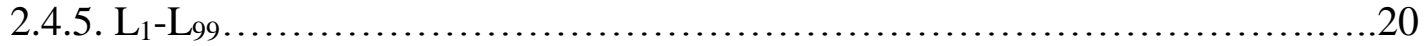

2.5 Incorporating Metrics for Sound Stimuli..................................... 20

2.6 Applications to This Research........................................... 22

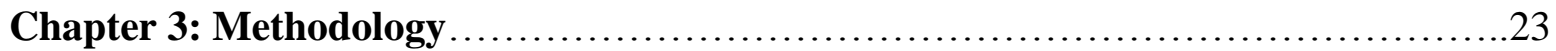

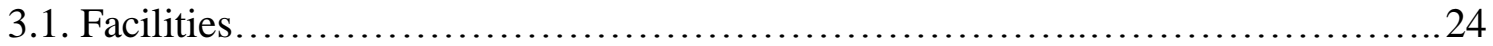

3.1.1. Nebraska Test Chamber.............................................. 24

3.1.2. Sound and Computer Systems ...................................... 27

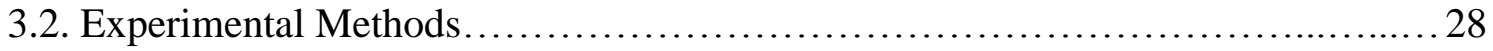

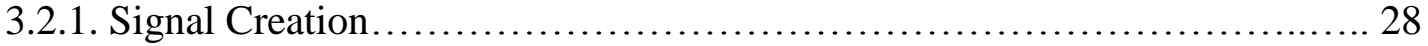

3.2.1.1. Impulse Sound Signals....................................... 28

3.2.1.2. Extended Noise Signals ........................................ 29

3.2.2. Signal Recordings and Measurements................................. 31

3.2.2.1. Signal Recordings.......................................... 32

3.2.2.2. Signal Measurements........................................ 33

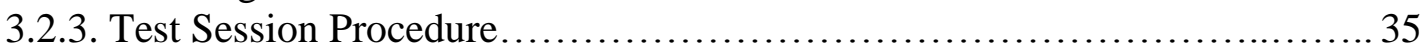

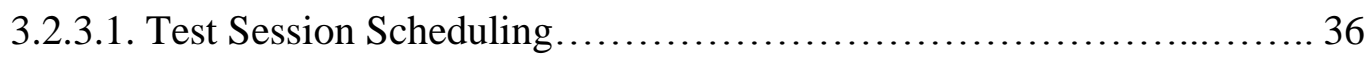

3.2.3.2. Test Session Design and Procedure............................... 37

3.2.3.3. Recruitment and Orientation Procedure.............................44 


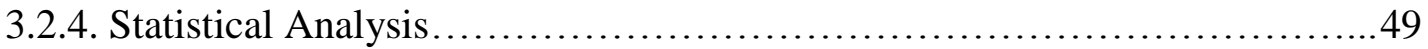

3.2.4.1. Standard Error of the Mean............................................ 49

3.2.4.2. Parametric Tests............................................... 50

3.2.4.3. Non-Parametric Tests........................................... 51

3.2.4.4. Statistical Power Analysis..........................................52

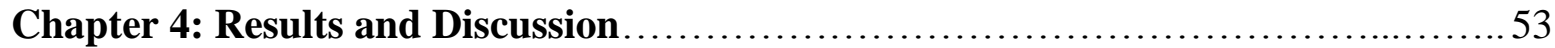

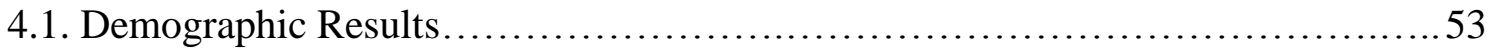

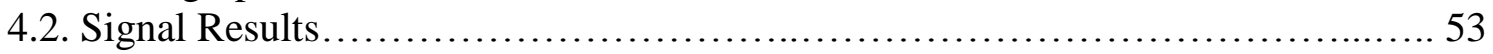

4.2.1. Background Noise Results............................................53

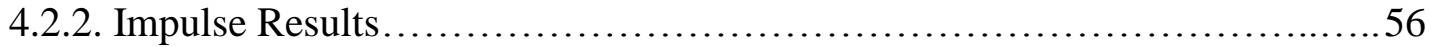

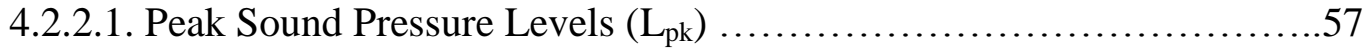

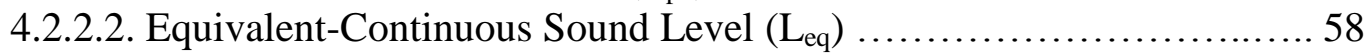

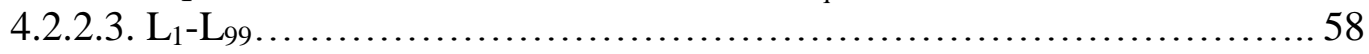

4.2.2.4. Sound Exposure Level (ASEL/CSEL) …...........................59

4.2.2.5. Perceived Level (PL) ............................................. 61

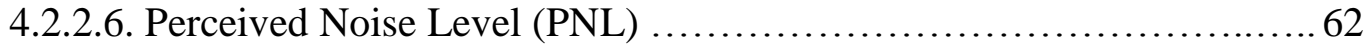

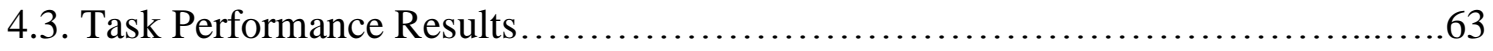

4.3.1. Task Performance Results across Noise Conditions.........................64

4.3.2. Task Performance Results across Presented Test Order ......................64

4.3.3. Comparison of Test Questions Linked to Impulses to the Same Test

Questions Presented Without Impulses............................................. 68

4.3.4. Relationships of Task Performance Results to Noise Metrics..................72

4.3.5. Comparisons of Task Performance to Subjective Perception..................72

4.4. Subjective Perception Results................................................ 74

4.4.1. Subjective Perception Results across Noise Conditions........................74

4.4.1.1. Loudness of Noise across Noise Conditions.............................74

4.4.1.2. Change in Noise over Time across Noise Conditions..................... 76

4.4.1.3. Rumble of Noise across Noise Conditions............................ 78

4.4.1.4. Annoyance to Noise across Noise Conditions......................... 81

4.4.1.5. Distraction to Noise across Noise Conditions.......................... 83

4.4.1.6. Discussion of Subjective Perception Results across Noise

Conditions. 85

4.4.2. Relationships of Subjective Perception Results to Noise Metrics............... 86

4.4.3. Relationships of Subjective Perception Results across Noise Conditions with Gender, Age, and Noise Sensitivity as Covariates................................. 87

Chapter 5: Conclusions............................................................... 92

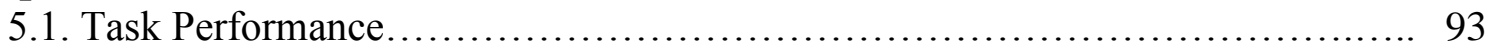

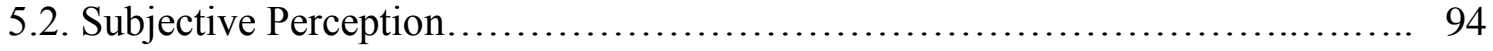

5.3. Noise Metrics .............................................................. 95

5.4. Future Research...................................................... 96

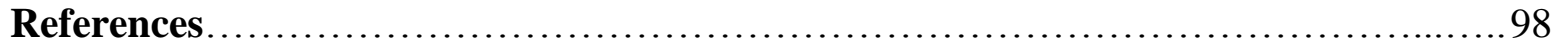

Appendix A: Additional Statistical Analyses Results................................ 104 


\section{List of Tables}

\section{Chapter 4}

Table 4.1 - Results of the Bonferroni post hoc test for overall percentage of correct answers for test questions in each test session in order as seen by each subject.

Table 4.2 - Results of the Bonferroni post hoc test for average time taken for test questions in each test session in order as seen by each subject.

Table 4.3 - The linear mixed model F values, Pearson

correlation coefficients, and Spearman correlation coefficients between subjective perception of noise and performance of the task. The only significant relationships occur between perception of changes in noise over time and the average time taken for each problem in a given session, $\mathrm{p}<0.05$

Table 4.4 - Wilcoxon Results between Noise Condition and Loudness of Noise. A Bonferroni correction was applied and all effects denoted with $* *$ are significant at a 0.005 level of significance.

Table 4.5 - Bonferroni Post Hoc Tests for Loudness of Noise Ratings across

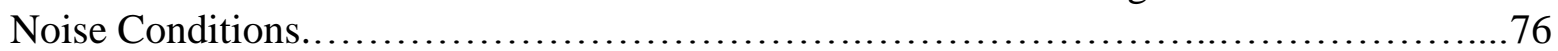

Table 4.6 - Wilcoxon Results between Noise Condition and Change of Noise over Time. A Bonferroni correction was applied and all effects denoted with ** are significant at a 0.005 level of significance.

Table 4.7 - Bonferroni Post Hoc Tests for Changes in Noise over Time Ratings across Noise Conditions. .78

Table 4.8 - Wilcoxon Results between Noise Condition and Rumble of Noise. A Bonferroni correction was applied and all effects denoted with $* *$ are significant at a 0.005 level of significance.

Table 4.9 - Bonferroni Post Hoc Tests for Rumble of Noise Ratings across

Noise Conditions

Table 4.10 - Wilcoxon Results between Noise Condition and Annoyance to Noise. A Bonferroni correction was applied and all effects denoted with $* *$ are significant at a 0.005 level of significance.

Table 4.11 - Bonferroni Post Hoc Tests for Annoyance to Noise Ratings across Noise Conditions

Table 4.12 - Wilcoxon Results between Noise Condition and Distraction to Noise. A Bonferroni correction was applied and all effects denoted with $* *$ are significant at a 0.005 level of significance. 
Table 4.13 - Bonferroni Post Hoc Tests for Distraction to Noise Ratings across Noise Conditions.

Table 4.14 - Analysis of variance for loudness to noise ratings across noise conditions with each combination of gender, age, and noise sensitivity as covariates. All results assume for sphericity except when stated otherwise

Table 4.15 - Analysis of variance for change in noise over time ratings across noise conditions with each combination of gender, age, and noise sensitivity as covariates. All results assume for sphericity except when stated otherwise.

Table 4.16 - Analysis of variance for rumble of noise ratings across noise conditions with each combination of gender, age, and noise sensitivity as covariates. All results assume for sphericity....

Table 4.17 - Analysis of variance for annoyance to noise ratings across noise conditions with each combination of gender, age, and noise sensitivity as covariates. All results assume for sphericity

Table 4.18 - Analysis of variance for distraction to noise ratings across noise conditions with each combination of gender, age, and noise sensitivity as covariates. All results assume for sphericity.

\section{Appendix A}

Table A.1 - Results of repeated measures ANOVA from SPSS analyzing task performance across noise conditions.

Table A.2 - Results of repeated measures ANOVA from SPSS analyzing task performance across test session order.

Table A.3 - Results of Pearson Product Correlation Coefficient, Spearman Coefficient, and a linear mixed model analysis for relations of subjective perception ratings to total peak sound pressure level (Lpk). All results denoted with $* *$ are significant at $\mathrm{p}<0.01$

Table A.4 - Results of Pearson Product Correlation Coefficient, Spearman Coefficient, and a linear mixed model analysis for relations of subjective perception ratings to equivalent-continuous sound level $\left(\mathrm{L}_{\mathrm{eq}}\right)$. All results denoted with $* *$ are significant at $\mathrm{p}<0.01$

Table A.5 - Results of Pearson Product Correlation Coefficient, Spearman Coefficient, and a linear mixed model analysis for relations of subjective perception ratings to $\mathrm{L}_{1}-\mathrm{L}_{99}$. All results denoted with $* *$ are significant at $\mathrm{p}<0.01$

Table A.6 - Results of Pearson Product Correlation Coefficient, Spearman Coefficient, 
and a linear mixed model analysis for relations of subjective perception ratings to A-weighted sound exposure level (ASEL). All results denoted with ** are significant at $\mathrm{p}<0.01$

Table A.7 - Results of Pearson Product Correlation Coefficient, Spearman Coefficient, and a linear mixed model analysis for relations of subjective perception ratings to $\mathrm{C}$-weighted sound exposure level (CSEL). All results denoted with ** are significant at $\mathrm{p}<0.01$

Table A.8 - Results of Pearson Product Correlation Coefficient, Spearman Coefficient, and a linear mixed model analysis for relations of subjective perception ratings to perceived level (PL). All results denoted with $* *$ are significant at $\mathrm{p}<0.01$

Table A.9 - Results of Pearson Product Correlation Coefficient, Spearman Coefficient, and a linear mixed model analysis for relations of subjective perception ratings to perceived noise level (PNL). All results denoted with $* *$ are significant at $\mathrm{p}<0.0$ 


\section{List of Figures}

\section{Chapter 3}

Figure 3.1 - The layout of the test chambers showing locations of the subject, test equipment, and loudspeakers used in this study (not to scale). Room height is 8 '....

Figure 3.2 - A picture from the interior of the test room............................ 26

Figure 3.3 - A diagram of the Nebraska Test Chamber system showing both the testing

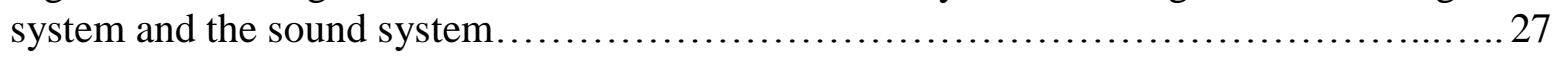

Figure 3.4 - Screenshot of envelope applied using CoolEdit to RC-47(RV) .wav files....... 31

Figure 3.5 - A diagram of the Nebraska Test Chamber system showing the equipment used for recording test signals in the test room.....................................

Figure 3.6 - A list of settings used for measurement of signals with a Larson-Davis 824 SLM.

Figure 3.7 - Screenshot from practice portion of arithmetic test program (a) displaying the first number, (b) displaying the second number, and (c) after answer submission with feedback......

Figure 3.8 - The order of test questions linked to bursts where X's represent the test questions linked with an impulse for each respective session and blank cells represent randomized non-impulse-presented questions. Dotted lines represent subsections used to spread out test questions.

Figure 3.9 - Order of impulse-presented questions and their corresponding control questions where bold capital letters represent the test questions linked with an impulse the corresponding capital letters represent those same test questions presented again without an impulse. Blank cells represent randomized non-impulse-presented questions. Dotted lines represent subsections used to spread out test questions.

Figure 3.10 - A copy of the subjective questionnaire that participants completed at the conclusion of each test session.

Figure 3.11 - A copy of the noise sensitivity questionnaire that participants completed at the conclusion of their final test session.

Figure 3.12 - A copy of the recruitment flyer that was posted on the campus of the University of Nebraska. 


\section{Chapter 4}

Figure 4.1 - Results of noise sensitivity questionnaires. Error bars represent the standard error of the mean........................................................... 54

Figure 4.2 - Measurement of Leq across frequency in test room. Results yield

Figure 4.3 - Measurement of Leq across frequency of the ambient BNL .wav when played back in test room. Results yield an overall SPL of $37 \mathrm{dBA}$ and an RC-29(H).......55

Figure 4.4 - Measurement of Leq across frequency of the louder ambient BNL .wav when played back in test room. Results yield an RC-47 (RV).

Figure 4.5 - Spectra of total peak sound pressure levels (Lpk) for the four impulse signals. Results yield overall peak SPL of $64,74,84$, and $100 \mathrm{~dB}$ respectively

Figure 4.6 - Overall Leq across each time interval of analysis for each impulse signal and the lower ambient BNL.................................................... 58

Figure 4.7 - L1-L99 across each time interval of analysis for each impulse signal and the lower ambient BNL

Figure 4.8 - ASEL across each time interval of analysis for each impulse signal and the lower ambient BNL

Figure 4.9 - CSEL across each time interval of analysis for each impulse signal and the lower ambient BNL

Figure 4.10 - PL across each time interval of analysis for each impulse signal and the lower ambient BNL

Figure 4.11 - PNL across each time interval of analysis for each impulse signal and the lower ambient BNL

Figure 4.12 - Overall percentage of correct answers for each test session. Error bars represent the standard error of the mean

Figure 4.13 - Average time taken in seconds for test questions in each test session averaged across all test sessions. Error bars represent the standard error of the mean

Figure 4.14 - The overall percentage of correct answers for each test session in order as seen by each subject. Error bars represent the standard error of the mean 
Figure 4.15 - The average time taken in seconds for test questions in each test session in order as seen by each subject. Error bars represent the standard error of the mean......... 67

Figure 4.16 - Number Average number of noise bursts presented to each subject for each test session. Error bars represent the standard error of the mean..........................69

Figure 4.17 - Results of the overall percentage of correct answers for questions linked to respective impulses and again for those same questions when presented without an impulse. Error bars represent the standard error of the mean........................... 70

Figure 4.18 - Results of the average time taken in seconds for questions linked to respective impulses and again for those same questions when presented without an impulse. Error bars represent the standard error of the mean

Figure 4.19 - Results of the perception ratings of changes in noise and the corresponding average time taken to solve task problems in a given session. Error bars represent the standard error of the mean. Numbers represent the sample size for each response..........73

Figure 4.20 - Results of the average perception ratings of loudness of noise across each noise condition. Error bars represent the standard error of the mean..................... 75

Figure 4.21 - Results of the average perception ratings of changes in noise over time across each noise condition. Error bars represent the standard error of the mean...........77

Figure 4.22 - Results of the average perception ratings of rumble of noise across each noise condition. Error bars represent the standard error of the mean..................... 79

Figure 4.23 -

Results of the average perception ratings of annoyance to noise across each noise condition. Error bars represent the standard error of the mean

Figure 4.24 -

Results of the average perception ratings of distraction to noise across each noise condition. Error bars represent the standard error of the mean

Figure 4.25 - Results of the average perception ratings of annoyance to noise across each noise condition with gender splits. Error bars represent the standard error of the mean......90 


\section{Chapter 1: Introduction}

\subsection{Introduction to Work}

There has been recent work in the design of aircraft that produces a low level sonic boom with the hope that these aircraft may one day be used for flight over land. NASA is interested in further studying what effect these low level sonic booms may have on humans on ground, particularly indoors. These booms are impulsive in nature and random in terms of timing. Recent research has grown regarding these effects of low level sonic booms on the ground and for the noise metrics used to measure these booms (Sullivan et al. 2010, Marshall and Davies 2010, Marshall and Davies 2011, Rathsam et al. 2012). Much work is still needed to fully explore and understand these relationships and their effect on human performance and perception.

Human performance has been analyzed in a number of different ways and under other types of noise conditions. Among the tasks that have been developed in previous work is an arithmetic task that involves memorization for an appropriate performance task under different noise conditions (Broadbent 1958). A task such as this is interesting for current research because it has been found that loud bursts of noise can impact performance of this test (Woodhead 1964).

While previous studies have analyzed the effects of different types of noise bursts on some combination of human performance and perception, there are still some areas that have yet to be fully analyzed. For instance, varying levels of short noise burst stimuli could be studied with relationship to the arithmetic task previously mentioned while using a lower range of noise burst levels than before. The benefit of this is to help determine the general sound pressure level at which the noise burst level compared to the ambient background noise becomes significantly different to a condition with the same ambient background noise level where no noise bursts are present. 
The goal of this research project is to better quantify human reactions in the form of human performance and perception to short bursts of broadband noise. Human performance was gauged by analyzing the total percentage of correct answers and average time taken for each problem in the arithmetic task. Human perception was gauged through subjective questionnaires that cover many common qualities of noise, including loudness and annoyance. This research studied the relationships of the varying noise bursts and human performance and perception as gathered via the arithmetic test and subjective questionnaires. The main questions involved are determining if there is a general level of noise bursts where there is a significant detriment in performance or significant difference in ratings of subjective perception, suggesting levels of acceptability for short noise bursts.

While this study does not directly implement sonic booms as sound stimuli, the experimental sound stimuli are still analyzed with noise metrics that are commonly associated with sonic boom analysis, such as sound exposure level and perceived level. In addition, all noise metrics are analyzed across a range of time intervals to study that parameter's significance on the resulting noise metric values.

\subsection{Outline of Thesis}

This study analyzes the effect of short noise bursts on human performance and perception. Subjects completed arithmetic tests and subjective questionnaires while exposed to varying levels of short noise bursts. Results from the arithmetic test and the subjective questionnaires are analyzed to help understand the effects of the noise conditions on human performance and perception, respectively. The short noise bursts and background noise are also analyzed using a number of noise metrics for comparison. Chapter 2 discusses previous research pertinent to this study and explains how this study was developed. Chapter 3 presents the 
methodology including the creation of the sound signals and test sessions, and the statistical analyses used in this study. Chapter 4 presents and discusses all results. Chapter 5 provides summaries of results and ideas for future work. 


\section{Chapter 2: Literature Review}

This chapter discusses previous research that led to the motivation for and application of this research. Previous research is separated into subsections involving (1) types of noise stimuli, (2) performance tasks, (3) subjective perception, (4) noise metrics, and (5) incorporating noise metrics for sound stimuli. Finally the application of the previous studies to this investigation will be discussed.

\subsection{Types of Noise}

Researchers have been trying to better understand the impact of noise on humans throughout the years, both in terms of performance and perception. What is known is that the results depend greatly on the type of noise and the type of task, as the noise stimuli can trigger facilitation or disruption, depending on the demands of the task in regards to attention as well as the relationship between the noise stimuli and the task (San Miguel et al. 2010).

\subsubsection{Continuous Noise Stimuli}

Some early research found that constant noise above and around $90 \mathrm{~dB}$ may be detrimental to specific tasks (Broadbent 1957). Broadbent studied the effect of both low and high frequency noise on a serial reaction task in which subjects touched one of five brass discs with a stylus when a corresponding light above each disc was lit. Subjects performed this task for two 25 minute sessions separated by 24 hours, once in low frequency noise and once in high frequency noise. Broadbent used recorded machinery noise as the low frequency noise and then filtered the same noise stimuli to create a high frequency noise. The noise was played back constantly throughout each session at intensity levels of 80,90 , or $100 \mathrm{~dB}$ for high frequency noise, where each level was $3 \mathrm{~dB}$ higher than the corresponding low frequency noises. Each 
subject was assigned to a respective group that corresponded to an intensity level. He found significant detriment in performance in the form of errors for the machine noise at $100 \mathrm{~dB}$.

Broadbent later studied the effect of noise on an intellectual task in the form of an arithmetic task (1958). Subjects experienced constant broadband noise of either $70 \mathrm{~dB}$ or $100 \mathrm{~dB}$ for the first and/or second arithmetic session, without knowing the environment for either day beforehand. Broadbent's results found that noise had a detrimental effect not only on the day it was presented, but also on the day after it was presented even if no noise was present on the second day.

Other work used the Norinder arithmetic task under continuous white noise of varying intensities of 56, 72.5, and $85 \mathrm{dBA}$ (Frankenhaeuser and Lundberg 1977). Their work found a detriment in performance as the noise level increased. Subjects participated in multiple sessions. Even though all subjects experienced the same noise level in the second session, performance significantly decreased for those who had louder previous sessions, which was consistent with Broadbent's previous study. They concluded that the results from the second session resulted from the cognitive set that was used to complete the first session.

\subsubsection{Low Frequency Noise Stimuli}

Some work has focused on the effect of low frequency noise specifically. Persson Waye et al. studied the effect of low frequency noise in work environments and found it to be a factor in annoyance and the quality of work performance for workers (2001). They also discussed noise sensitivity as being a factor. Subjects with a self-described sensitivity to low-frequency noise rated the noise more annoying and had lower performance.

Moorhouse et al. also studied low frequency noise and applied that work to fluctuations in low frequency noise (2007). They generally found that acceptable levels for constant low 
frequency noise that was not fluctuating were on average $5 \mathrm{~dB}$ lower than for the same low frequency noise that was fluctuating. Fluctuations were defined as when the difference between $\mathrm{L}_{10}$ and $\mathrm{L}_{90}$ is greater than $5 \mathrm{~dB}$ and when the rate of change for the rms fast sound pressure level is greater than $10 \mathrm{~dB}$ per second. Dittrich and Oberfeld additionally discussed level fluctuations and found that the first 100-300 ms of a level-fluctuating sound had the most impact on annoyance compared to the rest of the signal, demonstrating a primacy effect (2009).

\subsubsection{Noise Burst Stimuli}

Not all work on understanding impact of noise on humans involved constant noise. Much research focused on the effect of intermittent noise such as bursts of noise. Some research adapted previous performance tasks under constant noise environments and applied them to studies involving bursts of noise. Woodhead twice studied effects of noise bursts on a continuous visual task based on the Mackworth multichannel task, which involved male subjects matching cards with unique symbols as cards rotated in and out of view $(1958,1959)$.

Her first study incorporating this task used bursts of noise that were tape recordings of an explosive sound of about 4 seconds and peak intensity of $100 \mathrm{~dB}$ when played back (1958). The bursts were described to have an initial frequency spectrum centered around $300 \mathrm{~Hz}$ and then centered around $2000 \mathrm{~Hz}$ one second into the burst. The bursts of noise were played irregularly over four times in each session, while each session lasted for four minutes. Subjects were presented the noise ahead of time to prevent startle and may have been given warning before the burst via a warning light 3 seconds before the burst.

Woodhead found that the burst of noise caused an immediate detriment to the continuous visual task and that the effect lasted 30 seconds after the burst. The detriment held true even 
when subjects were aware that a burst would take place in the test. The warning light did not prevent any detriment in performance, and may have caused more distraction from the task.

In a second study by Woodhead involving the Mackworth multichannel task, the intensity of the burst of noise was varied to find any change in performance (1959). Noise bursts were varied to peak readings of 85,95 , and $115 \mathrm{~dB}$ and were varied across sessions using a Latin square design. Subjects were made aware that they may hear zero, one, or two noise bursts in a given session.

Woodhead again found detriment in the first 30 seconds after the bursts; however the effect did not have a significant impact over the entire session. Some detriment in performance appeared in all three levels of noise burst intensity, but was most significant in the 95 and $115 \mathrm{~dB}$ bursts of noise. Woodhead stated that these results corresponded with previous research that found detriment in tasks with noise presented above $90 \mathrm{~dB}$. Woodhead concluded that it appeared that noise at $90 \mathrm{~dB}$ was a critical level.

Another factor that must be discussed when addressing noise stimuli, especially when the noise is intermittent, is the background noise that is compared to the noise stimuli. Some research has found a great disturbance for a larger change in either increase or decrease of noise level (Teichner et al. 1963). For this reason, the noise level when no bursts of noise are present may be just as important of the analysis of the bursts of noise.

It might appear that most bursts of noise would always be detrimental to a given task. However some research found that to be the opposite, depending on the intensity and content of the noise burst as well as the task involved. Berlyne et al. found subjects retaining items in a paired-associate learning test where $75 \mathrm{~dB}$ bursts of white noise were presented (1966). Even with this noise burst present, items were remembered over an interval leading to a conclusion 
that the bursts of noise caused arousal in subjects. This is to say that subject's performance increased with the presence of noise. This matched results of other tests involving arousal outside of acoustics, including Walker and Tarte (1963), and Weiner and Walker (1966). The results for certain tasks change when the bursts of noise increase in intensity.

Another study found that a one second recorded rocket blast of $100 \mathrm{~dB}$ peak intensity caused detriment to an arithmetic task when presented during a time of memorization (Woodhead 1964). However when the burst arrived during a calculation time, there appeared to be no perceptual completion with the visual learning. In fact, the burst of noise may have been an arouser as the speed of calculation time increased without a detrimental effect to the correct answers.

Woodhead then compared her results to Broadbent's sensory input model where visual information was possibly temporally rejected when the burst arrived during the observation time which caused errors. Woodhead concluded that her results regarding change in speed of work with relation to noise differed from Broadbent's due to the type of noise presented in each study, where Broadbent used a stationary noise stimulus as opposed to the noise bursts.

This research is limited, however, because it only involves one type of sound stimulus at one intensity level. It would be interesting to apply varying levels of sound stimuli to a test such as this to see if there is any effect for noise bursts less than $100 \mathrm{~dB}$, particularly since the levels of low-level sonic booms indoors is expected to be lower than this.

Later research discussed the effect of different types of noise under a single setting and found that when the type of noise changed, such as a change in center frequency for a broadband noise burst, there was a greater detriment in a short-term memory task compared to no change in the type of broadband noise burst (Tremblay et al. 2001). 


\subsubsection{Sonic Boom Stimuli}

More recently, researchers have been studying the effects of sonic booms as noise burst stimuli on performance. Thackray discussed the effects of sonic booms in terms of the startle reflex and orienting response (1972).

The startle reflex is a muscular response that leads to involuntary contractions throughout the body, usually beginning at the head and working its way down. These can lead to an increase in activity in the central nervous system. Although habituation can take place for repeated stimulation, the eye blink usually takes place regardless. The disruptive nature of the involuntary muscular response from a startle reflex tends to impair performance.

He later discussed that the orienting response usually leads to the head or body turning toward the source to facilitate sensory intake. Ongoing activity is typically halted temporally, receptor sensitivity is increased, and there may be some autonomic changes. For orienting response, the brief shift of the eyes or head may cause a temporary disruption but it can also be a source of arousal and in some cases may assist performance.

Thackray, along with Touchstone and Bailey, later applied this knowledge to a studying comparing the startle effects resulting from simulated booms of $105 \mathrm{~dB}(74 \mathrm{dBA})$ and $111 \mathrm{~dB}$ (83 dBA) measured indoors (1974). Arm-hand startle responses were gathered from male subjects and were significantly greater for the louder boom level. They discussed the possible detrimental effect that these loud booms could have on an occupational task involving arm-hand coordination and steadiness. However they caution that the startle reactions could be much greater in non-laboratory settings.

Thackray et al. later expanded their work to study the effect of startle on male subjects from simulated booms of 74, 71, and $65 \mathrm{dBA}$ measured indoors to try and determine if there was 
a level where startle would not take place (1975). In both of the two higher levels of booms, about $20 \%$ of the subjects exhibited a startle reflex for each level. For the lowest level, none of the subjects exhibited a startle reflex and about $10 \%$ experienced an eye blink during the boom. They discussed that boom levels need to be lower than $71 \mathrm{dBA}$ measured inside (overpressures measured at $30 \mathrm{~N} / \mathrm{m}^{2}$ ) to avoid a measurable startle response. Across all levels, around 60-70\% of all subjects felt they would have adapted to the booms at these intensities over time.

In regards to boom research, work by Johnson and Robinson (1967) and Miller (2011) have also reported on the different subjective judgments comparing indoor and outdoor exposure, while still in at least quasi-laboratory settings. Subjects typically rate indoor exposure to booms more harshly. It is believed that this is due to expectations one may have when inside an enclosed room or building as opposed to the expectations outside.

\subsection{Task Performance under Different Noise Conditions}

The type of performance task used in a study is very important. For a study involving bursts of noise, a task must be selected that could possibly be affected and measured in a way that is beneficial to the study. One task like this that has been used and altered over the years is an arithmetic task that involves memorization.

Broadbent developed an arithmetic task that incorporated memorization for a performance task under different noise conditions (1958). At the time, Broadbent was interested in applying a more complex task than the simpler ones used in previous research. He also wanted to confirm a theory from previous research that suggested there may be an aftereffect from noise that may affect performance in quiet afterward.

He developed an arithmetic task to involve memorization and problem solving skills. Eighteen male subjects were presented with a six-digit number. After they felt they had 
adequately memorized the number, they pressed a button and the six-digit number disappeared. Immediately, a four-digit number was presented. The subject was then asked to provide the difference between the two numbers. This process was repeated for 30 problems in each session for two straight days after a day of practice. Time was recorded for each step: observation time for the first number and calculation time.

As previously mentioned, Broadbent found that noise had a detrimental effect on both days of testing even if no noise was present on the second day. Broadbent theorized that his results may be due to the limited sensory channels being used by a subject's attention among other things. He further suggested that if attention for a certain task was interrupted, it may be interrupted again even without the presence of noise. Additionally, Broadbent discussed that the arithmetic task required the skill to split between the memorization and calculation portions of the task.

Woodhead later studied the effects of bursts of noise when subjects performed an arithmetic task similar to Broadbent's arithmetic task (1964). Woodhead updated the task by only allowing the male subjects 10 seconds to memorize the first number before calculating the difference from memory until they could answer. This time interval was based on the average results from Broadbent's research.

The bursts were presented either 4 seconds into the observation time for the first number or 5 seconds into the calculation time. If the burst arrived during the observation time, there was a reduction in accuracy compared to a noiseless session. If the burst arrived during the calculation time, there was no change in overall accuracy. There was also a trend showing improvement in performance of the speed of work without an effect on variability of speed or accuracy, for problems with a noise burst compared to problems without the sound burst. As 
mentioned previously, it would be interesting to apply varying levels of sound stimuli to a test such as this to see if there is any effect for noise bursts less than $100 \mathrm{~dB}$.

Frankenhaeuser and Lundberg had male subjects perform a different arithmetic task developed by Norinder under continuous white noise of varying intensities (1977). This arithmetic task involved addition and subtraction, depending on the instructions, for a series of paired one digit numbers for two 75-minute sessions. The first session involved experiencing continuous white noise of either of $56,72.5$, or $85 \mathrm{dBA}$. The second session for all subjects involved experiencing continuous white noise of $72.5 \mathrm{dBA}$. Subjects gave subjective feedback regarding concentration and discomfort every 25 minutes in each session and heart rates were monitored.

They found significant decrease in performance for each increase in noise level but not in the change of speed for subjects, although the trend matched previous data that found the speed of performance to increase over time. They also found significant improvement in performance from the results between the first and second session, regardless if the noise increased or decreased between sessions, displaying an effect of practice.

Past research has studied effects of different variables on a version of an arithmetic task. Tafalla and Evans studied the role of effort on the Norinder arithmetic task under ambient noise of $45 \mathrm{dBA}$ while random 3-5 second bursts of intermittent background noise were played, separated by $0.25-1 \mathrm{~min}$, peaking at $90 \mathrm{dBA}$, and comprised of different sources such as superimposed traffic, office machinery, and unintelligible speech (1997). They found noise had a significantly detrimental effect on reaction time only when effort was low. They also found some psychophysiological indexes of stress, such as heart rate, norepinephrine, and cortisol, increase with noise only when effort was high. 
Belojevic et al. also incorporated a version of the arithmetic task to study the role of introversion and found that extroverts showed better mental performance in the form of speed (2001).

Many of the older studies listed involved only male subjects and do not take into account a number of other factors that may impact performance. Baker and Holding discussed a number of variables impacting cognitive task performance under noise conditions (1993). These factors include gender and time of day, which may have an effect on performance depending on the task and noise environment. It is important for current studies to at least consider and analyze these variables when testing.

The arithmetic task is a performance task of interest because it involves components of a digit span task involving memory and simple mathematics involving reasoning. In the past the task has generally been expressed in terms of short term and working memory. More detailed work regarding short term and working memory has been discussed by Baddeley (1997).

Baddeley and Hitch studied subjects concurrently performing a digit span task, which involves memorization, with a range of tasks involving learning, reasoning, and comprehending. There was no emphasis on noise for this study. Reasoning time increased with number of digits memorized, or an increase in concurrent memory load. This did not hold true for accuracy which, if anything, performed better with an increase in memorized digits. These results mean that one could not assume that working memory is simply a single unitary store with a limited capacity.

They concluded that it might be wise to not assume a unitary short-term storage. Rather, the limits created by a task such as a digit span task are merely one of a number of subsystems that may leave other components of working memory open. Therefore although performance 
tasks such as the arithmetic task can provide an adequate study involving components of working memory, it is important to not speak in absolute terms regarding the limits of working memory.

\subsection{Subjective Perception under Different Noise Conditions}

Annoyance is a key subjective factor for many people with regards to noise although there can be difficultly in evaluating annoyance in noise (Zimmer et al. 2008). Zimmer asked subjects to rate annoyance for a sound stimulus multiple times in a session. For more highly disruptive sound stimuli, such as speech, the ratings of annoyance differed depending on when the ratings were collected. There was no variation in annoyance ratings for sound stimuli that were less disruptive, such as an intermittent FM tone. They also found that as exposure time increased, so did reported annoyance. They concluded that based on their results annoyance may be more influenced by disruption to the task rather than purely a property to the noise stimuli.

Lim et al. also discussed the factor of background noise on annoyance in communities from aircraft noise (2008). They found that even for equal noise level, the annoyance was rated higher for the areas with a lower background noise level. This makes it essential to report background noise levels for research involving intermittent noise. Still, there are relevant cases where researchers study the effect of performance and perception under continuous noise stimuli.

Annoyance has also been a main interest for studies involving subjective perception to sonic booms (Sullivan et al. 2010, Rathsam et al. 2012). Although annoyance is a main concern for intermittent noise such as noise bursts, there are more subjective qualities used to describe noise. Other researchers asked about other qualities of subjective perception to noise, such as loudness, rumble, and distraction (Wang and Novak 2010). Other studies involving sonic booms have also asked for loudness and startle ratings (Marshall and Davies 2010, Marshall and Davies 2011). 


\subsection{Noise Metrics of Interest}

Recently there has been research studying a number of different metrics and their relationships with certain types of sound stimuli, especially sonic booms, applied to the results of human perception. Some of these metrics include, but are not limited to A-weighted and Cweighted sound exposure level (ASEL/CSEL), perceived level (PL), perceived noise level (PNL), and $\mathrm{L}_{1}-\mathrm{L}_{99}$. A brief background and description of the calculation methodology for each metric studied in this thesis is presented in this section.

There is a critical time that is required for a human auditory system to fully respond to a sudden noise stimulus. For a continuous noise source longer than this critical time, there is no greater sensation of loudness for the duration of the signal unless the intensity increases. For a stimulus that is shorter than this critical time, subjective magnitude depends on both intensity and duration of stimulus. This critical time is defined as an auditory time constant and has been suggested to be $70 \mathrm{~ms}$. This means all 1/3 octave band data are divided by the same auditory time constant to be effective for loudness calculations (Johnson and Robinson 1969).

Current research uses this methodology for calculations of PL and PNL for sonic booms. Although they may work with booms with durations of $200-400 \mathrm{~ms}$, it is assumed that the two overpressures of the $\mathrm{N}$-wave are the points of interest and are collectively less than the critical time. Sound pressure levels are reduced by $3 \mathrm{~dB}$ since the original data includes the entire waveform. This correction assumes both overpressures to be equally loud (Shepherd and Sullivan 1991).

This research will not be analyzing sonic booms in practice and therefore these exact corrections will not be used for the purposes of this study. However, an auditory time constant of an appropriate length is needed to correct the $1 / 3$ octave band data used for analysis of PL and 
PNL. $70 \mathrm{~ms}$ is not adequate because the noise bursts are longer than that critical time. Therefore a constant longer in length of the stimulus is needed. Based on the results from the noise stimuli used in this study, a constant of $1 \mathrm{sec}$ is selected as an adequate time constant. This value is merely a suggested value based on the length of the stimulus.

\subsubsection{Equivalent-Continuous Sound Level $\left(L_{e q}\right)$}

Equivalent-continuous sound level $\left(\mathrm{L}_{\mathrm{eq}}\right)$ during a time interval is found using equation 2.1:

$$
L_{e q}=10 \log _{10}\left[\left(\frac{\int_{t_{1}}^{t_{2}} p^{2}(t) d t}{T}\right) / p_{r e f}^{2}\right] d B \text { re } 20 \mu P a
$$

where $p(t)$ is the instantaneous sound pressure at measurement time, $t, p_{\text {ref }}$ is the standard reference sound pressure level at normal pressure and temperature conditions $(20 \mu \mathrm{Pa})$ and $\mathrm{T}$ is the time interval of analysis. For more information on $\mathrm{L}_{\mathrm{eq}}$ please refer to Harris (1998).

\subsubsection{Sound Exposure Level (ASEL/CSEL)}

Sound exposure level quantifies the cumulative amount of sound across certain durations of time. It can be calculated with both A-weighting and C-weighting, denoted as ASEL and CSEL, respectively. The A-weighted sound exposure level (ASEL; also denoted as $\mathrm{L}_{\mathrm{EA}, \mathrm{T}}$ ) is calculated by first finding $\mathrm{E}_{\mathrm{A}, \mathrm{T}}$, the A-weighted sound exposure which is proportional to the energy flow in a sound wave during a period of time:

$$
E_{A, T}=\int_{t_{1}}^{t_{2}} p_{A}^{2}(t) d t \quad P a^{2} \cdot s
$$

$\mathrm{E}_{\mathrm{A}, \mathrm{T}}$ is then applied to find $\mathrm{L}_{\mathrm{EA}, \mathrm{T}}$ using the following equation:

$$
L_{E A, T}=10 * \log \left(\frac{E_{A, T}}{E_{0}}\right) \quad d B \text { re } 20 \mu P a
$$

where $\mathrm{E}_{0}$ is a reference $(20 \mu \mathrm{Pa})^{2} \cdot \mathrm{s}$ (Beranek and Vér 1992). 
Since sound exposure level sums the data over time, the time interval selected may have significant impact. However for analysis of impulses of noise, the time interval should not significantly impact the final sound exposure level value if the impulse is loud enough compared to the background noise. This also assumes that the time interval selected is adequately larger that the length in time of the impulse. The problem is that exact values to determine what is "loud enough" for an impulse compared to the background noise are not stated (Beranek and Vér 1992).

\subsubsection{Perceived Level (PL)}

Perceived level (PL) is calculated using the Mark VII methodology developed by Stevens (1972). Sound pressure levels at each 1/3 octave band are converted to a perceived value in sones using equal sone contours and a total perceived value. The total is converted to a calculated perceived level using a power function that relates perceived magnitude to sound pressure and a reference sound consisting of a 1/3 octave band centered at $3150 \mathrm{~Hz}$.

An updated version of this calculation method was developed by Jackson and Leventhall (1972) in which they replaced the equal sone contours with equivalent equations to make the calculations simpler. This methodology was used for the specific calculations in this study.

Sound pressure levels, L, at each 1/3 octave band are first converted to an equivalent level, $\mathrm{L}_{\mathrm{eq}}$, of the $3150 \mathrm{~Hz}$ reference sound using equations related to the frequency region and band number, N. For example, sound pressure levels at $1 / 3$ octave bands greater than $8 \mathrm{kHz}$ (band levels greater than 39) were converted using equation 2.4:

$$
\mathrm{L}_{\mathrm{eq}}=\mathrm{L}+4 *(39-\mathrm{N}) \quad \mathrm{dB}
$$

Sound pressure levels at 1/3 octave bands between 3.15 and $8 \mathrm{kHz}$ (band levels of 35 to 39) were simply converted using equation 2.5 : 


$$
L_{e q}=\mathrm{L} \quad \mathrm{dB}
$$

Sound pressure levels at $1 / 3$ octave bands between 1.6 and $2.5 \mathrm{kHz}$ (band levels of 32 to 34) were converted using equation 2.6:

$$
L_{e q}=\mathrm{L}-2 *(35-\mathrm{N}) \quad \mathrm{dB}
$$

Sound pressure levels at $1 / 3$ octave bands between 400 and $1250 \mathrm{~Hz}$ (band levels of 26 to 31) were converted using equation 2.7 :

$$
L_{e q}=\mathrm{L}-8 \mathrm{~dB}
$$

For sound pressure levels below $400 \mathrm{~Hz}$ (band levels less than 26), the conversion equation implemented depended on the level. For levels less than $76 \mathrm{~dB}$, equation 2.8 was used:

$$
L_{e q}=107-26 * \frac{(115-\mathrm{L})}{\mathrm{N}} \mathrm{dB}
$$

For levels between 76 and $121 \mathrm{~dB}$, equation 2.9 was used:

$$
L_{e q}=\mathrm{L}-8-1.5 *(26-\mathrm{N}) \quad \mathrm{dB}
$$

For levels greater than $121 \mathrm{~dB}$, equation 2.10 was used:

$$
L_{e q}=152-26 * \frac{(160-\mathrm{L})}{N} \mathrm{~dB}
$$

For sound pressure levels below $80 \mathrm{~Hz}$ (band levels less than 19), the equations listed in the previous paragraph were used after two adjustments were made. First, the sound pressure level, $\mathrm{L}$, was converted to an equivalent $80 \mathrm{~Hz}$ SPL, B, using equation 2.11:

$$
\mathrm{B}=160-19 * \frac{(160-\mathrm{L})}{\mathrm{N}} \mathrm{dB}
$$

Second, the band level for each calculation in this region corresponded to the band level for the equivalent $80 \mathrm{~Hz}$ octave band $(\mathrm{N}=19)$. 
These new equivalent levels of the $3.15 \mathrm{kHz}$ reference sound were converted to loudness, S, in sones using a simple table printed in the reference (Jackson and Leventhall 1972). The total loudness, $\mathrm{S}_{\mathrm{t}}$, was found using equation 2.12:

$$
S_{t}=S_{m}+F *\left(\sum S-S_{m}\right) \text { sones }
$$

where $S_{m}$ is the loudness at the loudest band and $F$ is a factor that varies with $S_{m}$ and is read from a table printed in the reference (Jackson and Leventhall 1972). Finally PL was converted from total loudness using equation 2.13:

$$
P L=32+9 * \log _{2}\left(S_{t}\right) \quad d B
$$

A modified version of PL has been discussed in a recent study (Rathsam et al., 2012) that adjusted the sone curves by reducing the $1 \mathrm{~Hz}$ band pressure levels, which may possibly be a closer representation to the human hearing system. There was no experimental evidence behind the numbers they implemented, but the authors felt it may have been a more accurate representation of the human hearing system. However, this adjustment would not have had a large impact on this study as the test signals did not contain much low frequency content that this adjustment would have affected. Therefore, only the original sone curves reported by Stevens were used.

\subsubsection{Perceived Noise Level (PNL)}

Perceived noise level (PNL; also denoted as $\mathrm{L}_{\mathrm{PN}}$ ) is calculated using the methodology discussed in Harris and can take into account responses to aircraft noise, effects of pure tones, and single noise bursts (1998).

The PNL calculation involves analyzing 1/3 octave band SPL data between 50 and 10000 Hz. Sound pressure levels at each 1/3 octave band are converted to the corresponding "noisiness", $\mathrm{n}_{\mathrm{i}}$, in units of noys. These values are interpolated from the noy value tables printed in Hreinsson (1993). The total noisiness, $\mathrm{n}_{\mathrm{t}}$, is then found using equation 2.14: 


$$
n_{t}=n_{\max }+0.15\left(\sum_{i=1}^{24} n_{i}-n_{\max }\right) \quad \text { noys }
$$

where $n_{i}$ is the noisiness to each corresponding $1 / 3$ octave band and $n_{\max }$ is the maximum noisiness value found across all octave bands. The total noisiness is then applied to equation 2.15 to find PNL (Harris 1998):

$$
L_{P N}=40+33.22 * \log _{10}\left(n_{t}\right) \quad d B
$$

\subsection{5. $L_{1}-L_{g 9}$}

$\mathrm{L}_{1}-\mathrm{L}_{99}$ is found by the difference between $\mathrm{L}_{1}$ and $\mathrm{L}_{99}$. $\mathrm{L}_{1}$ and $\mathrm{L}_{99}$ correspond to the noise level that is exceeded for $1 \%$ and $99 \%$ of the measurement time interval, respectively. The total sound pressure level, or SPL, (dB re $20 \mu \mathrm{Pa})$ values at each measurement point across the time interval were ranked in ascending order based on value. The sound pressure levels that corresponded to $1 \%$ and $99 \%$ exceedance values across the time interval were found by interpolating the ranked data. There is interest that $\mathrm{L}_{1}-\mathrm{L}_{99}$ may help to quantify time varying fluctuations in noise (Wang and Novak 2010), similar to $\mathrm{L}_{\max }-\mathrm{L}_{\min }$.

\subsection{Incorporating Metrics for Sound Stimuli}

This section reviews recent research that involved the noise metrics of interest. There are some limitations reported with weighted metrics when testing jet aircraft noise as some metrics such as weighted sound pressure levels, PNL, and PL may not be able to accurately penalize the annoyance related to more high-frequency energy (Gee et al. 2007).

Another potential issue is the lack of clear information regarding the time interval around an impulse of noise used for calculation of these metrics. Some standards such as ANSI S12.71986 supply general information for the time interval that may be applicable to impulses of very loud levels under otherwise quiet conditions. However if the difference in noise between the burst and background noise is reduced, it may have an effect on the results for the single number metrics that are reported. 
Other research has focused on the use of noise metrics in analyzing sonic booms on the ground. This includes research that involved human responses to booms under both indoor and outdoor environments corresponding to the metrics listed above (Sullivan et al. 2010). Sullivan et al. generally found that all of the metrics used correlated well with each other and to the ratings of annoyance for both indoor and outdoor conditions.

Research from Marshall and Davies involved human responses using a semantic differential test to booms played back over high-quality headphones (2011). In this study, they found that ASEL and PL were able to predict loudness ratings for the sonic boom stimuli.

Work has also been done by Rathsam et al. at the NASA Langley Research Center to correlate subjective ratings of annoyance to different boom signals and corresponding metrics as previously mentioned (2012). In their research, PL was modified by adjusting the sone curves at very low frequencies as previously mentioned.

The modified version of PL best predicted equivalent annoyance for the signals in this study out of all the metrics used, which agreed with previous research. ASEL was also able to predict equivalent annoyance to a lesser extent. The authors also discuss the possible role of vibration and suggest future research evaluating the role of vibration on annoyance along with possible improper modeling of low-frequencies in regards to loudness.

In most studies involving sonic booms, PL and ASEL have shown in no order to be among the best predictors of annoyance, loudness, and startle.

Other work has studied additional metrics, such as $\mathrm{L}_{1}-\mathrm{L}_{99}, \mathrm{~L}_{\mathrm{Ceq}}-\mathrm{L}_{\text {Aeq }}$, and Room Noise Criteria (RNC), while relating them to mechanical noise. This includes work done by Wang and Novak that analyzed these metrics across a number of sound stimuli and correlated those results 
to performance and subject questionnaire results (2010). There is interest in further studying how $\mathrm{L}_{1}-\mathrm{L}_{99}$ in particular could be applied to the study of fluctuating noises.

\subsection{Applications to This Research}

The current research applied the arithmetic task used in previous studies by Broadbent (1958) and Woodhead (1964) under noise bursts of varying intensities, which was not combined before. The goal is to study any correlations and significant relationships in the performance of the task and subjective perception of the noise under different noise burst intensities and typical background noise conditions.

The bursts of noise were analyzed using the metrics addressed in this chapter to correlate the results from the performance task and subjective questionnaires. Additionally, the time interval around the noise bursts was varied to compare the effect that has on the final result for each metric.

The results will be compared to previous studies and hopefully provide useful information for future studies. This information should help add to the research and knowledge already completed on this topic. 


\section{Chapter 3: Methodology}

The purpose of this study was to evaluate the performance and perception of humans under noise bursts of assorted amplitudes. Subjects were asked to participate in an arithmetic test under different acoustic conditions across nine different test sessions and gave subjective reviews of the test environment at the end of each test. Each session was thirty minutes long and was comprised of three parts: (1) a five minute practice session where results were not recorded, (2) a twenty minute test session that served as the main part of the test, and (3) five minutes at the end to complete subjective questionnaires.

Nine different noise conditions were tested, separated into two groups: (1) five sessions involving noise bursts and (2) four sessions involving extended noise. Each subject first experienced the five sessions of the first group followed by the four sessions for the second group. The order of presentation within each group was randomized using a Latin square design.

For each impulse session, subjects experienced anywhere from zero to five bursts during the main twenty-minute testing period. For all tests, there was a synthesized, continuous background noise with a room criteria rating of RC-29(H). The bursts of noise were broadband noise signals that were presented at four levels within a range of peak A-weighted sound pressure levels $\left(\mathrm{L}_{\mathrm{Apk}}\right)$ of $47-77 \mathrm{dBA}$. The level of the noise burst remained constant within a single session but varied across four of the five test sessions. One additional session was designed without any impulses during the main test and only contained the RC-29(H) background noise.

For each session involving extended noise, subjects experienced two levels of background noise at room criteria ratings of $\mathrm{RC}-29(\mathrm{H})$ and $\mathrm{RC}-47(\mathrm{RV})$, respectively. The period 
of exposure alternated between each background noise level and would vary across each session for periods of 2, 5, 8, or 10 minutes. For example, during the test session involving exposure periods of 2 minutes, subjects would be exposed to the RC-29(H) for 2 minutes followed by the $\mathrm{RC}-47(\mathrm{RV})$ for 2 minutes, with this sequence repeating throughout the entire test session.

This thesis only analyzes the results from the first group of test sessions, the sessions involving noise bursts. Although there will be no results to report from the second group, this chapter will discuss the methodology involving the creation and testing of these signals as they were initially part of the overall experimental design.

\subsection{Facilities}

\subsubsection{Nebraska Test Chamber}

All testing was conducted at the Peter Kiewit Institute on the campus of the University of Nebraska. Test sessions were held in a test room made to look like an office with carpet, gypsum board wall construction, and acoustical ceiling tile. The test room was adjacent to two rooms on either side, collectively named the Nebraska Test Chambers. The Nebraska Test Chambers are acoustically isolated from the surrounding rooms with walls that consist of a staggered wood stud construction and result in STC 47. The average mid-frequency reverberation time is 0.25 seconds. The dimensions of the test room used in this study are $10^{\prime} \times 10^{\prime} 10^{\prime \prime} \times 8^{\prime}$. The layout of the Nebraska Test Chambers is shown in Figure 3.1.

The test room housed a chair for the subject, computer monitor to display the test program, wireless keyboard for the subject to complete the task, and two loudspeakers to output the sound signals in the room. The location of the subject's chair was placed so that the head position of the subject was approximately 4'8" away from the wall adjacent to the unused room, 3'6" away from the wall with the door, and at a height of 3'6" from the ground to the ears of the 
subject. Head movements were not tracked during testing so it was possible for a subject's head to deviate slightly from this position during testing. However, this position was used as the sound level meter measurement position as discussed later in section 3.2.2.

\section{Monitor Room Test Room}

Unused Room

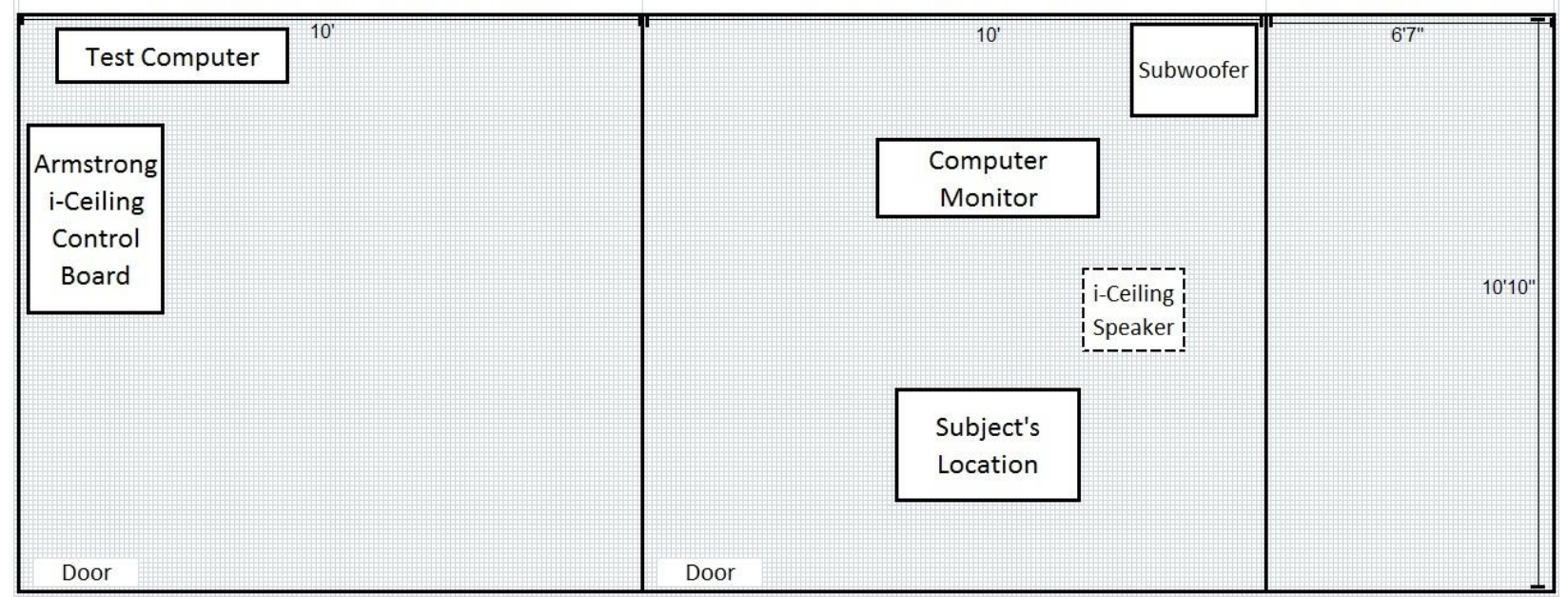

Fig. 3.1. The layout of the test chambers showing locations of the subject, test equipment, and loudspeakers used in this study (not to scale). Room height is 8 '.

The computer monitor was $23.5^{\prime \prime}$ diagonally and was kept at approximately 4 ' directly in front of the subject. Large text fonts of at least 36 point size were implemented in the test program to ensure that all users could see the screen from this distance. No subject expressed any difficulty in reading the text on the screen when prompted during orientation.

The two loudspeakers used were a JBL Northridge ESeries subwoofer that is covered with fabric in the corner in the room to resemble an end table and an Armstrong i-ceiling loudspeaker that sits in the ceiling grid and appears as an ordinary acoustic ceiling tile. The Armstrong i-ceiling speaker was located right next to a dummy diffuser to lead the subject to believe that the noise was coming from an air ventilation system. During the time of testing there were two other loudspeakers in the room on tripods that were covered with fabric. These 
loudspeakers were for another test that was running concurrently with this research and were not used. Subjects were told that those tripods were not a part of this study and were to be ignored. A picture taken inside the test room is shown in Figure 3.2.

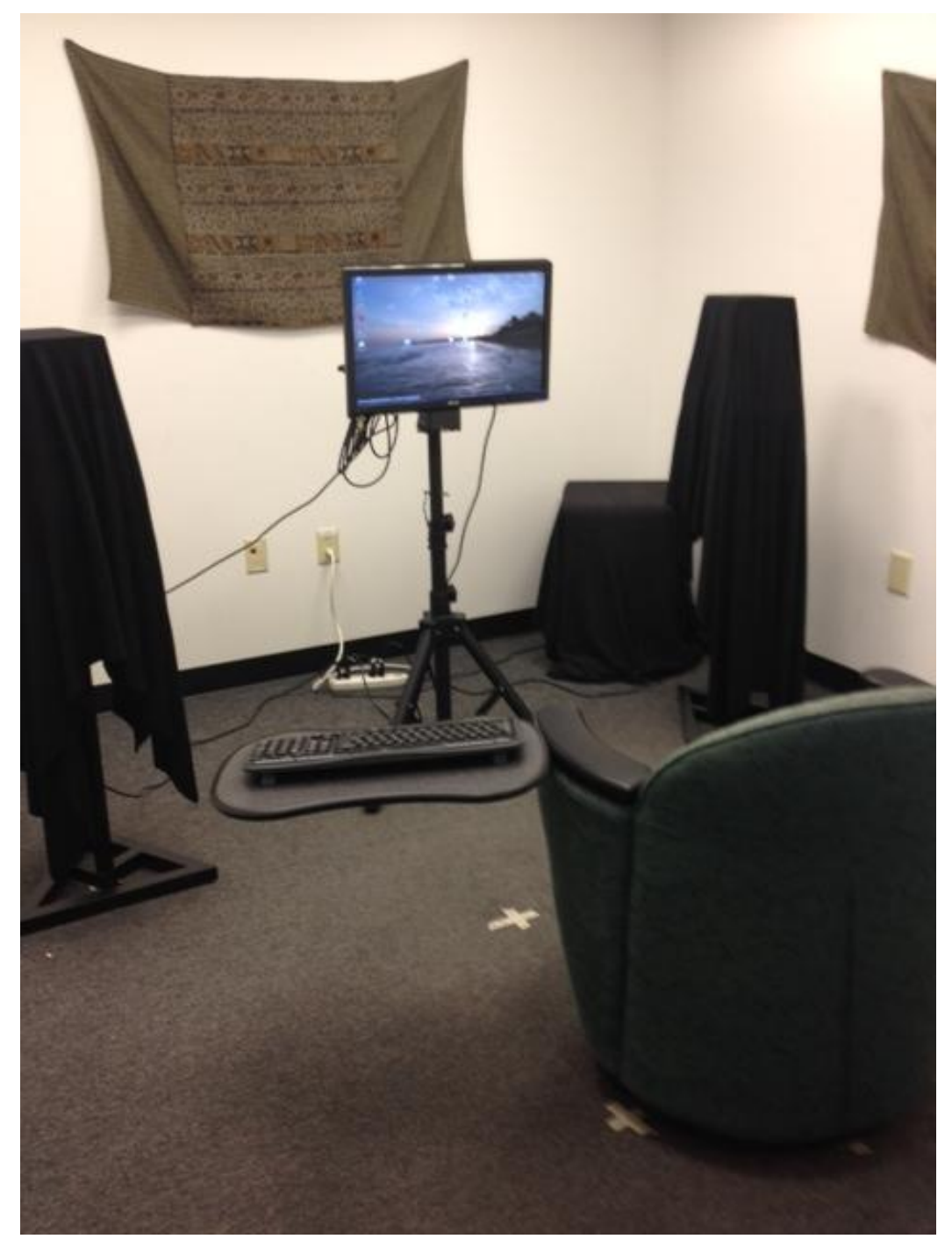

Fig. 3.2. A picture from the interior of the test room.

One of the rooms adjacent to the test room was specified to be the monitor room. This room housed the test computer and controls for the Armstrong i-ceiling loudspeaker. The other adjacent room was unoccupied and unused for this research. 
The temperature was recorded from a digital thermometer at the conclusion of each test session. Testing was done in the month of May which yields slightly warmer weather. An average of $77.1^{\circ} \mathrm{F}$ was recorded across all testing sessions. When needed, a portable air conditioner was used before and in between sessions to cool down the room.

\subsubsection{Sound and Computer Systems}

The configuration of the loudspeakers and computer equipment is shown in Figure 3.3. All testing was run from one computer. The JavaScript program used for testing was designed to trigger specific sound files and therefore had to be connected to the same device that was connected to the loudspeakers. A wireless keyboard was used for the ease of the participant. Since the test computer was housed in the monitor room, fan noise from the computer was not a concern in the test room.

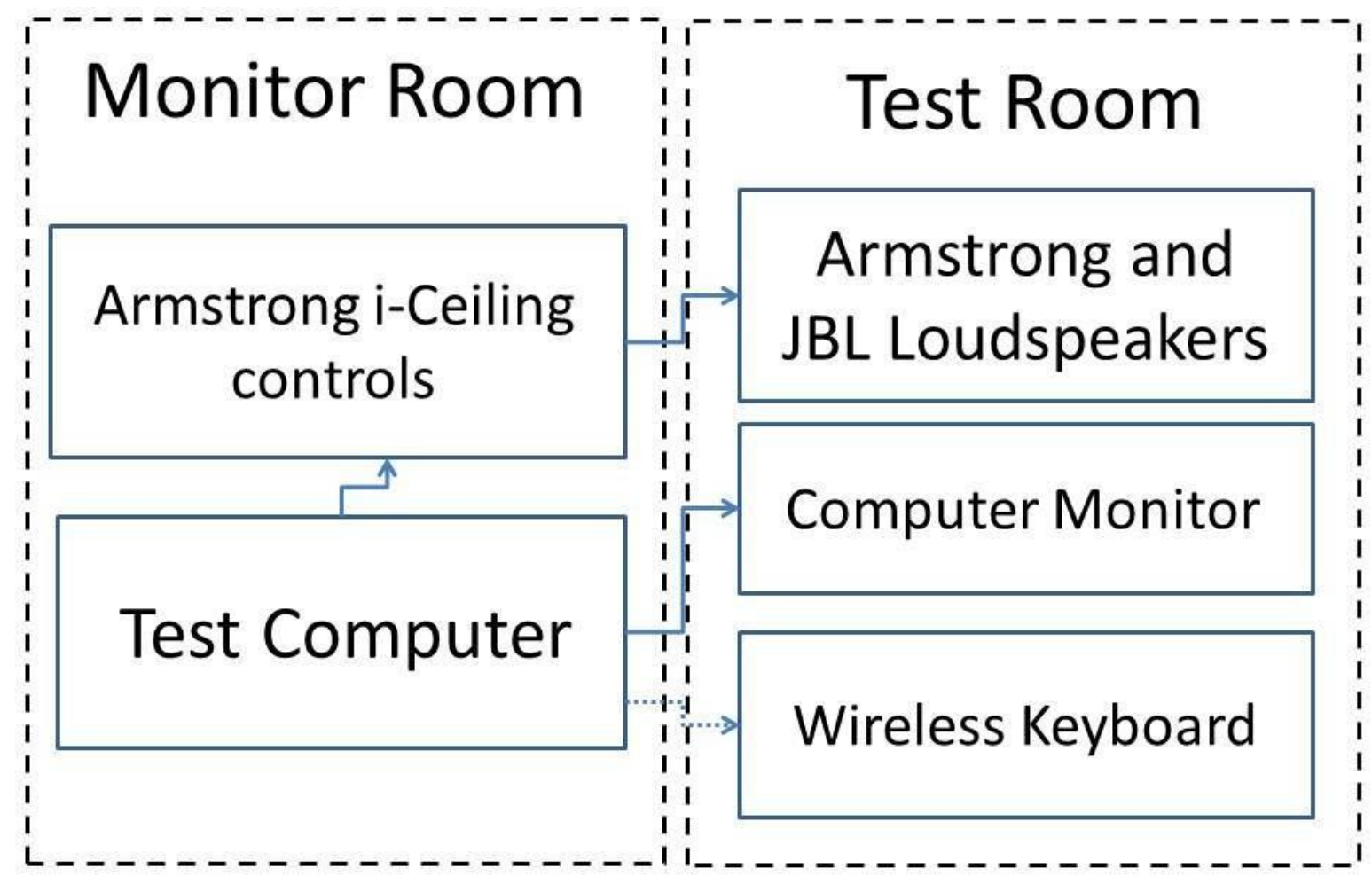

Fig. 3.3. A diagram of the Nebraska Test Chamber system showing both the testing system and the sound system. 


\subsection{Experimental Methods}

This section reviews the methodology used in the experiment and is separated into four subsections: (1) creation of the signals used, (2) recording and measurement procedures used to analyze each signal, (3) procedure involved behind the creation and running of the test sessions, and (4) statistical analyses used for analysis of data.

\subsubsection{Signal Creation}

Certain sound files was created and calibrated for the purposes of both parts of the study. The methodology for the creation and calibration of each signal is discussed in this section. For the noise burst testing, there were four levels of a broadband noise burst as well as a synthesized background noise that resembles an RC-29(H) required for this study. For the extended noise study, there were two types of signals resembling an RC-29(H) and RC-47(RV) that were presented at different periods of exposure as required for this study.

A total of thirteen .wav files were created to recreate specific sound environments desired for all test sessions. Four of these .wav files were the broadband noise bursts of varying levels. The additional nine .wav files were variations of the periods of exposure for both the RC-29(H) and RC-47(RV) signals. The spectral analysis of all signals related to the impulse sessions will be reported in the next chapter.

\subsubsection{Impulse Sound Signals}

Four broadband impulse sound signals of varying intensity were desired for the test. These signals were created from white noise generated in CoolEdit at a length of $250 \mathrm{~ms}$, which was reported to be within the typical lengths of sonic booms (Shepherd and Sullivan 1991). It was desired to have signals with equal perceived loudness across octave bands so an A- 
weighting was applied at each octave band. Additionally, it was desired to study impulses with a range of loudness levels to compare to the synthesized background noise of RC-29(H).

The $250 \mathrm{~ms}$ signals were looped and then calibrated using the equalizer in CoolEdit until two conditions were met: the sound pressure level at each octave band with respective Aweightings were within $2 \mathrm{dBA}$ across all other octave bands to fit to the A-weighting spectral profile and the total sound pressure level in $\mathrm{dBA}$ was 50, 60, 70, and $80 \mathrm{dBA}$ respectively. This established a range for comparisons to be made to the RC-29(H) which was approximately 37 $\mathrm{dBA}$ in terms of overall sound pressure level. Since these signals would be played over the RC29(H) signal, they were calibrated while both signals were played over the loudspeakers.

The total sound pressure levels of 50,60, 70, and $80 \mathrm{dBA}$ were initially established for each .wav file when the signal was looped and not played as a single impulse. Therefore for the rest of the tests the impulses were respectively named "Impulse 50", "Impulse 60", "Impulse 70", and "Impulse 80". However these names were only created for organizational purposes and do not indicate final levels measured in the rooms under the test conditions. Final results of the frequency analysis of the impulse .wav files when played in the test room will be presented in the next chapter.

\subsubsection{Extended Noise Signals}

Extended noise signals were used to synthesize a background noise around RC-30(N) for the first group of test sessions and to synthesize the two levels of extended noise, representing approximately RC-30(N) and RC-48(V), for the second group of test sessions.

A continuous background noise level was used with a room criteria rating of RC-30(N). This signal was calibrated using the equalizer in CoolEdit until an RC-30(N) curve was initially measured in the test room over the JBL subwoofer and the Armstrong i-ceiling loudspeaker. 
Final results would show that the signal was actually an RC-29(H) when played back in the room. For all impulse sessions, this .wav file was looped through WinAmp on the test computer.

Another louder, continuous background noise level file was used with a room criteria rating of RC-50(V). This signal was calibrated using the equalizer in CoolEdit until an RC-48(V) curve was initially measured in the test room over the JBL subwoofer and the Armstrong iceiling loudspeaker. Final results would show that the signal was actually an RC-47(RV) when played back in the room. This signal was only used for the second part of the experiment for a louder background noise.

In the second half of the experiment, each test session would switch between the RC29(H) and RC-47(RV) sound files of equal periods of exposure of 2, 5, 8, or 10 minutes for each respective test session. These final four test sessions were titled by the periods of exposure for each signal: "2 minutes", "5 minutes", "8 minutes", and "10 minutes". For example, during the test session involving exposure periods of 2 minutes, subjects would be exposed to the RC-29(H) for 2 minutes followed by the RC-47(RV) for 2 minutes, with this sequence repeating throughout the entire test session. Both the RC-29(H) and RC-47(RV) 10 second .wav files were edited to longer time intervals of 2, 5, 8, and 10 minutes to achieve this. For these sessions, these .wav files were looped through a playlist on WinAmp on the test computer.

To adjust for a natural transition between the two sound files, an envelope was applied to the RC-47(RV) .wav file using CoolEdit. The envelope utilized a spline curve and is defined by selecting control points across the time of the signal to correspond to the percentage of amplification of the original signal. The resulting envelope as presented in CoolEdit is reported in Figure 3.4. This application yielded a more realistic change between the two background levels, similar to HVAC systems turning on and off. 


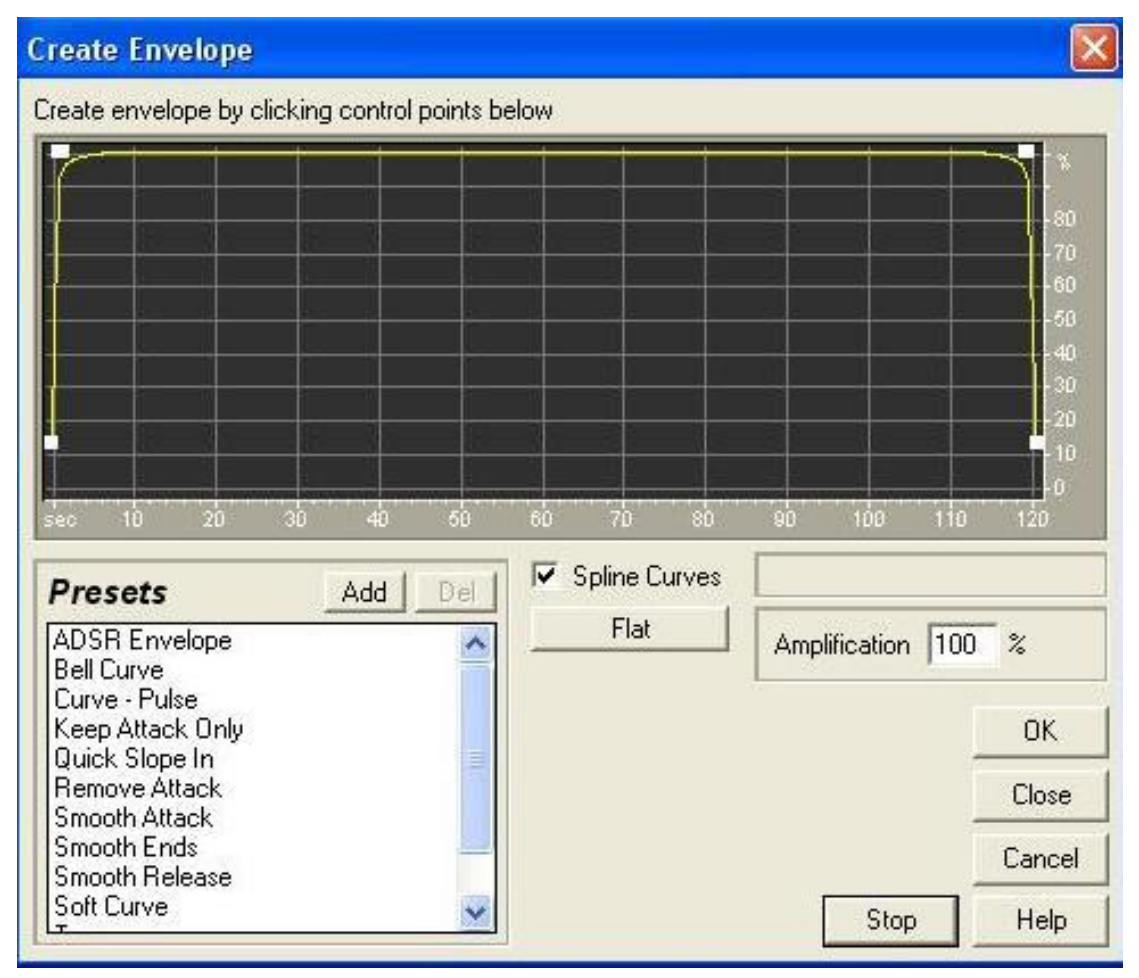

Fig. 3.4. Screenshot of envelope applied using CoolEdit to RC-47(RV) .wav files

\subsubsection{Signal Recordings and Measurements}

All signal files were recorded and measured in the test room at the head position of the subject using a Larson-Davis 824 sound level meter. Signals were measured initially and then analyzed using a number of different metrics: Equivalent-Continuous Sound Level ( $\left.\mathrm{L}_{\mathrm{eq}}\right), \mathrm{L}_{1}-\mathrm{L}_{99}$, Sound Exposure Level (ASEL/CSEL), Perceived Level (PL), and Perceived Noise Level (PNL). The calculation procedures for each metric are presented in the previous chapter.

The noise bursts were measured at the 5 minute mark of an overall time measurement period of 10 minutes with the RC-29(H) signal playing continuously throughout the 10-minute measurement period. It was desired to analyze each noise burst for a number of different time intervals to compare any differences in the final results. The noise bursts were then analyzed for time intervals of $1,5,10,30,60$, and 120 seconds around the noise bursts. This range of time 
intervals was deemed more than adequate to analyze an impulse with a length of $250 \mathrm{~ms}$. The recording and measurement procedures for each signal are reported in the following subsections.

\subsubsection{Signal Recordings}

All signals used for test sessions were played over the loudspeaker configuration in the test room and recorded into .wav files for archiving purposes. The sound level meter was used as a microphone and the Presonus AudioBox 44VSL was used as an external sound card for the recording computer in the monitor room. Signals were recorded on the recording computer using Presonus Studio One recording software. All equipment was controlled in the monitor room. This allowed for recording to take place without the sound of a keystroke or mouse click when playing an impulse file. The configuration of equipment used to record the signals is shown in Figure 3.5.

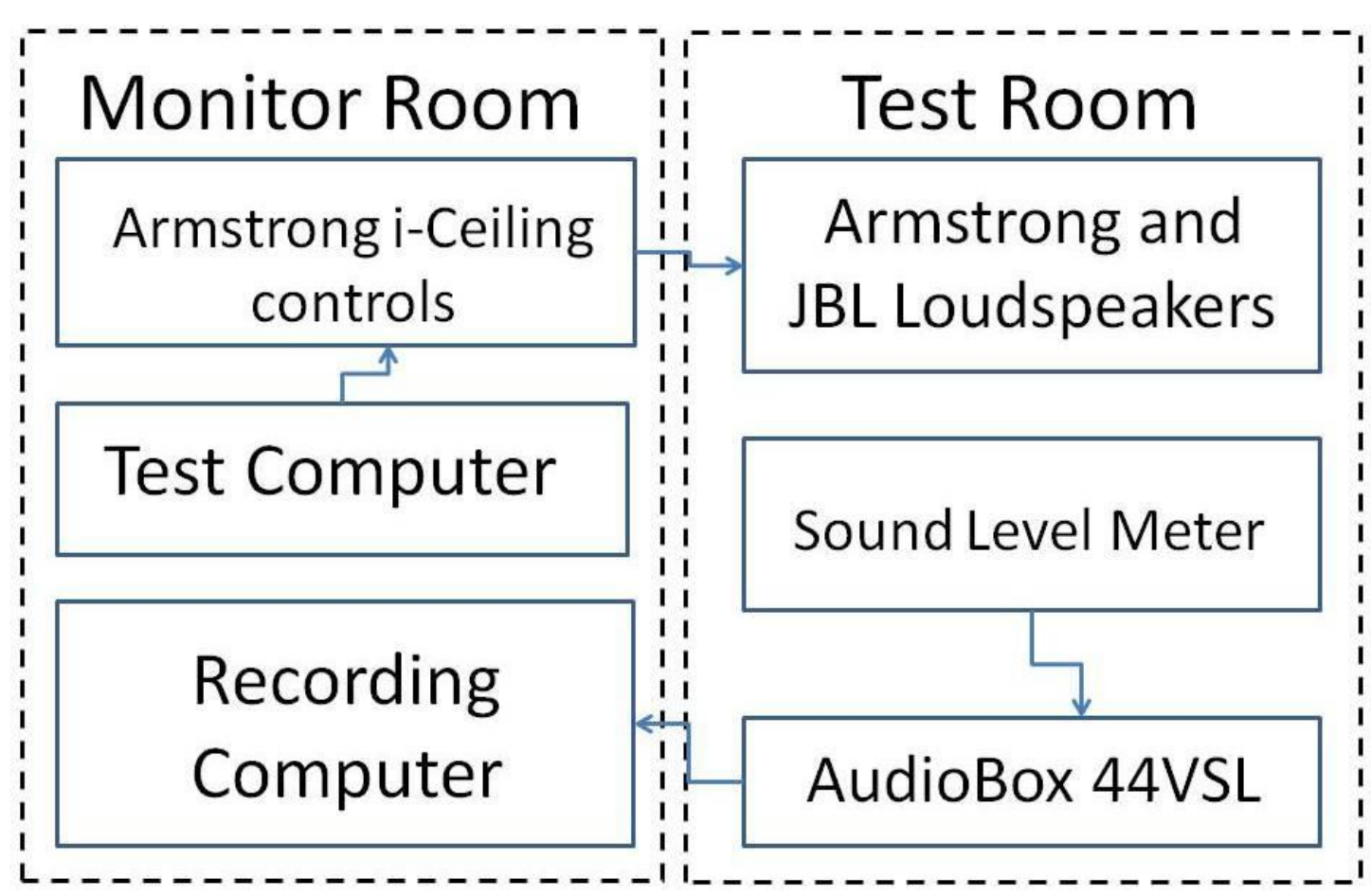

Fig. 3.5. A diagram of the Nebraska Test Chamber system showing the equipment used for recording test signals in the test room. 
Each signal was recorded across an 8 second length of time. Impulses were played at the 4 second mark of each recording, with the RC-29(H) playing throughout the 8 seconds of those recordings. For the varying periods of exposure, a single period of both the RC-29(H) and RC47(RV) signals was captured as was each change between the RC-29(H) and RC-47(RV) signals. Recordings used a $44.1 \mathrm{kHz}$ sampling rate.

A $1 \mathrm{kHz}$ tone was generated in CoolEdit and was also recorded over a period of 8 seconds in the room using the same recording settings. The $1 \mathrm{kHz}$ tone was measured to be 45 $\mathrm{dB}$ at the $1 \mathrm{kHz}$ octave band in the room using the Larson-Davis 824 sound level meter averaged over a 20 second time interval, and may then be used to calibrate the other .wav recordings, assuming a flat frequency response of measurement equipment.

\subsubsection{Signal Measurements}

Signals were additionally measured using a Larson-Davis 824 sound level meter using the settings shown in Figure 3.6. Signals were recorded over a period of 10 minutes. For impulse measurements, the impulse was presented halfway through the 10-minute measurement period so that an equal interval of RC-29(H) was presented before and after the impulse. Additionally, RC29(H) and RC-47(RV) signals, both 5 minutes in length, were measured when played sequentially. A 2-minute time period of both RC-29(H) and RC-47(RV) measurements was analyzed.

Measurements were taken at every $125 \mathrm{~ms}$, which is the smallest time interval allowed on this sound level meter. The sound level meter was in 'fast' mode for the initial measurements. Later in the analysis procedure, measurements were again tested in 'impulse' mode. There were little to no differences (on the order of $1 \mathrm{~dB}$ or less) between the $1 / 3$ octave band data from either 
setting. Therefore, the original data taken from the 'fast' mode set on the sound level meter was used.

\begin{tabular}{|l|l|}
\hline \multicolumn{2}{|c|}{ Sound Level Meter / RTA Settings } \\
\hline Bandwidth: & $1 / 3$ \\
\hline Detector: & Fast \\
\hline Weighting: & Flat \\
\hline Peak-1 Weighting: & Flat \\
\hline Second Display: & TWA \\
\hline Gain: & 0 \\
\hline RTA Detector: & Fast \\
\hline RTA Weighting: & Flat \\
\hline Filter Range & $12.5-20 \mathrm{k}$ \\
\hline
\end{tabular}

\begin{tabular}{|l|l|}
\hline \multicolumn{2}{|c|}{ Ln } \\
\hline Ln: & Enabled \\
\hline Ln Start Level: & $15 \mathrm{~dB}$ \\
\hline Spectral Ln Option: & Interval \\
\hline Ln Percentiles & \\
\hline Ln Percentiles & \\
\hline L 1.0 & \\
\hline L 10.0 & \\
\hline L 50.0 & \\
\hline L 90.0 & \\
\hline L 95.0 & \\
\hline L 99.0 & \\
\hline
\end{tabular}

\begin{tabular}{|l|l|}
\hline \multicolumn{2}{|c|}{ Intervals } \\
\hline Intervals: & Enabled \\
\hline Interval Time Sync: & No \\
\hline Interval Save Ln: & Yes \\
\hline Interval Save Ln Table: & No \\
\hline Interval Auto Stop: & Yes \\
\hline Interval Period: & $0: 10: 20$ \\
\hline Interval Threshold: & 0 \\
\hline Interval Exchange Rate: & $3 \mathrm{~dB}$ \\
\hline Interval Spectra Option: & At Max \\
\hline
\end{tabular}

\begin{tabular}{|l|l|}
\hline \multicolumn{2}{|c|}{ Time History } \\
\hline Time History: & Enabled \\
\hline Time History Period: & 4 \\
\hline Time History Units: & $1 / 32$ seconds \\
\hline Resolution: & $0.1 \mathrm{~dB}$ \\
\hline
\end{tabular}

Fig. 3.6. A list of settings used for measurement of signals with a Larson-Davis 824 SLM.

$1 / 3$ octave band data for each measurement point over time were collected and were used to analyze each signal using additional appropriate metrics. Although certain percentile-exceeded sound levels $\left(\mathrm{L}_{\mathrm{n}}\right)$ were calculated with the sound level meter, these values were not used. Instead, $L_{n}$ values were recalculated for a number of different time intervals using the $1 / 3$ octave band results. 
All of the data were exported to Excel spreadsheets. Sound pressure level data at each measurement point were converted to pressure values to find average sound pressure level values over each time interval, which was needed for some calculations of certain metrics.

Other metrics, such as PL and PNL, required the squared pressure data across the time interval to be divided by a time constant. As discussed in the previous chapter, other research involving sonic booms has used an auditory time constant of $70 \mathrm{~ms}$. This constant may be acceptable for sonic booms because the main auditory information is contained to the two main overpressures related to the $\mathrm{N}$-wave shape of a sonic boom, which can be assumed to be less than $70 \mathrm{~ms}$ even when the total length of the sonic boom is longer than that time (Shepherd and Sullivan 1991). This may not be applicable to this study as the main auditory information of the broadband noise bursts encompasses the entire $250 \mathrm{~ms}$ of the signal. Therefore, a time constant of 1 second is suggested and used for the purposes of this study.

The respective $1 / 3$ octave band data were used to calculate peak sound pressure levels $\left(\mathrm{L}_{\mathrm{pk}}\right)$ and the metrics previously discussed across the time intervals of 1, 5, 10, 30, 60, and 120 seconds around the noise bursts. The results of the metrics for each signal across each time interval are presented in the next chapter.

\subsubsection{Test Session Procedure}

The following section discusses the preparation and implementation of the testing procedures for this experiment. This section is broken up into three subsections.

The first subsection discusses the scheduling of each test session, including order of test sessions. The second subsection discusses the design and procedure for individual test sessions. This includes the schedule for each test session, the design of the arithmetic used for this study, and the subjective and noise sensitivity questionnaires used. The final subsection discusses the 
recruitment and orientation procedures for the study, as approved by the UNL Institutional Review Board.

\subsubsection{Test Session Scheduling}

Each subject participated in an orientation session and nine test sessions that were all 30 minutes each. The nine test sessions were split into two groups: the noise burst tests and the extended noise tests. Each subject first experienced the five sessions of the first group followed by the four sessions for the second group. Each subject was asked to participate only in one session per day. Due to scheduling issues, there are a few instances when subjects were allowed to participate in two sessions in one day as long as they were separated by more than 4 hours between sessions.

The first five test sessions were devoted to the impulse tests. This included a control session denoted as "Ambient BNL" and the four impulse sessions: "Impulse 50", "Impulse 60", "Impulse 70", and "Impulse 80". As stated previously, these names were only created for organizational purposes and do not indicate final levels measured in the rooms under the test conditions. The last four sessions were devoted to the extended noise tests of different periods of exposure: "2 minutes", “5 minutes", "8 minutes", and "10 minutes".

Latin squares were used for both groups of test sessions to ensure a unique and balanced order of test sessions across all participants to help avoid bias. For the design of the impulse test group, there were five sessions and 30 test subjects. Six 5 by 5 Latin squares were created to cover this group of experiments.

The second group of experiments involved four sessions and the same 30 test subjects. Seven 4 by 4 Latin squares were created to cover the first 28 subjects. The sequences for the final two subjects were created using a random order function in Excel. 


\subsubsection{Test Session Design and Procedure}

This subsection describes the design and procedure used for the arithmetic test. During each test session, the subjects had five minutes of practice tests to reacquaint themselves with the testing procedure. Test scores were not recorded during this practice period. Subjects were prompted when the practice session had concluded. This was immediately followed by the main test which was twenty minutes long.

The creation of the arithmetic test took many steps. Each arithmetic test problem required the subject to find the difference between a six-digit number and a four-digit number using only their memory. Test questions were created to match the rules of the test questions used in similar previous studies, specifically Broadbent (1958) and Woodhead (1964). A six-digit number was present on the screen for ten seconds. After ten seconds, that six-digit number was erased from the screen and replaced by a four-digit number and a single-row text box. This configuration remained on the screen until the subject typed and submitted their answer in the text box. Subjects were not allowed to write out their work. After an answer was submitted, there was a fifteen second intermission before the next test problem began.

During the practice portion of the test session, subjects were given feedback on their performance of the previous problem during the fifteen second intermission. This feedback to the previous problem included their answer, the correct answer (if different from the subject's answer), and the length of time it took for the subject to answer. This feedback was not present during the main testing period for each test session. The subject was prompted before the next test with a "ready, set, go!" warning that ran during the final three seconds of the intermission. At no time during the test was there a clock or timer present in the room. Screenshots of the 
arithmetic test program during the practice portion of the test session, which includes feedback to the test question, are shown in Figure 3.7.

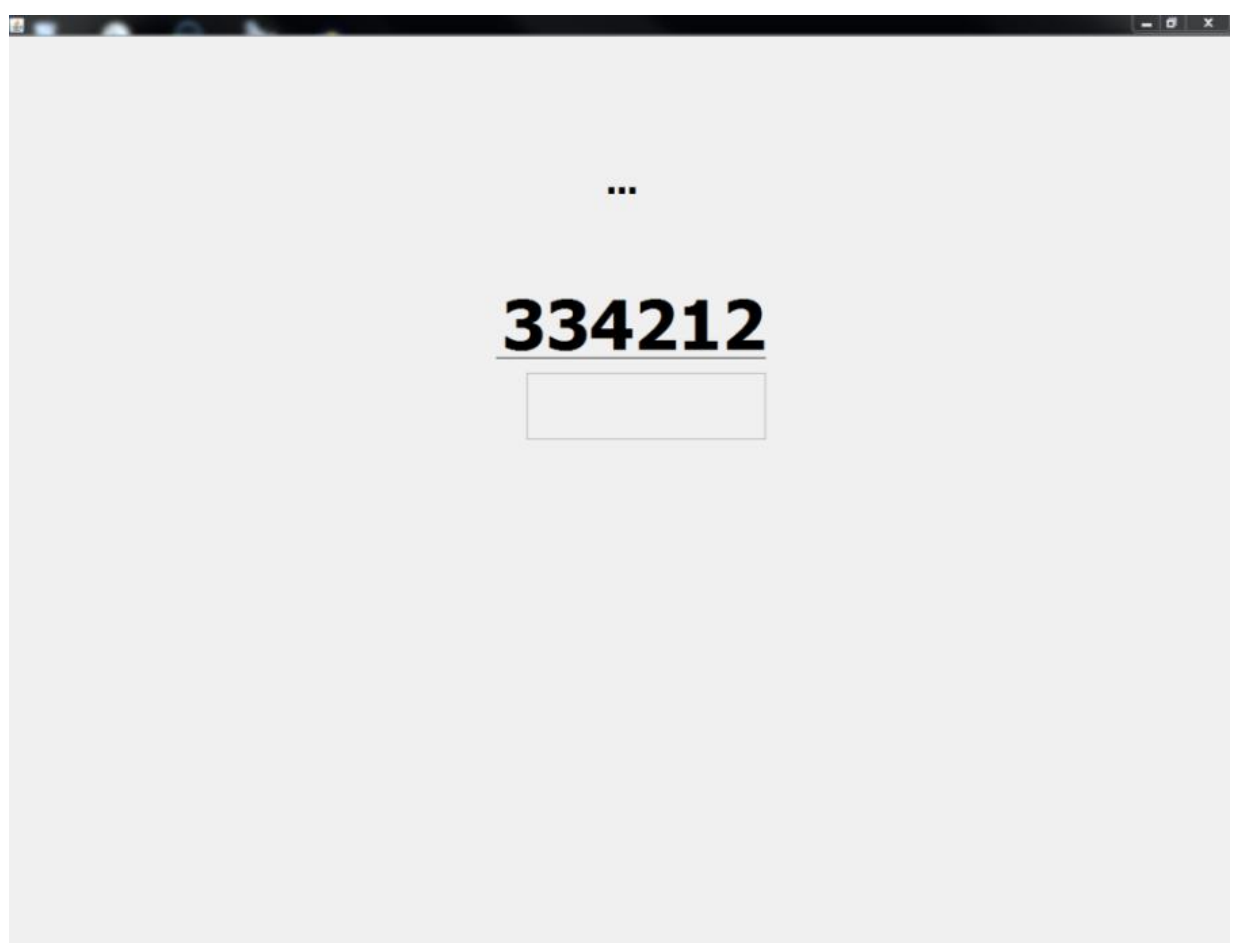

(a)

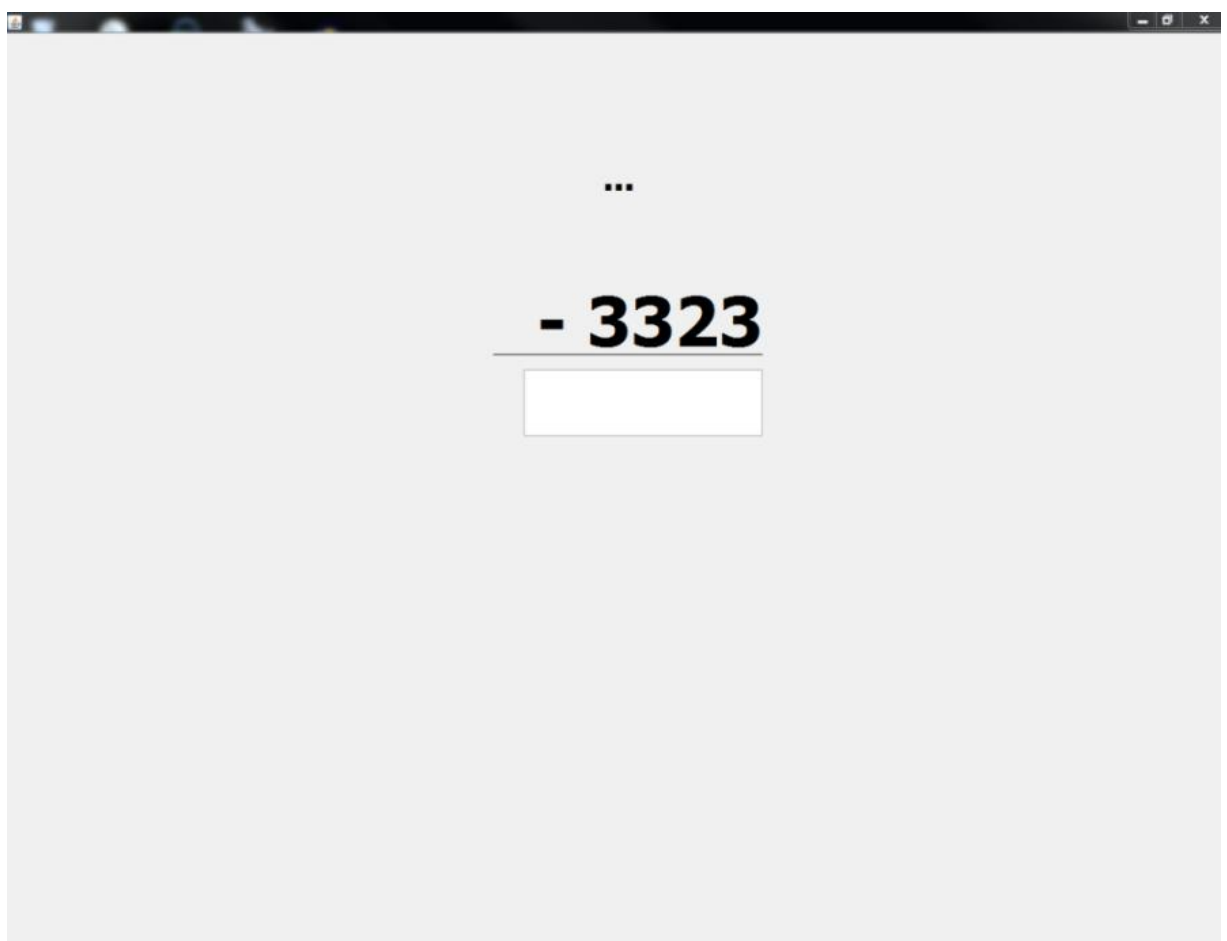

(b) 


\section{The next test will begin soon.}

Previous Problem: 334212 - 3323

Your Answer: 330889

Correct!

You took 63 seconds to answer.

(c)

Fig. 3.7. Screenshot from practice portion of arithmetic test program (a) displaying the first number, (b) displaying the second number, and (c) after answer submission with feedback.

The only digits used in each number were 1,2,3, and 4. During the first five minutes of practice in each session, the difficulty of each question began at an easy level and increased in difficulty. For this test, difficulty is defined by the number of times a subject had to "borrow" for each test question. In an individual column of a subtraction problem, if the number in the top row is less than the number in the bottom row, the number in the top row has to borrow from the number column adjacent to the left. During the main test, the difficulty of each question remained constant by requiring the subject to borrow three times for each question. Due to the specific conditions required for the test questions, all test questions were written from scratch by the author. 
Unique test question lists were created for each respective noise condition and the presentation of these test lists were the same for each subject. Based on the average completion times of subjects in previous testing (Woodhead, 1964), it was expected that the average subject could complete between 21-23 questions in a twenty minute session. Test question lists were created to be long enough so that subjects would not complete the test before the assigned duration of time. Practice test question lists consisted of 20 questions and main test question lists consisted of 45 questions. No subject was fast enough to complete all of the questions before the end of the allotted time.

For the test sessions that involve bursts of noise, specific test questions were chosen in advance during which the burst of noise would play when the six-digit number was presented during that question. The .wav file for the given impulse played four seconds after the six-digit number first appeared on the screen, as was done in previous testing (Woodhead, 1964).

The test questions that were linked to the noise bursts were spread out so the subject would not know exactly when to expect them. The total number of noise bursts also varied between tests for this same purpose. In the "Impulse 50" and "Impulse 70" tests, there were four test questions that were linked to the noise burst wav file. In the "Impulse 60" and "Impulse 80" tests, there were five test questions that were linked to the noise burst .wav file.

All test questions linked to noise bursts were restricted to the first twenty questions in a test session to ensure that a subject with an average pace would experience the maximum number of bursts. This meant that depending on the pace of a specific subject, any subject could encounter $0,1,2,3,4$, or 5 noise bursts in a given session. Each subject was presented with the same test question order and therefore the same order of test questions linked to noise bursts. Although the pace of some subjects was below average, every subject experienced the respective 
burst of noise in each session at least two times. The final numbers for each subject's exposure to bursts will be presented in the next chapter.

Test questions linked to noise bursts were spread out in a random order within the first 20 questions out of the total 45 for a given test session. Figure 3.8 displays the resulting order of test questions linked to noise bursts for each test. Each question linked to a noise burst is denoted with an "x". The noise bursts were separated into subsections that would hold a single noise burst. The length of the subsections depended on the possible number of bursts in a given test. When five bursts were possible, the subsections were four questions long. When four bursts were possible, the subsections were five questions long. The dotted lines in Figures 3.8 and 3.9 represent the resulting subsections. Within each subsection, the placement of the burst was determined using a random order function in Excel.

\begin{tabular}{|c|c|c|c|c|c|c|c|c|c|c|c|c|c|c|c|c|c|c|c|c|}
\hline question \# & 1 & 2 & 3 & 4 & 5 & 6 & 7 & 8 & 9 & 10 & 11 & 12 & 13 & 14 & 15 & 161 & 171 & 1819 & 20. & .45 \\
\hline \multicolumn{21}{|l|}{ Ambient BNL } \\
\hline Impulse 80 & & $x$ & & & & & $x$ & & & $x$ & & & & & & $x$ & & & $x$ & \\
\hline Impulse 70 & & & & & $x$ & & $x$ & & & & & & $x$ & & & $x$ & & & & \\
\hline Impulse 60 & & & & $x$ & & $x$ & & & $x$ & & & & & & $x$ & & & $x$ & & \\
\hline Impulse 50 & $x$ & & & & & & & $x$ & & & & $x$ & & & & & & & $x$ & \\
\hline
\end{tabular}

Fig. 3.8. The order of test questions linked to bursts where X's represent the test questions linked with an impulse for each respective session and blank cells represent randomized non-impulsepresented questions. Dotted lines represent subsections used to spread out test questions.

To isolate the effect of noise bursts on the performance of the test questions, the same test questions were presented two more possible times in separate tests: once in the ambient background noise only session and once in another impulse session as a non-impulse presented question. These questions were denoted as "control questions." The locations of these control questions were created using random order functions in Excel. Figure 3.9 displays the resulting 
order of test questions linked to noise bursts (bold capital letter) and their corresponding control questions (corresponding capital letter). A few minor corrections were made to ensure that each control question was presented at least once within the first ten questions of any session. This would help to increase the chances that at least one comparison could be made even if the subject worked at a very slow pace.

\begin{tabular}{|c|c|c|c|c|c|c|c|c|c|c|c|c|c|c|c|c|c|c|c|c|c|}
\hline question \# & 1 & 2 & 3 & 4 & 5 & 6 & 7 & 8 & 9 & 10 & 11 & 12 & 13 & 14 & 15 & 16 & 17 & 18 & & 20. & 45 \\
\hline Ambient BNL & $\mathrm{L}$ & C & A & $P$ & & $\mathrm{H}$ & $\mathrm{N}$ & D & $\mathrm{E}$ & 0 & G & $\mathrm{J}$ & $\mathrm{F}$ & Q & & M & B & $\mathrm{K}$ & $\mathrm{R}$ & I & \\
\hline Impulse 80 & & A & & & $\mathrm{R}$ & & B & & $\mathrm{J}$ & C & & & & & $\mathrm{H}$ & D & & & & E & \\
\hline Impulse 70 & & & & B & $\mathbf{F}$ & & G & & M & & & $\mathrm{L}$ & H & & & I & $\mathrm{N}$ & & & D & \\
\hline Impulse 60 & & & 0 & J & & K & $\mathrm{F}$ & & $\mathbf{L}$ & Q & & & & $P$ & M & & & & $\mathbf{N}$ & & \\
\hline Impulse 50 & 0 & $\mathrm{~K}$ & & & G & & & $\mathbf{P}$ & I & & & $\mathbf{Q}$ & C & & & $\mathrm{E}$ & & & A & $\mathbf{R}$ & \\
\hline
\end{tabular}

Fig. 3.9. Order of impulse-presented questions and their corresponding control questions where bold capital letters represent the test questions linked with an impulse the corresponding capital letters represent those same test questions presented again without an impulse. Blank cells represent randomized non-impulse-presented questions. Dotted lines represent subsections used to spread out test questions.

At the beginning of each test session, subjects were told the following: "Remember that you may experience some environmental fluctuations in temperature, lighting, and noise during today's test. Also, remember for this experiment, we are mainly interested in memory, accuracy, and speed." Subjects were also reminded to completely shut down any cell phones or other devices that could make noise. Any bags or additional material that was non-vital to the subject were kept in the monitor room during testing.

So that the noise bursts would not unduly surprise participants in a particular main testing session, the respective burst of noise used in each session was presented in the five-minute 
practice portion of the test session. In the case of the control session, the "Impulse 60" .wav file was presented in the practice portion; however there were no bursts present in the main test.

To further help avoid startle, the subjects were made aware that bursts of noise may be present during the first group of test sessions. At the beginning of each impulse test session, subjects were additionally told the following: “Additionally, for today's test you may experience bursts of noise. A burst of noise will take place once in the first 30 seconds of the practice session. The burst will remain the same throughout the remainder of the session. You may experience the burst 0, 1, 2, 3, 4, or 5 times in the main 20 minute test. You may find the burst startling depending on your noise sensitivity. Just remember that the levels are non-harmful and do your best to focus on the test."

At the beginning of the extended noise sessions, subjects were additionally told the following: "You will not experience bursts of noise as presented in earlier sessions, but you may experience other environmental fluctuations."

An automatic program was written in Java to conduct the arithmetic test for each session. The program would display test questions with desired periods of time, record the subject's answer, play impulse signals at desired times for specific test sessions, and time stamp all actions during the session. The program only required the test monitor to upload the wav file of the respective impulse, .txt files of the arithmetic problems, and a location folder for the output data in a .csv worksheet format.

Test questions were written into a text file that was imported into the test program. Each test problem was written on a single row with a comma separating the six-digit and four-digit numbers. When an impulse was desired for a test problem, an exclamation point was added at the 
end of the row. A unique text file was required for each five minute practice portion and twenty minute main test portion of each session.

The final five minutes of each test session were allotted for the subjects to fill out a brief subjective questionnaire about their experience in the room on that day (Figure 3.10). Subjects were allowed to add any additional comments about that specific session in the space below the questions.

On their final test session, subjects were additionally asked to complete a noise sensitivity questionnaire. This questionnaire was taken from the reduced version of the Noise Sensitivity Questionnaire (NoiSeQ) developed by Schutte et al. (2007) (Figure 3.11). Total noise sensitivity for each participant as a percentage was calculated based on the information provided on the questionnaire. Subjects were allowed to add any additional comments about the overall test on the back side of this questionnaire.

\subsubsection{Recruitment and Orientation Procedure}

Subjects were recruited by fliers posted around the University of Nebraska campus. The flier shown in Figure 3.12 was approved by the UNL Institutional Review Board.

For their first session, subjects participated in an orientation session. Subjects were presented with a PowerPoint presentation covering the instructions of the test procedure. The subjects then participated in a hearing screen and a practice session of the arithmetic test.

The hearing screen tested hearing thresholds of both the left and right ears individually using an audiometer. A pure tone of each octave band between 125 to $8000 \mathrm{~Hz}$ was used. Subjects were initially presented with a single tone at $30 \mathrm{~dB}$ hearing level. If the subject failed to signal with a trigger that they heard the tone, the signal was increased by $5 \mathrm{~dB}$. This was repeated until the subject correctly signaled that they heard the tone. If the subject correctly signaled that 
they heard the tone, the signal was decreased by $5 \mathrm{~dB}$. This continued until the subject failed to signal that they heard the tone or when the tone reached $15 \mathrm{~dB}$. Subjects were required to have hearing thresholds below $25 \mathrm{~dB}$ hearing level in each ear at each tested octave band to participate in the main experiment. Testing was done in the test chamber with no controlled external noise present.

The subject was then introduced to the test program. Subjects were introduced to the wireless keyboard to be used with the testing program and were given specific instructions on how to operate the keyboard for the purposes of the experiment. Only the number key pad, arrow keys, backspace key, and enter key were to be used for this test. Subjects were made aware that they would not be able to write out their work and had to input their answer on one line of text on the computer. Because they were free to use a line of text, subject were made aware that they were able to work "right to left" or "left to right" when entering their answer by using the arrow keys to command the cursor.

The subject completed a five minute practice session with the proctor present to answer any general questions about the test for the user. The test proctor ensured that each subject met two conditions: subjects answered at least two questions correct and subjects felt "comfortable" taking this specific type of test. If not, subjects were allowed to take another five minute practice session to see if those conditions were met. If at the end of the orientation session the subjects were not able to answer two questions correctly or feel "comfortable" taking the test, they were not asked to participate in the main experiment. Subjects were encouraged to think about the test, review subtraction skills, and develop a methodology for taking the test before participating in the next test session. 


\section{Questionnaire}

Please rate the conditions in this room based on the following attributes. Please do not skip any questions.

Please base your ratings only on the session today. Do not base your ratings on any previous sessions.

\begin{tabular}{|c|c|c|c|c|c|c|c|c|}
\hline 1 & Air freshness & $\begin{array}{c}1 \\
\text { fresh air }\end{array}$ & 2 & 3 & 4 & 5 & 6 & $\begin{array}{c}7 \\
\text { stale air }\end{array}$ \\
\hline 2 & Temperature comfort & $\begin{array}{c}1 \\
\text { too cold }\end{array}$ & 2 & 3 & 4 & 5 & 6 & $\begin{array}{c}7 \\
\text { too hot }\end{array}$ \\
\hline 3 & Air movement & $\begin{array}{c}1 \\
\text { circulating }\end{array}$ & 2 & 3 & 4 & 5 & 6 & $\begin{array}{c}7 \\
\text { stuffy }\end{array}$ \\
\hline 4 & Loudness of noise & $\begin{array}{c}1 \\
\text { very quiet }\end{array}$ & 2 & 3 & 4 & 5 & 6 & $\begin{array}{c}7 \\
\text { very loud }\end{array}$ \\
\hline 5 & Changes in noise over time & $\begin{array}{c}1 \\
\text { not changing }\end{array}$ & 2 & 3 & 4 & 5 & 6 & $\begin{array}{c}7 \\
\text { changing a lot }\end{array}$ \\
\hline 6 & Rumble of noise & $\begin{array}{c}1 \\
\text { not rumbly }\end{array}$ & 2 & 3 & 4 & 5 & 6 & $\begin{array}{c}7 \\
\text { very rumbly }\end{array}$ \\
\hline 7 & Annoyance to noise & $\begin{array}{c}1 \\
\text { not annoying }\end{array}$ & 2 & 3 & 4 & 5 & 6 & $\begin{array}{c}7 \\
\text { very annoying }\end{array}$ \\
\hline 8 & Noise distractions & $\begin{array}{c}1 \\
\text { not a } \\
\text { problem }\end{array}$ & 2 & 3 & 4 & 5 & 6 & $\begin{array}{c}7 \\
\text { very distracting }\end{array}$ \\
\hline 9 & How bright lights are & $\begin{array}{c}1 \\
\text { not too } \\
\text { bright }\end{array}$ & 2 & 3 & 4 & 5 & 6 & $\begin{array}{c}7 \\
\text { too much light }\end{array}$ \\
\hline 10 & Comfort of work station & $\begin{array}{c}1 \\
\text { comfortable }\end{array}$ & 2 & 3 & 4 & 5 & 6 & $\begin{array}{c}7 \\
\text { uncomfortable }\end{array}$ \\
\hline
\end{tabular}

Fig. 3.10. A copy of the subjective questionnaire that participants completed at the conclusion of each test session. 


\section{Final Questionnaire}

Please provide your gender and age.

Gender: Male Female

Age:

Please rate each statement in order. Please do not skip any questions. If possible, imagine yourself in each situation and response accordingly without spending too much time considering if you agree or disagree with a given statement. We are looking for your personal opinions. There are no correct or incorrect responses.

\begin{tabular}{|c|c|c|c|c|c|}
\hline & & $\begin{array}{l}\text { Strongly } \\
\text { agree }\end{array}$ & $\begin{array}{l}\text { Slightly } \\
\text { agree }\end{array}$ & $\begin{array}{l}\text { Slightly } \\
\text { disagree }\end{array}$ & $\begin{array}{l}\text { Strongly } \\
\text { disagree }\end{array}$ \\
\hline 1 & $\begin{array}{l}\text { I need an absolutely quiet environment to } \\
\text { get a good night's sleep. }\end{array}$ & 1 & 2 & 3 & 4 \\
\hline 2 & $\begin{array}{l}\text { I need quiet surroundings to be able to } \\
\text { work on new tasks. }\end{array}$ & 1 & 2 & 3 & 4 \\
\hline 3 & $\begin{array}{c}\text { When I am at home, I habituate to noise } \\
\text { quickly. }\end{array}$ & 1 & 2 & 3 & 4 \\
\hline 4 & $\begin{array}{l}\text { I become very agitated if I can hear } \\
\text { someone talking while I am trying to fall } \\
\text { asleep. }\end{array}$ & 1 & 2 & 3 & 4 \\
\hline 5 & I am very sensitive to neighborhood noise. & 1 & 2 & 3 & 4 \\
\hline 6 & $\begin{array}{l}\text { When people around me are noisy I don't } \\
\text { get on with my work. }\end{array}$ & 1 & 2 & 3 & 4 \\
\hline 7 & I am sensitive to noise. & 1 & 2 & 3 & 4 \\
\hline 8 & $\begin{array}{l}\text { My performance is much worse in noisy } \\
\text { places. }\end{array}$ & 1 & 2 & 3 & 4 \\
\hline 9 & $\begin{array}{l}\text { I do not feel well rested if there has been a } \\
\text { lot of noise the night before. }\end{array}$ & 1 & 2 & 3 & 4 \\
\hline 10 & $\begin{array}{c}\text { It would not bother me to live in a noisy } \\
\text { street. }\end{array}$ & 1 & 2 & 3 & 4 \\
\hline 11 & $\begin{array}{c}\text { For a quiet place to live I would accept } \\
\text { other disadvantages. }\end{array}$ & 1 & 2 & 3 & 4 \\
\hline 12 & I need peace and quiet to do difficult work. & 1 & 2 & 3 & 4 \\
\hline 13 & I can fall asleep even when it is noisy. & 1 & 2 & 3 & 4 \\
\hline
\end{tabular}

Fig. 3.11. A copy of the noise sensitivity questionnaire that participants completed at the conclusion of their final test session. 


\section{Participants Needed for Research!!}

- Ten 30-minute sessions at your convenience (for a total of 5 hours)

- Must be 19 years of age or older

Sessions will take place in PKI on UNO south campus (Pacific and $67^{\text {th }}$ Street).

\section{You will get PAID for your participation!!! You may earn up to $\$ 100$ for completing all test sessions!}

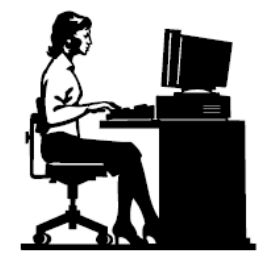

[NOTE: Hearing screening will be administered upon arrival on test site during initial visit. If you are found to have a minimum hearing threshold below $25 \mathrm{~dB} \mathrm{HL}$ from the $125 \mathrm{~Hz}$ to $8 \mathrm{kHz}$ octave bands, you may participate in the main experiment.]

This project is sponsored by UNL; IRB\# 20120412512EP AA/EEO Institution. For special needs or assistance please contact cainley@unomaha.edu

Please contact Christopher Ainley at cainley@unomaha.edu for more information.

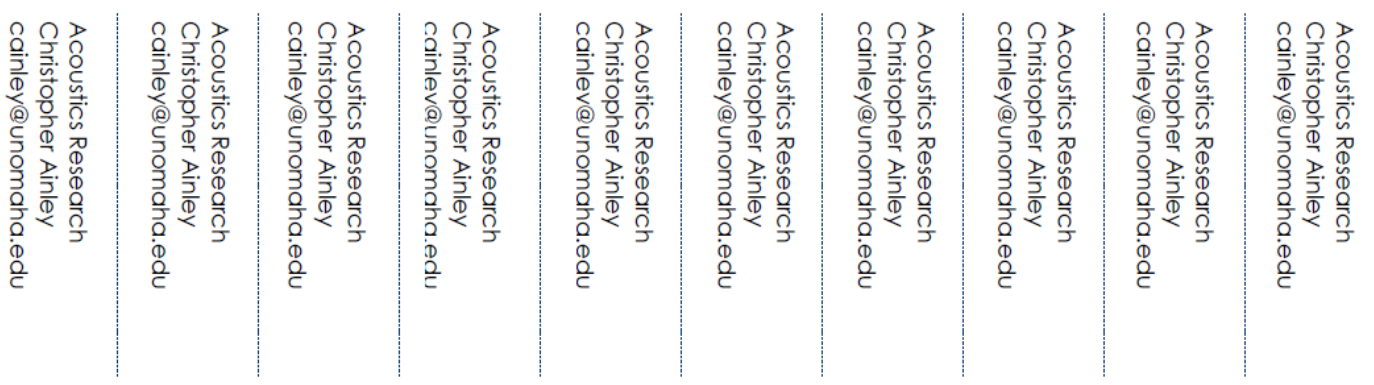

Fig. 3.12. A copy of the recruitment flyer that was posted on the campus of the University of Nebraska. 
Due to the difficulty of this test, five participants dropped out or were asked not to participate after the orientation session. One other participant was asked not to participate because they did not pass the hearing screen. Five additional participants dropped out of the study due to other factors involving scheduling issues.

\subsubsection{Statistical Analysis}

Data were collected from the study and were analyzed using a number of statistical methods in Microsoft Excel and SPSS. Performance data were collected in the form of percentages of correct questions and average time taken to solve each arithmetic problem. Performance data were analyzed across each session as well as across those questions linked to impulses. Perception data were collected from the subjective questionnaires with subjects rating certain attributes on respective number scales.

For most cases, the data exhibited features that required non-parametric tests. Data may be considered suitable for parametric tests if they meet the following conditions: data are measured at an interval or ratio level, data sets have equal variances, and that data set yields a normal distribution. Equal variances across data sets, or homogeneity of variance, may be found by using Levene's test. Normal distribution in a data set was determined by using the Kolmogorov-Smirnov, or K-S, test (Field and Hole 2003). Both parametric and non-parametric tests were implemented so that all possible results from the statistical analysis may be presented and discussed.

\subsubsection{Standard Error of the Mean}

Standard error of the mean (SE) is a standard deviation of the sample means and used to represent how accurate a sample can be. As SE increases, so does the variability of the sample 
means. SE is reported in the form of error bars in results graphs in the next chapter. SE is found by equation 3.1:

$$
\mathrm{SE}=\frac{\mathrm{s}}{\sqrt{\mathrm{N}}}
$$

where $s$ is the sample standard deviation and $N$ is the sample size (Field and Hole 2003).

\subsubsection{Parametric Tests}

General relationships between a single dependent and independent variable were determined using Pearson Product Moment Correlations and linear mixed model analysis in SPSS. An example was the relationship between performance scores and different noise metrics related to each session. Any significant relationships were reported using these test statistics. The Pearson Product Moment Correlations reported the correlation, r, between the two variables and the linear mixed model reported the F value with the numerator and denominator degrees of freedom, or df. The final report for these tests are reported with the respective significance in the following format: $\mathrm{F}_{\mathrm{dfn}, \mathrm{dfd}}=\ldots, \mathrm{r}=\ldots \ldots$, where $d f n$ was the numerator degrees of freedom and $d f d$ was the denominator degrees of freedom as reported by SPSS.

A repeated measures ANOVA was used to compare a dependent variable across multiple independent variables. An example for this was the relationship in perception ratings across the five analyzed test sessions, gender, age, and/or noise sensitivity ratings. Each repeated measures ANOVA test statistic, $\mathrm{F}$, was reported with significance in the following format: $\mathrm{F}(\mathrm{df}, \mathrm{N})=$ where $\mathrm{df}$ is degrees of freedom and $\mathrm{N}$ is sample size. The effect size, also represented by $\mathrm{r}$, was found by using a complex version of effect size, $\omega$, and was found by taking the square root of equation 3.2:

$$
\omega^{2}=\frac{M S_{M}-M S_{R}}{M S_{M}+\left((n-1) * M S_{R}\right)}
$$


where $\mathrm{MS}_{\mathrm{M}}$ is the mean sum of squares, $\mathrm{MS}_{\mathrm{R}}$ is the mean squared error, and $\mathrm{n}$ is the sample size. When the F test statistic was significant, Bonferroni post hoc tests were implemented to find significant differences between the test sessions (Field and Hole 2003).

\subsubsection{Non-Parametric Tests}

In most cases data were found to not have normal distributions which meant that nonparametric tests were appropriate. The parametric tests above may not be accurate for these cases because of a possible inaccurate $\mathrm{P}$ value. Therefore, some non-parametric tests were used and were compared to the parametric tests. A Spearman Correlation, r, was reported with significance in place of the Pearson Product Moment Correlation to find general relationships between a single dependent and independent variable for non-parametric data.

A Friedman's ANOVA, which also utilizes a Wilcoxon test, was used in place of the repeated measures ANOVA to compare a dependent variable across a single independent variable with multiple levels. For example, annoyance ratings were compared across the five analyzed test sessions. Each Friedman test statistic was reported with degrees of freedom, or df, and significance in the following format: $\chi^{2}(\mathrm{df})=$ To find exactly where there were differences between sessions, a Wilcoxon test was utilized with a Bonferroni correction. The Wilcoxon test statistic, T, was reported along with the effect size, r. Effect size is found using equation 3.3:

$$
r=\frac{Z}{\sqrt{N}}
$$

where $\mathrm{Z}$ is the $\mathrm{z}$-score produced by SPSS and $\mathrm{N}$ is the total number of observations compared (Field and Hole 2003). 


\subsubsection{Statistical Power Analysis}

A power analysis was also implemented to determine the probability of each result presenting a genuine effect. This is reported as an observed power from 0 to 1 , as reported by SPSS with $\alpha=0.05$, and it is reported for each repeated measures ANOVA test. Some references state that a power of at least 0.8 is recommended for most tests to conclude that the result exhibits a genuine effect (Field and Hole 2003). 


\section{Chapter 4: Results and Discussion}

This chapter presents the results from analysis of the test signals, task performance, and subjective perception. Test signals are analyzed and reported using the noise metrics previously discussed. Task performance and subjective perception results are reported and analyzed using the statistical analysis methodology previously discussed.

\subsection{Demographic Results}

There were 27 total test subjects: 15 males and 12 females. The average age was 24 years old. The youngest and oldest participants were 19 and 38, respectively.

Noise sensitivity questionnaires were distributed at the end of each participant's final session; the results are shown by question in Figure 4.1. Each question was weighted and then an average was calculated according to work by Schutte et al. to calculate a total noise sensitivity percentage for each subject (2007). The average total noise sensitivity percentage was $47.3 \%$ across all subjects with a standard error of the mean of $3.5 \%$.

Noise sensitivity, gender, and age were factored as additional variables when analyzing complex relationships between noise conditions, task performance, and subjective perception. This will be further discussed later in this chapter.

\subsection{Signal Results}

\subsubsection{Background Noise Results}

Figure 4.2 reports the natural background noise level of the test room as $\mathrm{L}_{\mathrm{eq}}$ measured over 10 seconds on a Larson-Davis 824 sound level meter. Although the noise level was too low to generate a room criteria $(\mathrm{RC})$ reading on the sound level meter, it can be reported as an NCB$22(\mathrm{H})$. This value was too low for the purposes of this study, which was one reason why a generated background noise .wav file was implemented. 


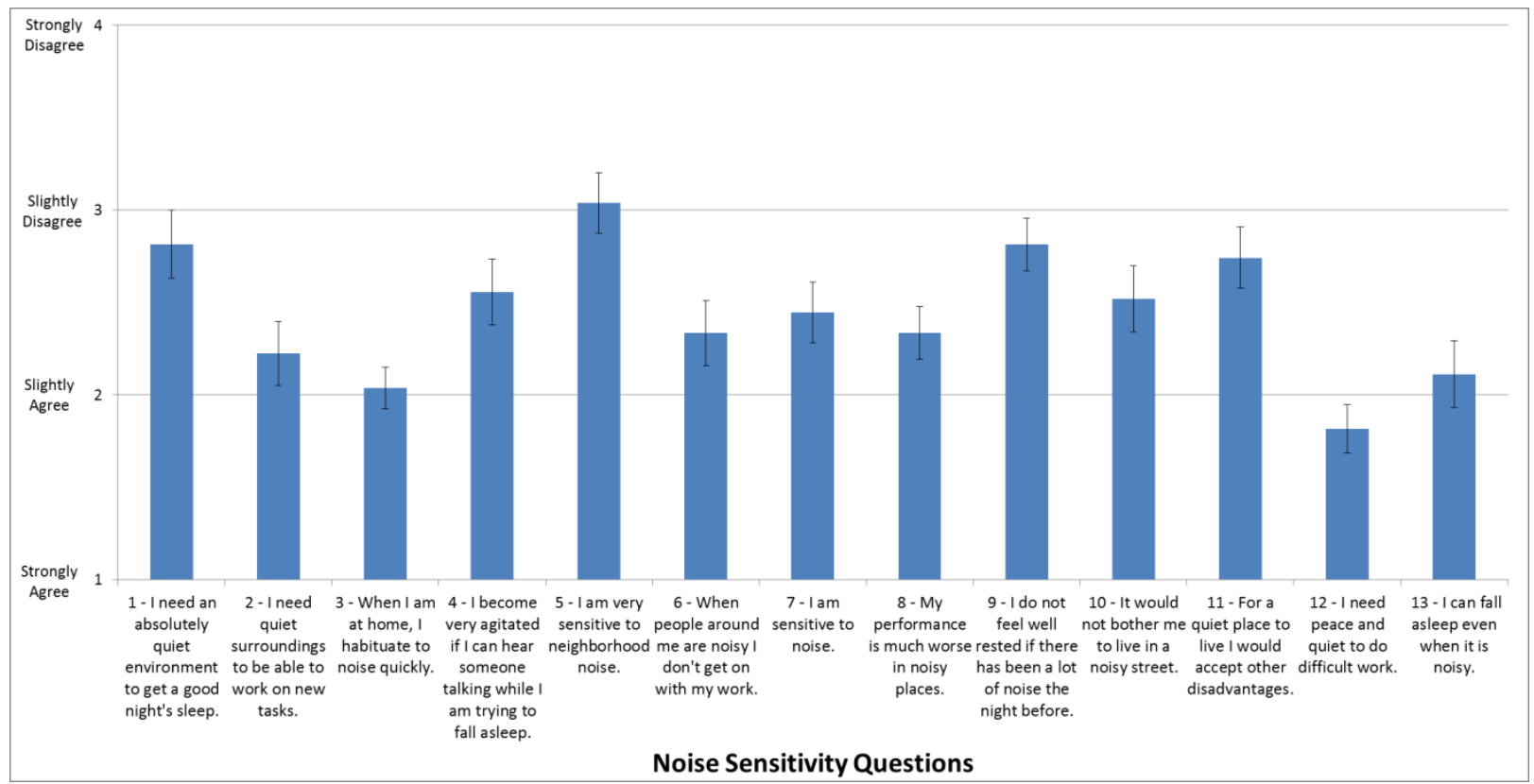

Fig. 4.1. Results of noise sensitivity questionnaires. Error bars represent the standard error of the mean.

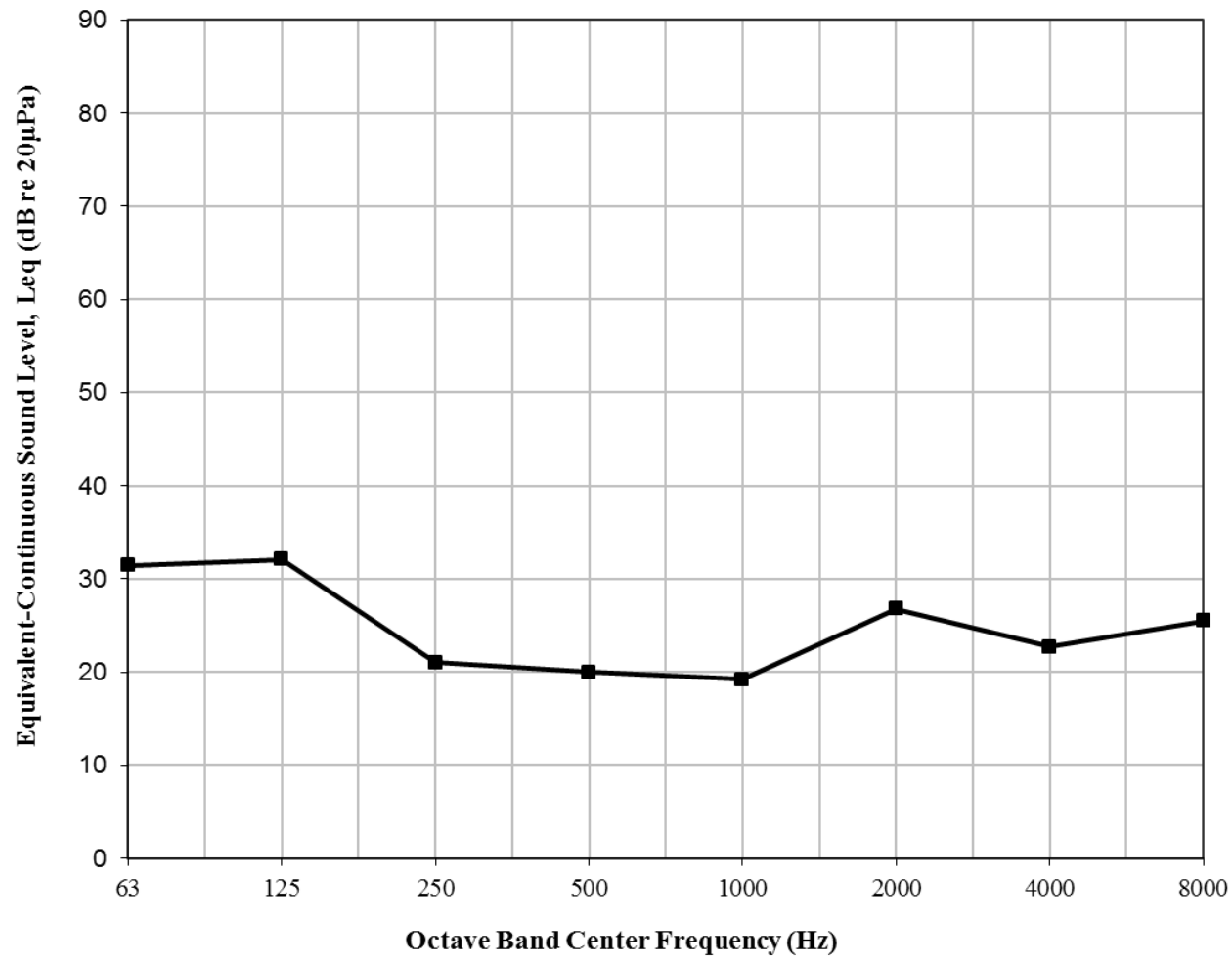

Fig. 4.2. Measurement of $\mathrm{L}_{\mathrm{eq}}$ across frequency in test room. Results yield an NCB-22 (H) 
A higher ambient background noise level was generated as discussed in the previous chapter in section 3.2.1.2. Figure 4.3 reports the measured ambient level in the room under this setup as measured with a Larson-Davis 824 sound level meter over a 2 minute analysis interval. The final result was an overall sound pressure level of $37 \mathrm{dBA}$ and an RC-29 (H).

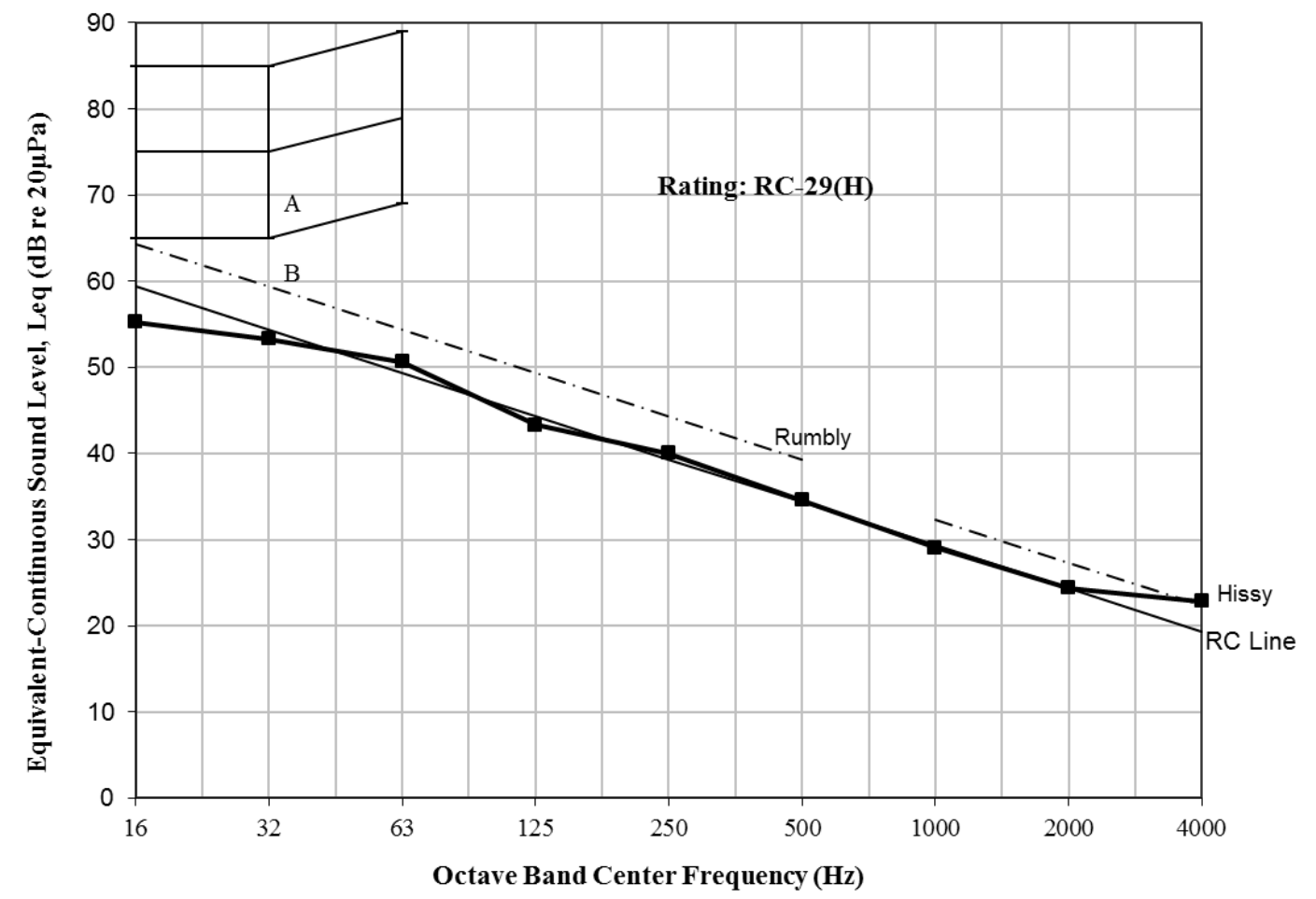

Fig. 4.3. Measurement of $\mathrm{L}_{\mathrm{eq}}$ across frequency of the ambient BNL .wav when played back in test room. Results yield overall SPL of $37 \mathrm{dBA}$ and an RC-29 (H).

A louder ambient background noise was also generated as discussed in the previous chapter in section 3.2.1.2. Figure 4.4 reports the measured ambient level in the room under this setup as measured with a Larson-Davis 824 sound level meter over a 2 minute analysis interval. The final result was an RC-47 (RV). This signal was only used in the second group of testing as discussed throughout the previous chapter. No further analysis was done on this group of testing or on this signal. 


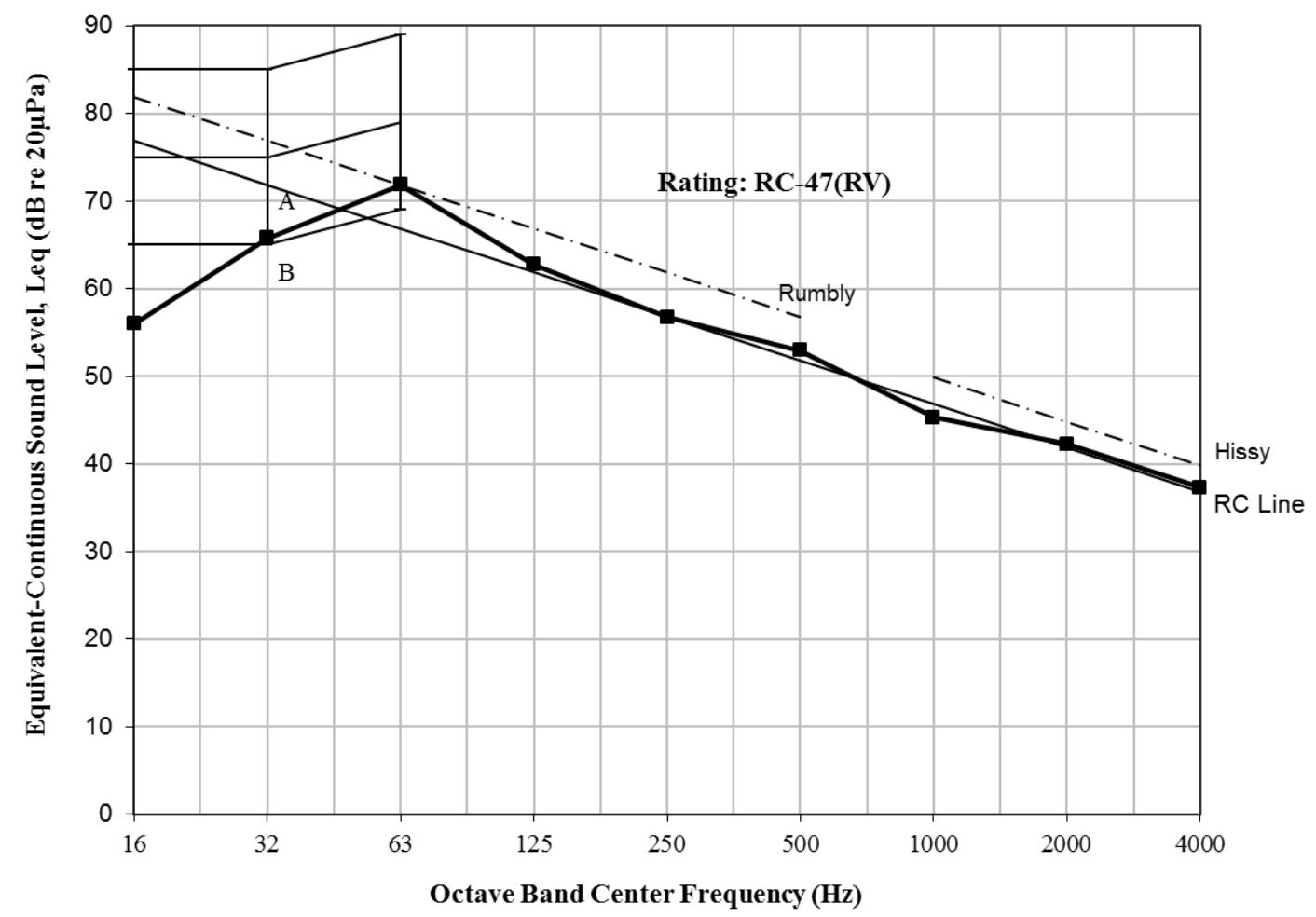

Fig. 4.4. Measurement of $\mathrm{L}_{\mathrm{eq}}$ across frequency of the louder ambient BNL .wav when played back in test room. Results yield an RC-47 (RV).

\subsubsection{Impulse Results}

Impulses were measured as discussed in section 3.2.2.2. Original impulse calibrations found that the continuously played signals had overall sound pressure levels with A-weightings to be approximately 50, 60, 70 and $80 \mathrm{dBA}$. Therefore, the impulses were titled, "Impulse 50", "Impulse 60", "Impulse 70", and "Impulse 80", respectively.

Assorted metrics as listed in the previous chapter were additionally calculated for each impulse signal across different time intervals: 1, 5, 10, 30, 60, and 120 seconds. For some calculations, such as $\mathrm{L}_{\mathrm{eq}}$ and $\mathrm{L}_{1}-\mathrm{L}_{99}$, the squared pressure data was averaged across the respective time interval and then converted back to sound pressure level. Other calculations, such as 
Perceived Level (PL) and Perceived Noise Level (PNL), required the squared pressure data to be averaged over an auditory time constant and then converted back to sound pressure level as discussed previously in section 3.2.2.2. Results are presented for each noise metric in this section.

\subsubsection{Peak Sound Pressure Levels $\left(L_{p k}\right)$}

Peak sound pressure levels $\left(\mathrm{L}_{\mathrm{pk}}\right)$ were analyzed for each noise burst. Total peak values correspond to the maximum instantaneous sound pressure level during the measurement. The overall peak sound pressure levels for the four levels of the impulse were $64,74,84$, and $100 \mathrm{~dB}$. The spectral results for the total peak $\left(\mathrm{L}_{\mathrm{pk}}\right)$ of each impulse are shown in Figure 4.5.

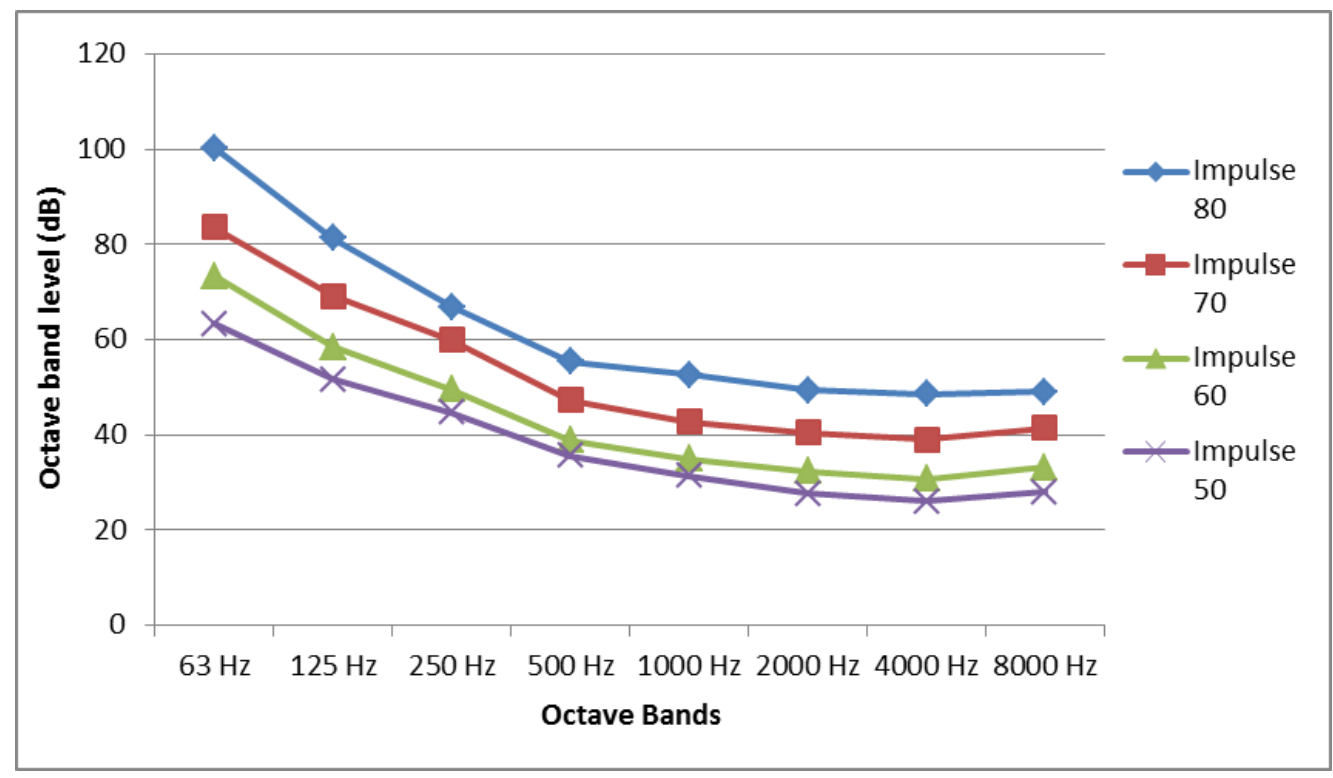

Fig. 4.5. Spectra of total peak sound pressure levels $\left(\mathrm{L}_{\mathrm{pk}}\right)$ for the four impulse signals. Results yield overall peak SPL of $64,74,84$, and $100 \mathrm{~dB}$ respectively.

The peak A-weighted sound pressure levels $\left(\mathrm{L}_{\mathrm{Apk}}\right)$ were additionally analyzed for each noise burst. These values correspond to the maximum instantaneous A-weighted sound pressure level during the measurement. Note that the maximum instantaneous sound pressure level $\left(\mathrm{L}_{\mathrm{pk}}\right)$ 
and the maximum instantaneous A-weighted sound pressure level $\left(\mathrm{L}_{\mathrm{Apk}}\right)$ are not necessarily at the same measurement point in time. The overall peak A-weighted sound pressure levels for the four levels of the impulse were $47,57,67$, and $77 \mathrm{dBA}$.

The ambient background noise, RC-29 (H), was also analyzed for both $\mathrm{L}_{\mathrm{pk}}$ and $\mathrm{L}_{\mathrm{Apk}}$. The values for these metrics were $56 \mathrm{~dB}$ and $39 \mathrm{dBA}$, respectively.

\subsubsection{Equivalent-Continuous Sound Level $\left(L_{e q}\right)$}

Overall $\mathrm{L}_{\mathrm{eq}}$ was measured from the data and is shown in Figure 4.6 for each impulse signal and the lower ambient BNL across each time interval. Generally, $\mathrm{L}_{\mathrm{eq}}$ increases as the time interval around each impulse is narrowed, as expected.

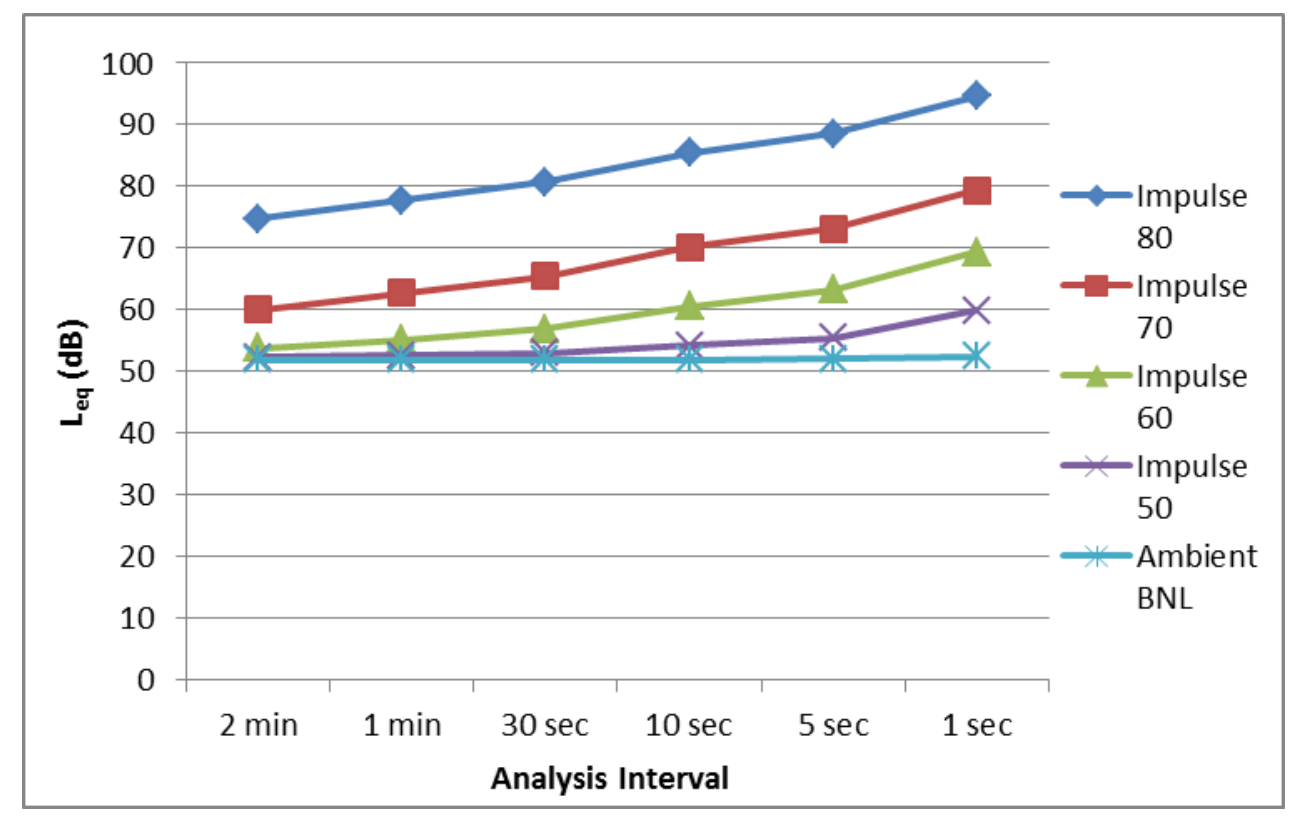

Fig. 4.6. Overall $\mathrm{L}_{\mathrm{eq}}$ across each time interval of analysis for each impulse signal and the lower ambient BNL.

\subsubsection{3. $L_{1}-L_{99}$}

$\mathrm{L}_{1}-\mathrm{L}_{99}$ results are shown in Figure 4.7 for each impulse signal and the lower ambient BNL across each time interval of analysis. The values for $\mathrm{L}_{1}-\mathrm{L}_{99}$ generally increase for the 
impulse signals as the time interval decreases. Likewise, at a time interval of one second there is not as much background noise so L 99 typically increases relative to the level of the impulse, which causes the decrease between time intervals of five seconds to one second for $\mathrm{L}_{1}-\mathrm{L}_{99}$.

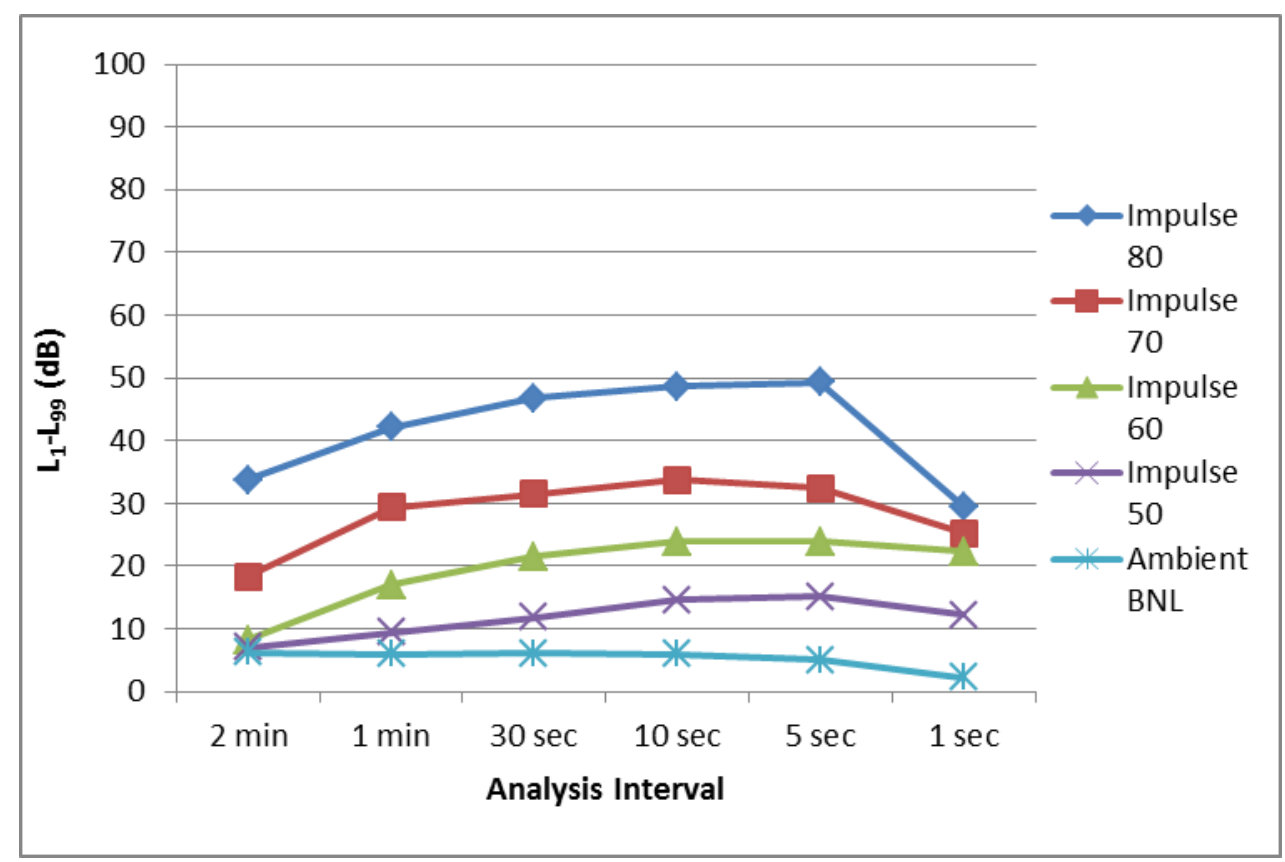

Fig. 4.7. $\mathrm{L}_{1}-\mathrm{L}_{99}$ across each time interval of analysis for each impulse signal and the lower ambient BNL.

\subsubsection{Sound Exposure Level (ASEL/CSEL)}

Results for A-weighted sound exposure level (ASEL) and C-weighted sound exposure level (CSEL) are shown in Figure 4.8 and Figure 4.9, respectively, for each impulse signal and the ambient BNL across each time interval of analysis. Results show that as the impulse level increases, the time interval of analysis is no longer a factor. This should be expected for sound exposure level measurements. However, the time interval becomes a factor as the level of impulse decreases. This is due to the calculation procedure for SEL. For example when measuring ASEL, the A-weighted sound exposure, $\mathrm{E}_{\mathrm{A}, \mathrm{T}}$, is found at each measurement point in 
time and then summed over the analysis interval. The A-weighted sound exposure values at measurement points during the impulse are significantly higher than the A-weighted sound exposure values at measurement points during the remaining ambient background noise. For example, A-weighted sound exposure values during the "Impulse 80" were approximately around the range of $10^{-3}$ to $10^{-4} \mathrm{~Pa}^{2} \cdot \mathrm{s}$. A-weighted sound exposure values during the background noise were typically around $10^{-7} \mathrm{~Pa}^{2} \cdot \mathrm{s}$.

It should be noted that there was some issue when selecting which 1 second time interval to analyze. This is because one second did not adequately cover all of the significant data for each impulse relative to the ambient background noise. In this case, the impulse was analyzed in the center of the time interval. This was especially clear in the "Impulse 80" data. This is curious since impulses were only $250 \mathrm{~ms}$ in length. It is possible that this was due to residual vibrations that were not completely damped in the room during the experiment.

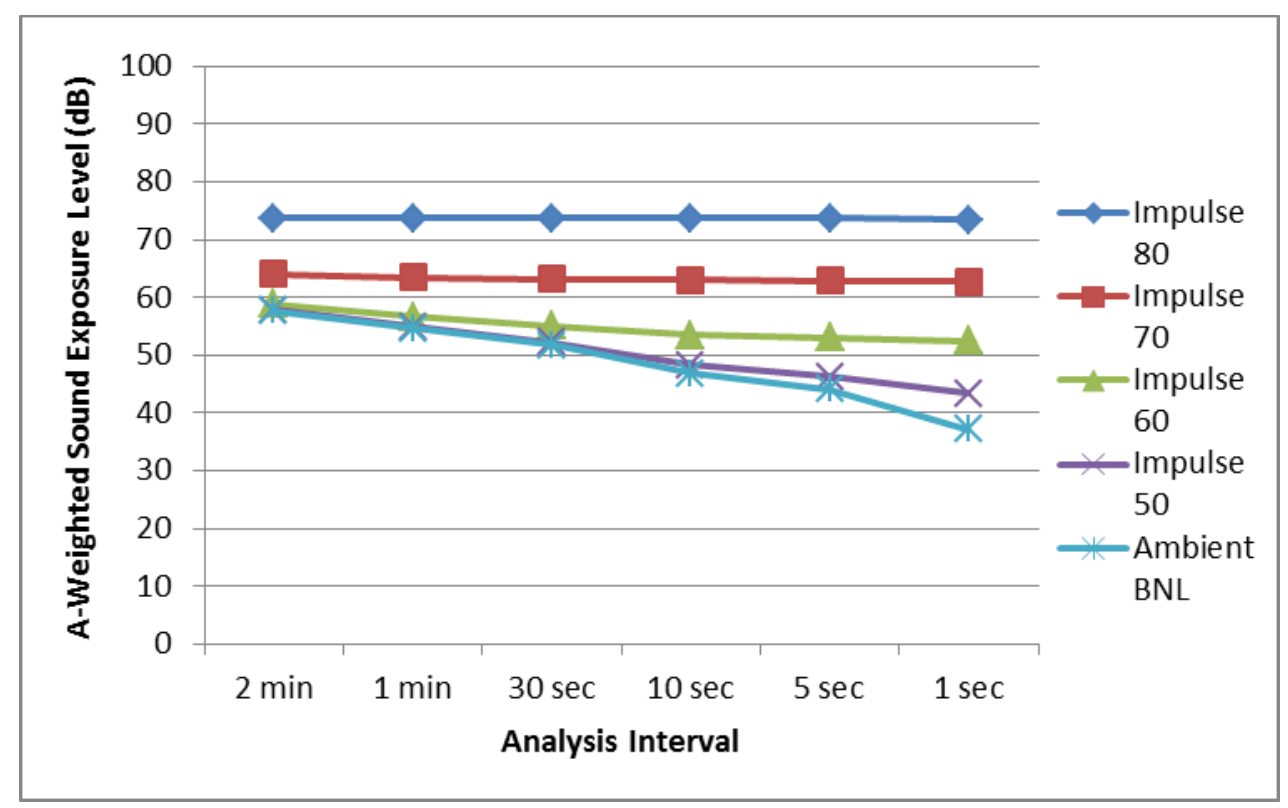

Fig. 4.8. ASEL across each time interval of analysis for each impulse signal and the lower ambient BNL. 


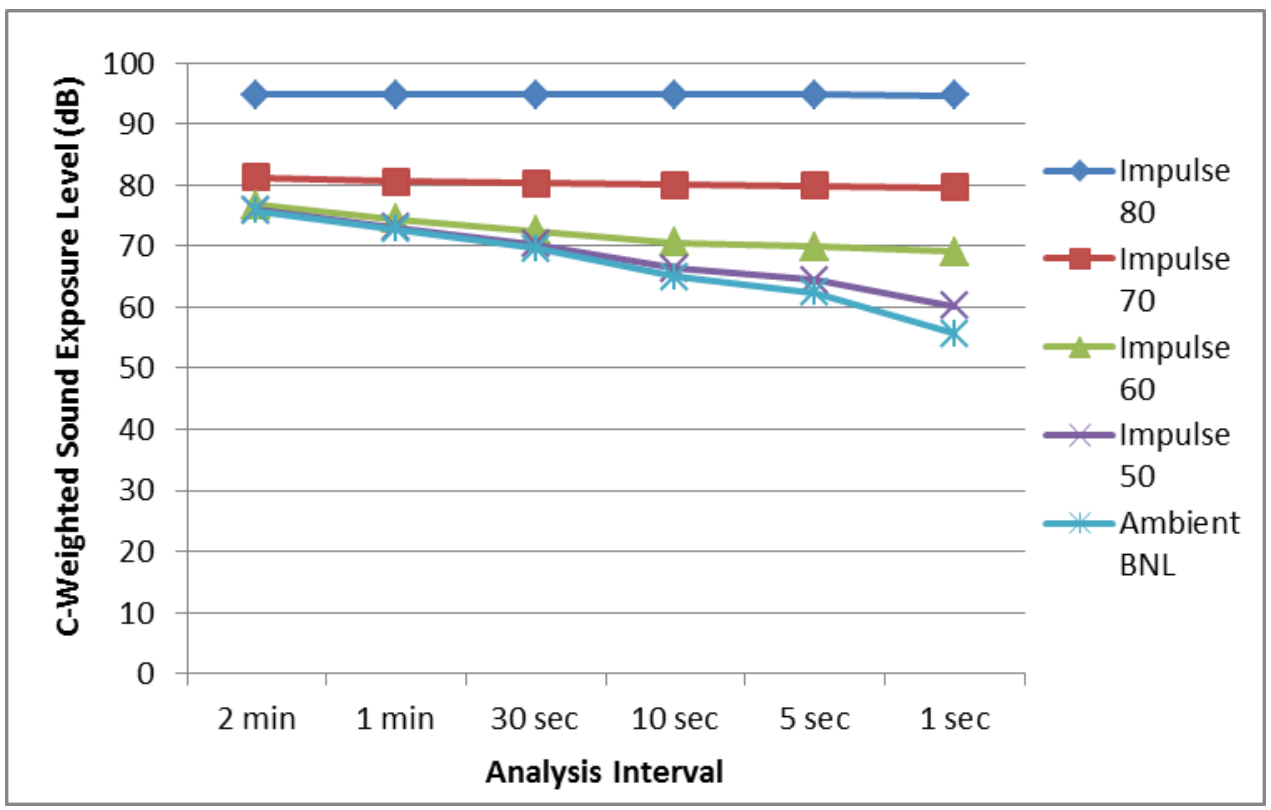

Fig. 4.9. CSEL across each time interval of analysis for each impulse signal and the lower ambient BNL.

\subsubsection{Perceived Level (PL)}

1/3 octave band data for both PL and PNL are acquired slightly differently. Rather than a $\log$ average of the $1 / 3$ octave band data over a time interval, the data are divided over an auditory time constant as reported in section 3.2.2.2.

PL results are shown in Figure 4.10 for each impulse signal and the ambient BNL across each time interval of analysis. PL results match trends of SEL in that as the impulse increases, the time interval does not impact the results as much. 


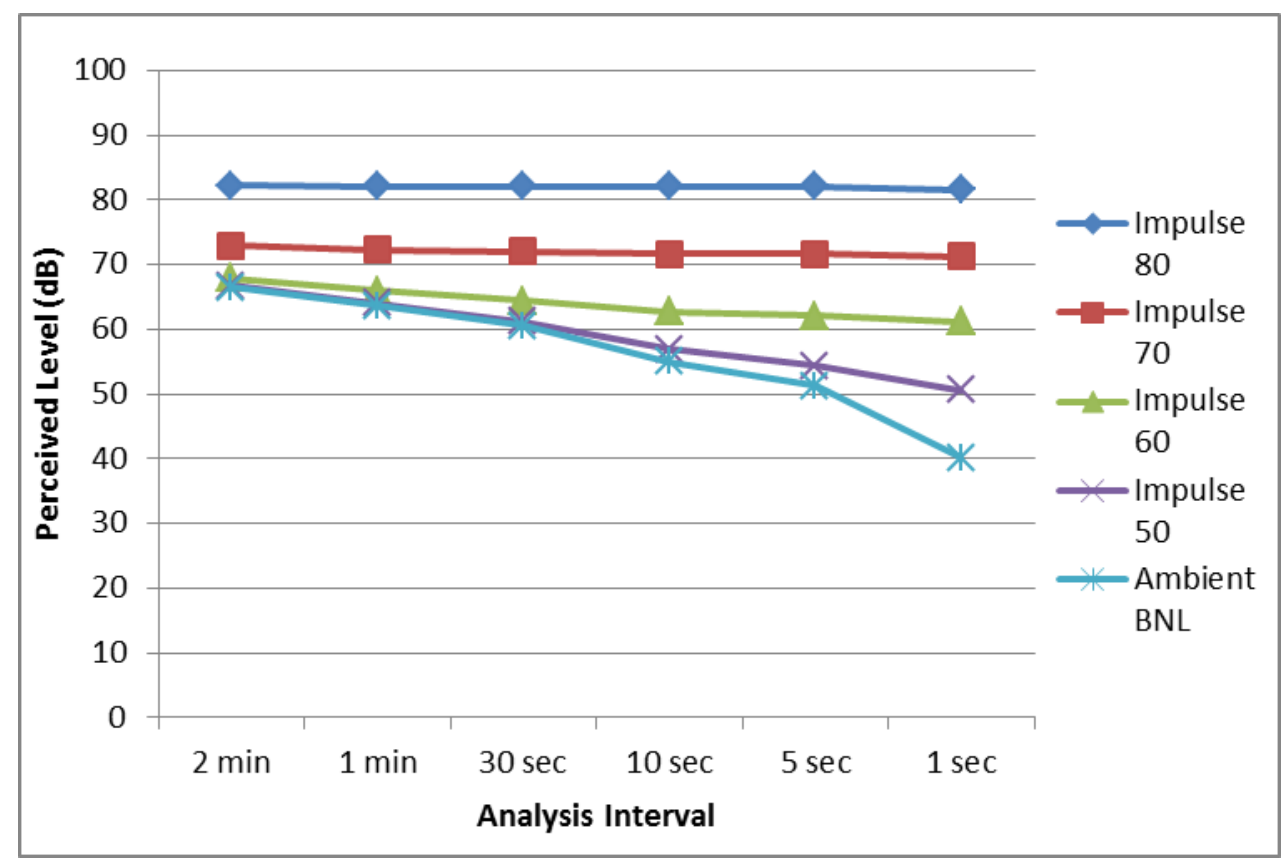

Fig. 4.10. PL across each time interval of analysis for each impulse signal and the lower ambient BNL.

\subsubsection{Perceived Noise Level (PNL)}

PNL results are shown in Figure 4.11 for each impulse signal and the ambient BNL across each time interval of analysis. As with SEL and PL, the results generally do not change across time intervals of analysis for higher level impulses. However the PNL of the lower level impulses decrease with a decrease in time interval. This highlights the significance of time intervals for analysis of impulsive signals, especially for lower noise burst levels. However if the lower level impulses are found to not have a significant effect on human performance and/or perception, this may not be a great concern. 


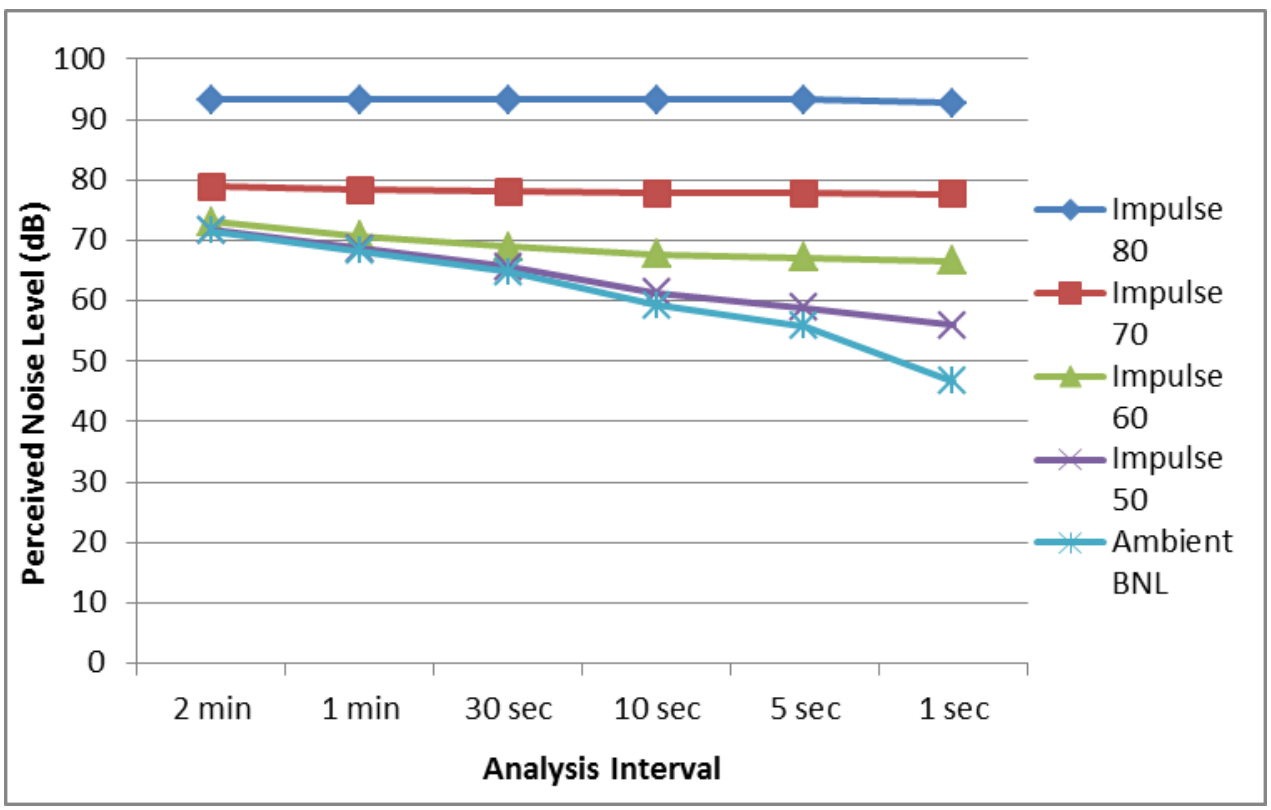

Fig. 4.11. PNL across each time interval of analysis for each impulse signal and the lower ambient BNL.

\subsection{Task Performance Results}

Task performance was measured in terms of the total percentage of correct answers and the average time taken, in seconds, to perform the arithmetic tasks. Statistical analyses using SPSS were conducted as described earlier in section 3.2.4. Some results exhibited a non-normal distribution, as concluded by a Kolmogorov-Smirnov test. In those cases, a Spearman correlation coefficient was used in addition to the Pearson coefficient. The Friedman ANOVA, a nonparametric test, was also used to analyze these relationships. Wilcoxon tests were used to further analyze the relationships between each noise condition. A Bonferroni correction was applied and all effects are reported at a 0.005 level of significance since a number of 10 statistical tests were completed (Field and Hole 2003).

Additionally, repeated measures ANOVA was still used to further strengthen the results even though it is a parametric test. The observed power, as reported by SPSS with $\alpha=0.05$, is 
reported for each repeated measures ANOVA test. Further results of the repeated measures ANOVA from SPSS, including sum of squares, mean square, and degrees of freedom are reported in Appendix A.

\subsubsection{Task Performance Results across Noise Conditions}

The overall task performance results across all test sessions are shown in Figures 4.12 and 4.13. There are no apparent general trends. The standard error of the mean bars overlap, suggesting that there are no significant relationships to report.

These relationships were further analyzed using Pearson Product Correlation Coefficient as well as a linear mixed model analysis. These tests were deemed appropriate after running a Kolmogorov-Smirnov test on the results of total percent correct and average time taken for each test session. The test found each data set had a normal distribution. However both statistical tests found no significant relationships between the total percentage of correct answers or the average time taken for each question across different impulse sessions.

\subsubsection{Task Performance Results across Presented Test Order}

This section discusses the performance results across the order of test sessions as seen by the subject. The overall task performance results across all test sessions as presented in order to each subject are shown in Figures 4.14 and 4.15. A trend can initially be seen that subjects performed better in terms of increase in total percentage of correct answers accompanied with faster response times, as each subject participated in more sessions. The Pearson Correlation Coefficient and a repeated measures ANOVA were used to further analyze the relationships. 


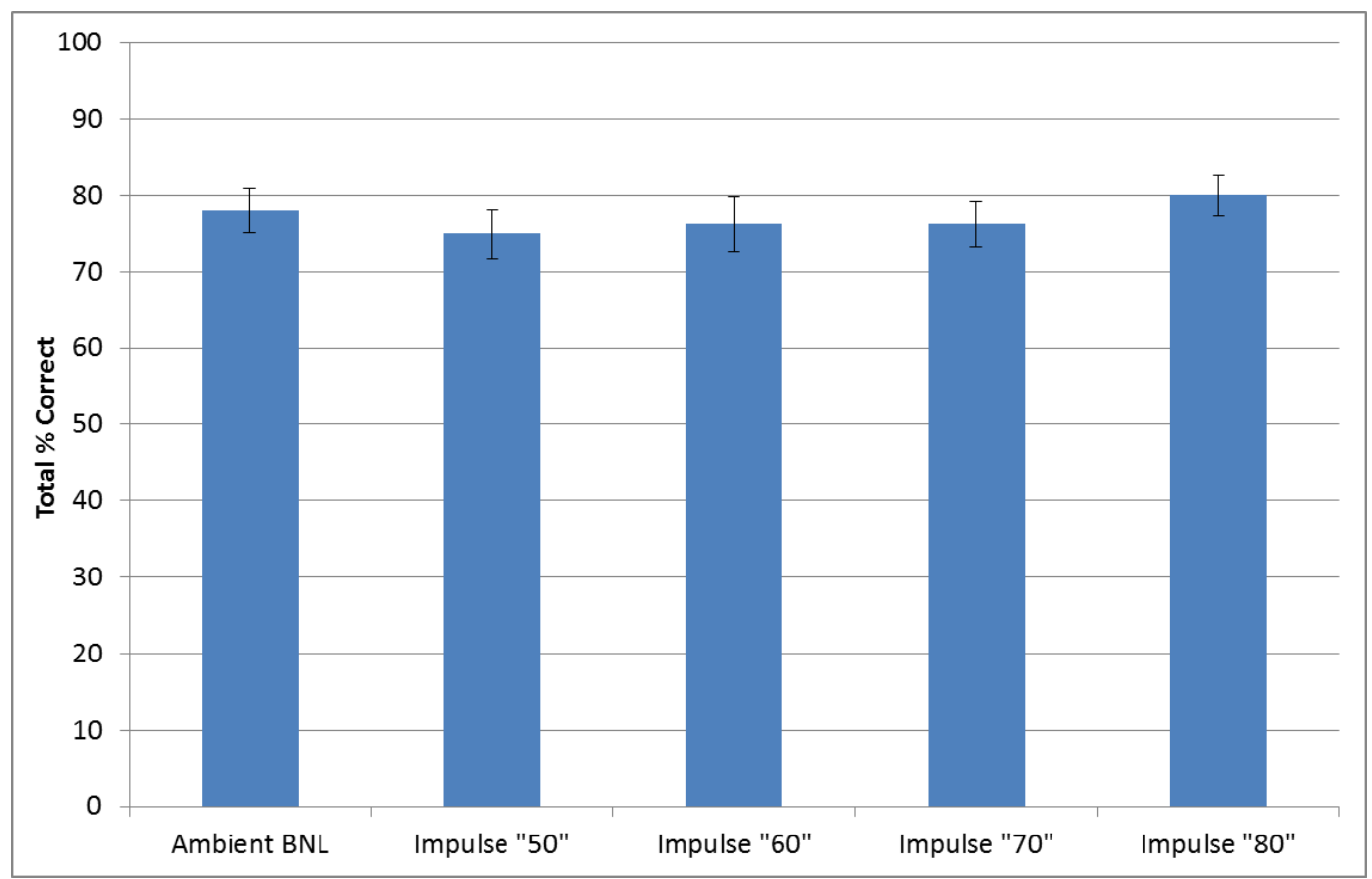

Fig. 4.12. Overall percentage of correct answers for each test session. Error bars represent the standard error of the mean.

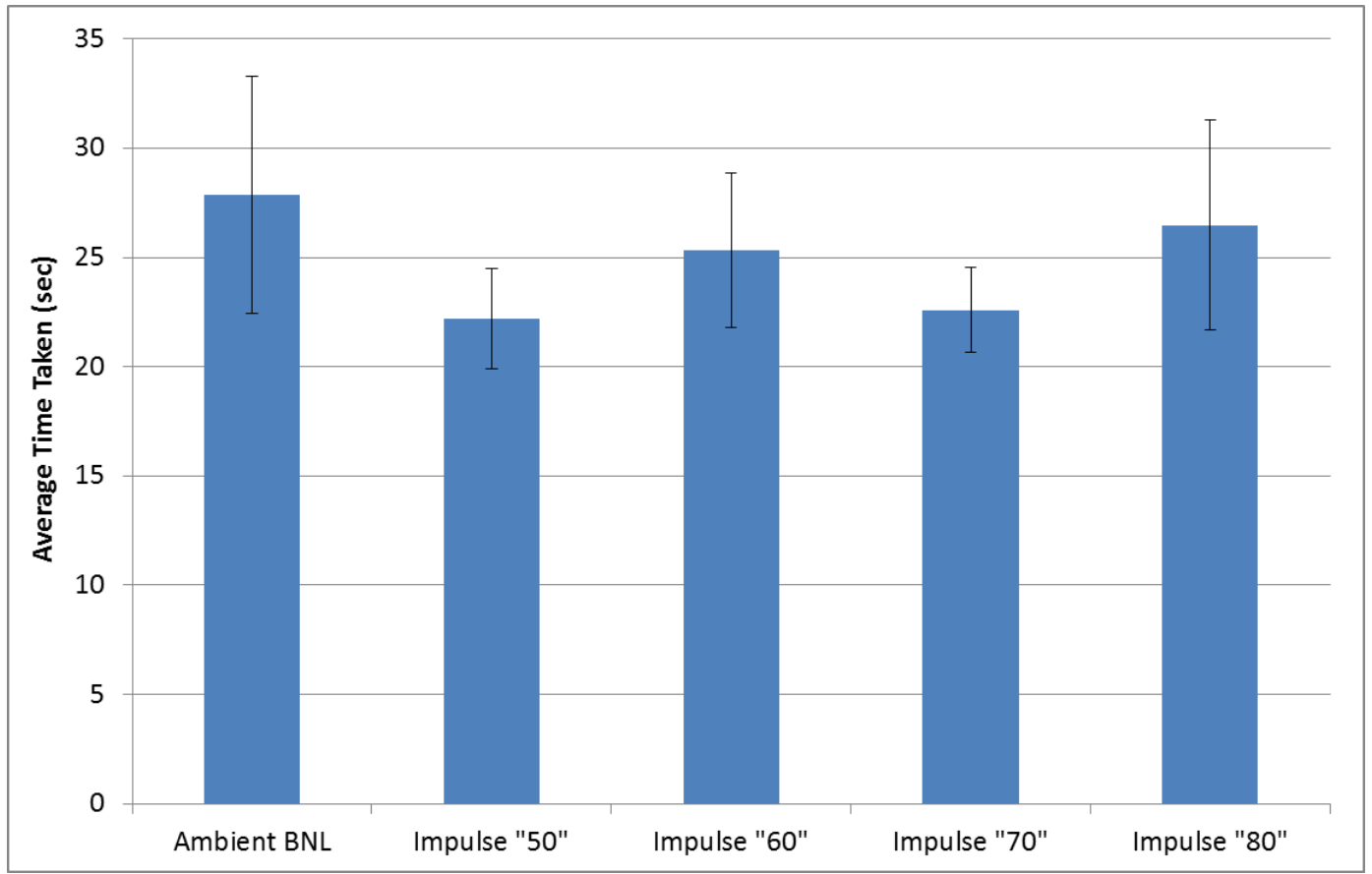

Fig. 4.13. Average time taken in seconds for test questions in each test session averaged across all test sessions. Error bars represent the standard error of the mean. 
For total percentage of correct answers across test sessions in order of presentation, there was a small, positive correlation that was significant according to the Pearson Correlation Coefficient, $\mathrm{r}=0.35, \mathrm{p}<0.01$. For ANOVA testing, Mauchly's sphericity was violated $\left(\chi^{2}(9)=\right.$ $16.98, \mathrm{p}<0.05)$. Greenhouse-Geisser estimates of sphericity were used to correct the degrees of freedom and still displayed a significant effect with a large effect size, $F(2.844,73.94)=12.39$, $p$ $<0.001, \mathrm{r}=0.70$. The observed power for this test was 1.000 , or $100 \%$, according to the results reported by SPSS with $\alpha=0.05$. This is not to suggest that there is a $100 \%$ chance that these results are exhibiting a genuine effect, but just that the probability is very good. Bonferroni post hoc tests found significance between the first presented test session when compared to the next four presented test sessions. However, no other significant relationships between test sessions were found. The results of these relationships are shown in Table 4.1.

For average time taken for each test question across test sessions in order of presentation , there was a small, negative correlation that was significant according to the Pearson Correlation Coefficient, $\mathrm{r}=-0.38, \mathrm{p}<0.01$. For ANOVA testing, Mauchly's sphericity was violated $\left(\chi^{2}(9)=\right.$ 163.47, $\mathrm{p}<0.01)$. Greenhouse-Geisser estimates of sphericity were used to correct the degrees of freedom and still displayed a significant effect with a large effect size, $\mathrm{F}(1.123,29.19)=17.592$, $\mathrm{p}<0.001, \mathrm{r}=0.63$. The observed power for this test was 0.988 , or $98.8 \%$, according to the results reported by SPSS with $\alpha=0.05$. This is an acceptable power result. Bonferroni post hoc tests found significant relationships as shown in Table 4.2.

In both of these measures of task performance, subjects significantly improved from the first test session to each of the next four test sessions. Subjects also significantly increased their pace of answering problems in concurrent test sessions between the first three sessions. This exhibits a practice effect which was seen in previous experiments (Woodhead, 1964). This is the 
reason that a Latin square design was implemented to evenly distribute the types of test sessions across test order.

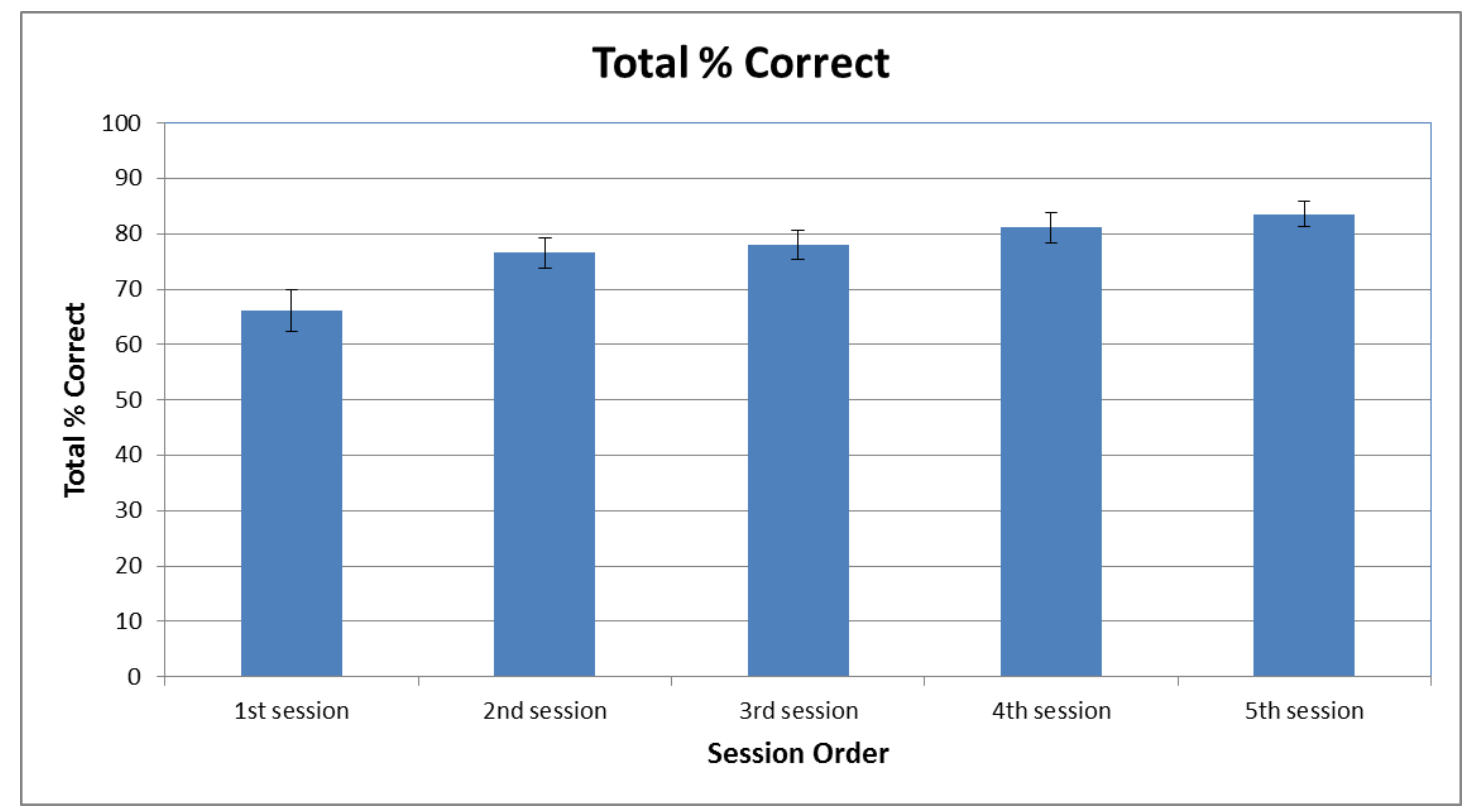

Fig. 4.14. The overall percentage of correct answers for each test session in order as seen by each subject. Error bars represent the standard error of the mean.

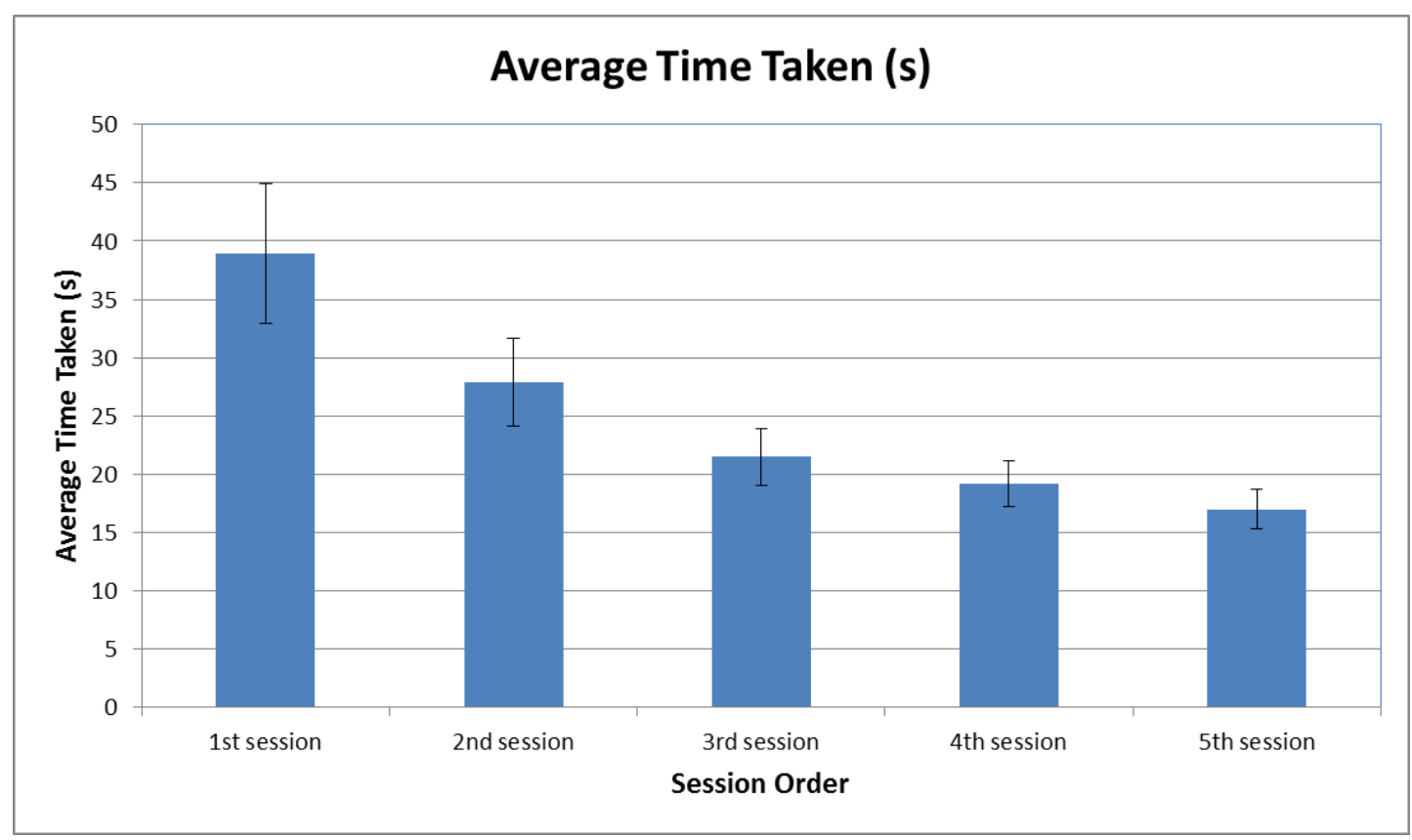

Fig. 4.15. The average time taken in seconds for test questions in each test session in order as seen by each subject. Error bars represent the standard error of the mean. 
Table 4.1. Results of the Bonferroni post hoc test for overall percentage of correct answers for test questions in each test session in order as seen by each subject.

\begin{tabular}{|l|l|l|l|l|l|}
\hline \multicolumn{7}{|c|}{ Task Total \% Correct across Test Session Order } \\
\hline & 1st Session & 2nd Session & 3rd Session & 4th Session & 5th Session \\
\hline 1st Session & - & $* *$ & $* *$ & $* *$ & $* *$ \\
\hline 2nd Session & $* *$ & - & & & \\
\hline 3rd Session & $* *$ & & - & & \\
\hline 4th Session & $* *$ & & & - & \\
\hline 5th Session & $* *$ & & & & - \\
\hline
\end{tabular}

${ }^{* *}$ Indicates the mean difference between noise conditions is significant, $p<0.05$

Table 4.2. Results of the Bonferroni post hoc test for average time taken for test questions in each test session in order as seen by each subject.

\begin{tabular}{|l|l|l|l|l|l|}
\hline \multicolumn{6}{|c|}{ Task Total Average Time across Test Session Order } \\
\hline & 1st Session & 2nd Session & 3rd Session & 4th Session & 5th Session \\
\hline 1st Session & - & $* *$ & $* *$ & $* *$ & $* *$ \\
\hline 2nd Session & $* *$ & - & $* *$ & $* *$ & $* *$ \\
\hline 3rd Session & $* *$ & $* *$ & - & & $* *$ \\
\hline 4th Session & $* *$ & $* *$ & & - & \\
\hline 5th Session & $* *$ & $* *$ & $* *$ & & - \\
\hline
\end{tabular}

$* *$ Indicates the mean difference between noise conditions is significant, $p<0.05$

\subsubsection{Comparison of Test Questions Linked to Impulses to the Same Test Questions Presented}

\section{Without Impulses}

Another analysis of performance involved the specific test questions linked to the impulses. These results are compared to the same test questions presented at a different time without an impulse, which will be referred to as "non-impulse-presented questions". The nonimpulse-presented questions may have appeared up to two additional times for each participant, depending on the pace of the subject. The impulse-presented questions were presented to subjects at a minimum of two times in a given session depending on the pace of the subject as discussed in section 3.2.3.2. The number of impulse-presented questions that each subject 
experienced for each test session is shown in Figure 4.16. In the case that a subject did not complete a certain impulse-presented question, the results of the corresponding questions were removed from the final analysis. The total percentage correct and average time taken, in seconds, for questions linked to an impulse and the same questions presented without an impulse are shown in Figures 4.17 and 4.18, respectively.

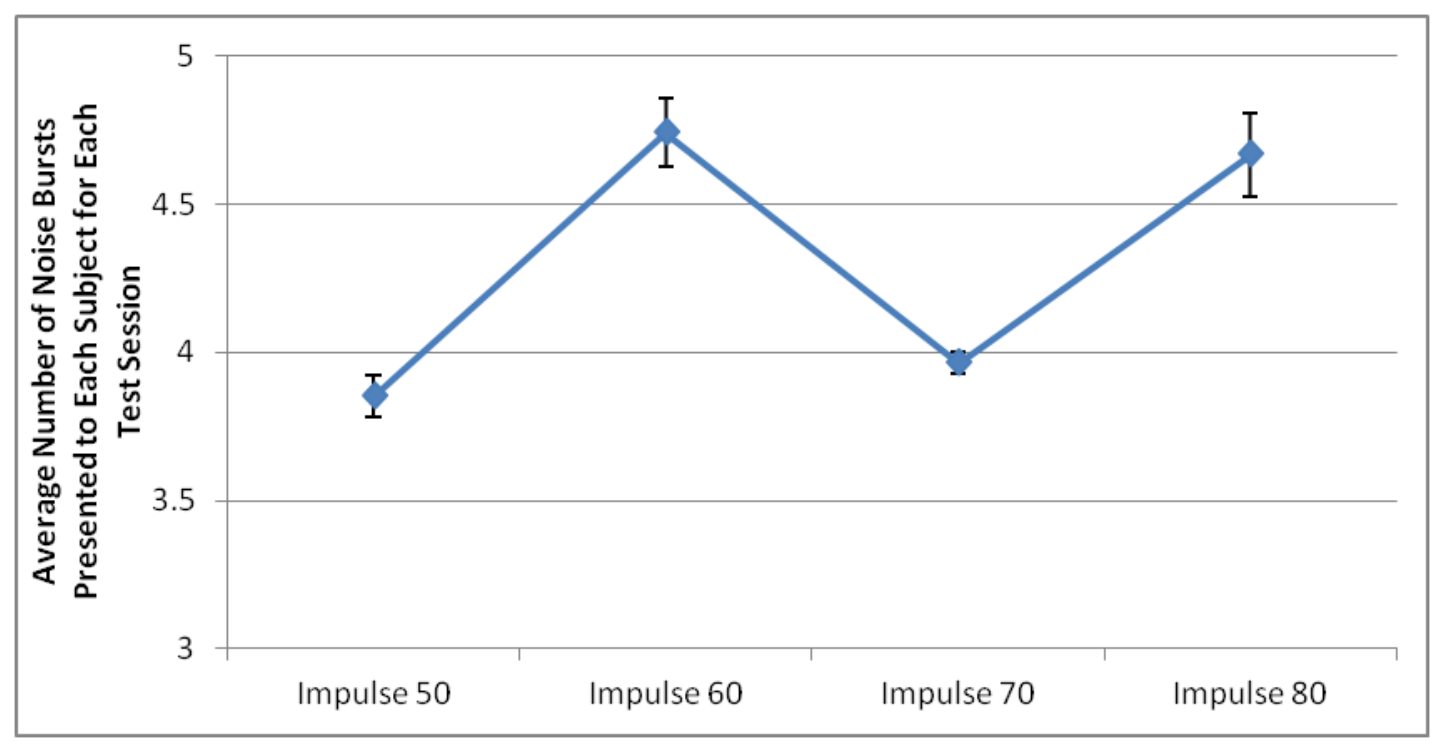

Fig. 4.16. Average number of noise bursts presented to each subject for each test session. Error bars represent the standard error of the mean. 


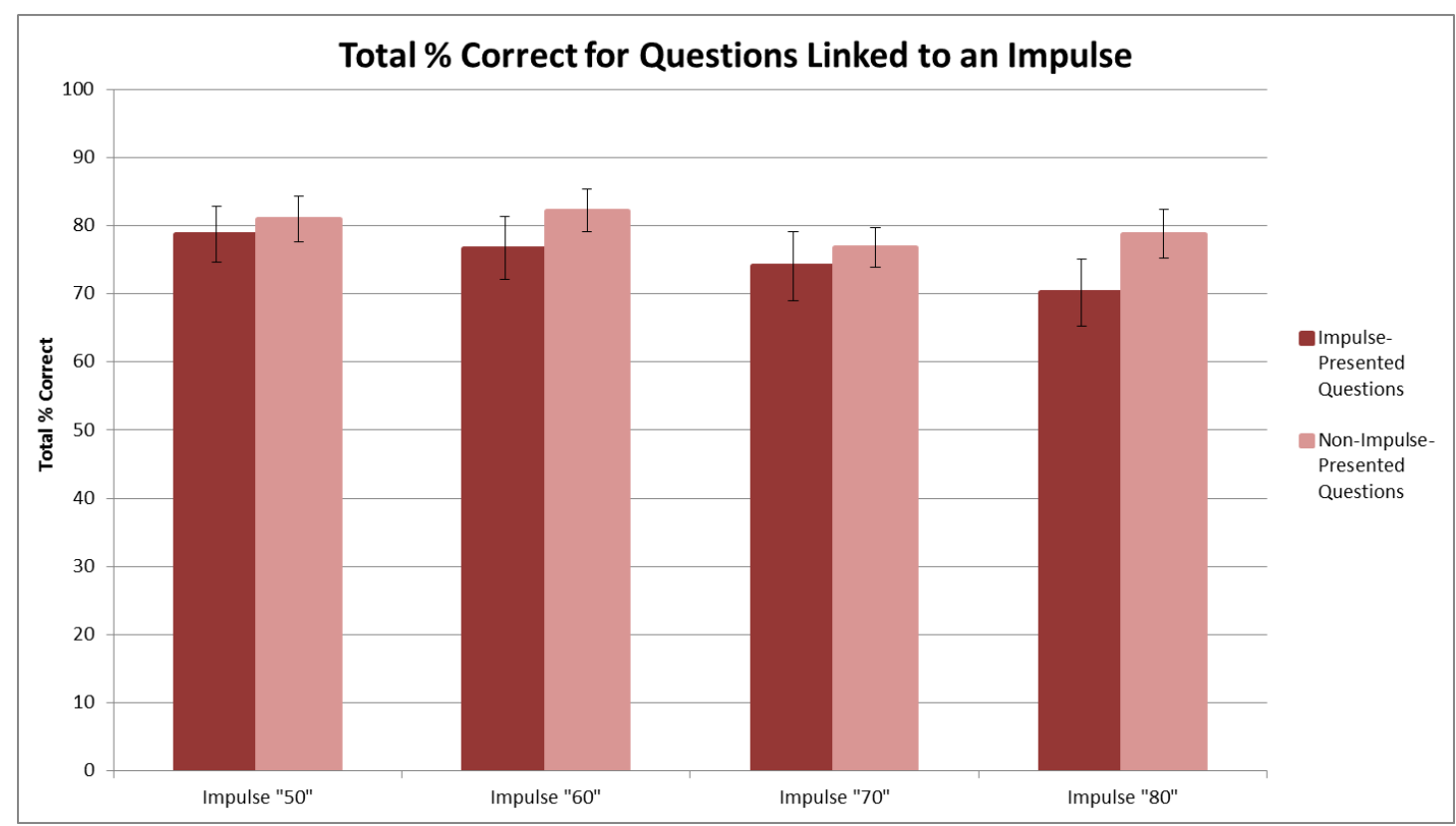

Fig. 4.17. Results of the overall percentage of correct answers for questions linked to respective impulses and again for those same questions when presented without an impulse. Error bars represent the standard error of the mean.

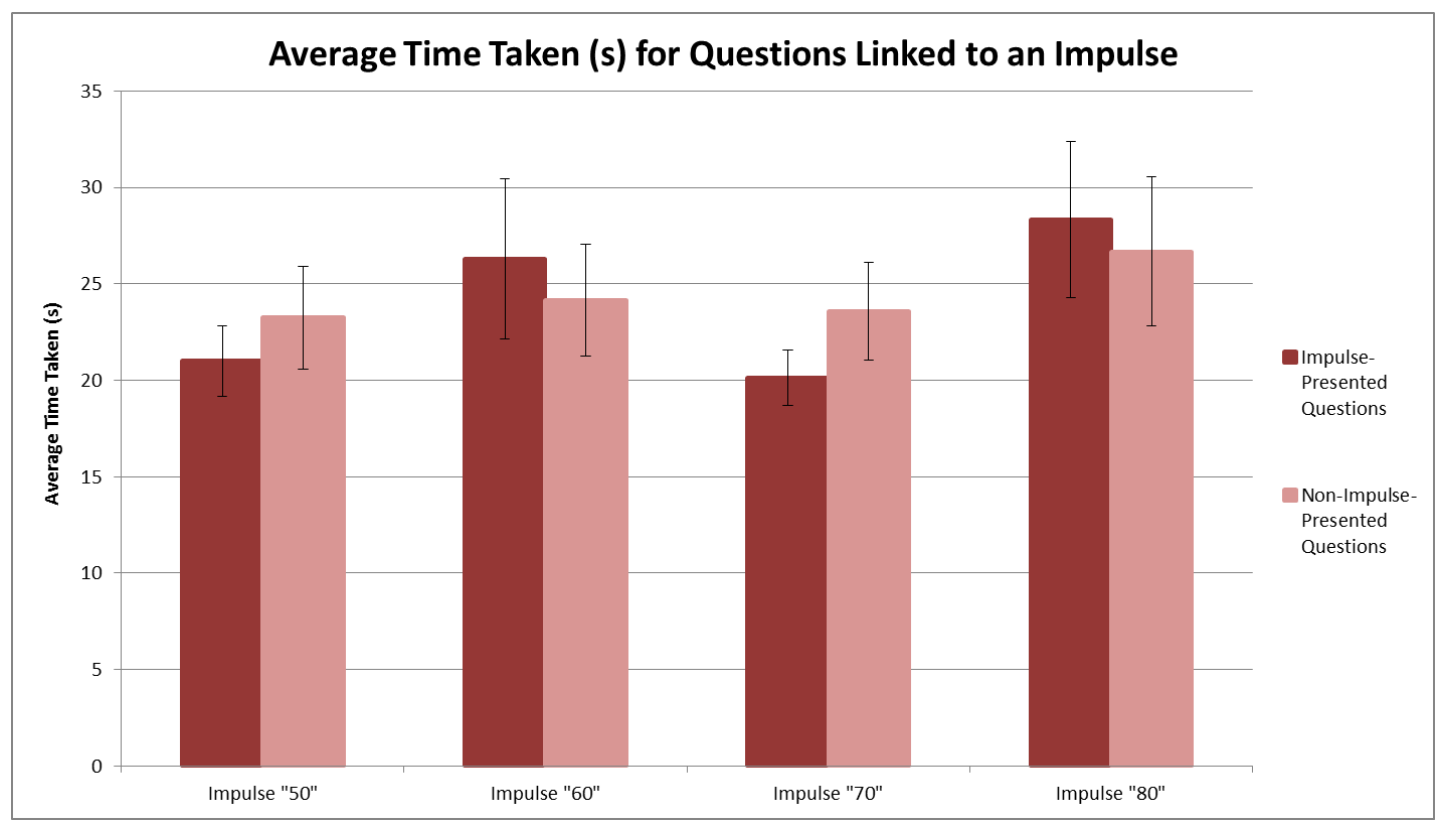

Fig. 4.18. Results of the average time taken in seconds for questions linked to respective impulses and again for those same questions when presented without an impulse. Error bars represent the standard error of the mean. 
The percentages of correct impulse-presented questions by subjects were generally worse than when those same questions were presented without an impulse. Additionally, the percentage of correct impulse-presented questions decreased as the impulse level increased. However, these trends remain within the range of the standard error of the mean bars and appear to not have significant relationships. The relationships across test sessions were further analyzed using repeated measures ANOVA and Friedman ANOVA. All statistical tests found no significant relationships across test sessions.

The average time taken for impulse-presented questions by subjects across noise conditions was analyzed using a repeated measures ANOVA where a significant relationship was found, $\mathrm{F}(2.45,526.72)=3.266, \mathrm{p}<0.05, \mathrm{r}=0.33$. This was found after the Huynh-Feldt correction for non-sphericity was used since Mauchly's sphericity was violated, $\chi^{2}(5)=26.23$, $\mathrm{p}<0.05$. Bonferroni post hoc tests did not find any significant relationships. The effect size was considered medium and the observed power reported by SPSS with $\alpha=0.05$ was only 0.661 , or $66.1 \%$. These results are presented with caution because a power of 0.8 or higher is generally considered acceptable. Friedman's ANOVA was also used and did not find any statistically significant relationships between noise conditions, $\mathrm{p}<0.001$.

The relationship between impulse-presented and non-impulse-presented questions that were the same was analyzed using paired $t$ tests and Wilcoxon tests. Wilcoxon tests were chosen as many of the data sets exhibited non-normal distributions based on results from the Kolmogorov-Smirnov test. Although there are trends that show a decrease in total percentage of correct answers of impulse-presented questions and a decrease in performance from nonimpulse-presented questions, the statistical analyses indicate no significant relationships between the performance between impulse-presented questions and non-impulse-presented questions. 


\subsubsection{Relationships of Task Performance Results to Noise Metrics}

Task performance was compared to the different noise metric results for each impulse to find any correlations between task performance and each noise metric. A Pearson Product Correlation Coefficient, Spearman Coefficient, and a linear mixed model analysis were analyzed for each relationship. No significant relationships were found for either test. This is not surprising since there were not many significant relationships found when testing ANOVA on task performance across noise conditions.

\subsubsection{Comparisons of Task Performance to Subjective Perception}

Task performance was related to subjective perception results by using Pearson and Spearman Correlation Coefficients, as well as a linear mixed model analysis. The results for all three tests are shown in Table 4.3. No significance was found between any combination of task performance and subjective perception, except for a significant relationship between the average time taken for each problem and the reported change in noise over time for the corresponding session, $\mathrm{p}<0.05$.

The relationship between the changes in noise perception ratings and corresponding average time taken for test problems are shown in Figure 4.19. They show a small, positive correlation that means when ratings for changes in noise over time increased, the average time taken for each test question generally increased. These results are presented with caution because there are small sample sizes for the highest perception ratings and because the standard error of the mean increases dramatically for the highest rating. 


\section{$\underline{\text { Table } 4.3}$}

The linear mixed model F values, Pearson correlation coefficients, and Spearman correlation coefficients between subjective perception of noise and performance of the task. The only significant relationships occur between perception of changes in noise over time and the average time taken for each problem in a given session, $\mathrm{p}<0.05$.

\begin{tabular}{|c|c|c|c|c|c|c|}
\cline { 2 - 7 } \multicolumn{2}{c|}{} & \multicolumn{4}{c|}{ Subject Questionnaire Results } \\
\hline \multirow{3}{*}{ Task Performance Results } & $\begin{array}{c}\text { Statistical } \\
\text { Measure }\end{array}$ & Loudness & $\begin{array}{c}\text { Change in } \\
\text { Noise Over } \\
\text { Time }\end{array}$ & Rumble & Annoyance & Distraction \\
\hline \multirow{3}{*}{ Average Time } & $\mathrm{F}_{1,134}$ & $\mathrm{~ns}$ & $4.36^{*}$ & $\mathrm{~ns}$ & $\mathrm{~ns}$ & $\mathrm{~ns}$ \\
\cline { 2 - 8 } & Pearson $(\mathrm{r})$ & $\mathrm{ns}$ & $.178^{*}$ & $\mathrm{~ns}$ & $\mathrm{~ns}$ & $\mathrm{~ns}$ \\
\cline { 2 - 8 } & Spearman $(\mathrm{r})$ & $\mathrm{ns}$ & $.202^{*}$ & $\mathrm{~ns}$ & $\mathrm{~ns}$ & $\mathrm{~ns}$ \\
\hline \multirow{3}{*}{ Correct } & $\mathrm{F}_{1,134}$ & $\mathrm{~ns}$ & $\mathrm{~ns}$ & $\mathrm{~ns}$ & $\mathrm{~ns}$ & $\mathrm{~ns}$ \\
\cline { 2 - 8 } & Pearson $(\mathrm{r})$ & $\mathrm{ns}$ & $\mathrm{ns}$ & $\mathrm{ns}$ & $\mathrm{ns}$ & $\mathrm{ns}$ \\
\cline { 2 - 8 } & Spearman $(r)$ & $\mathrm{ns}$ & $\mathrm{ns}$ & $\mathrm{ns}$ & $\mathrm{ns}$ & $\mathrm{ns}$ \\
\hline
\end{tabular}

*significant at $p<0.05$, ns $=$ not significant

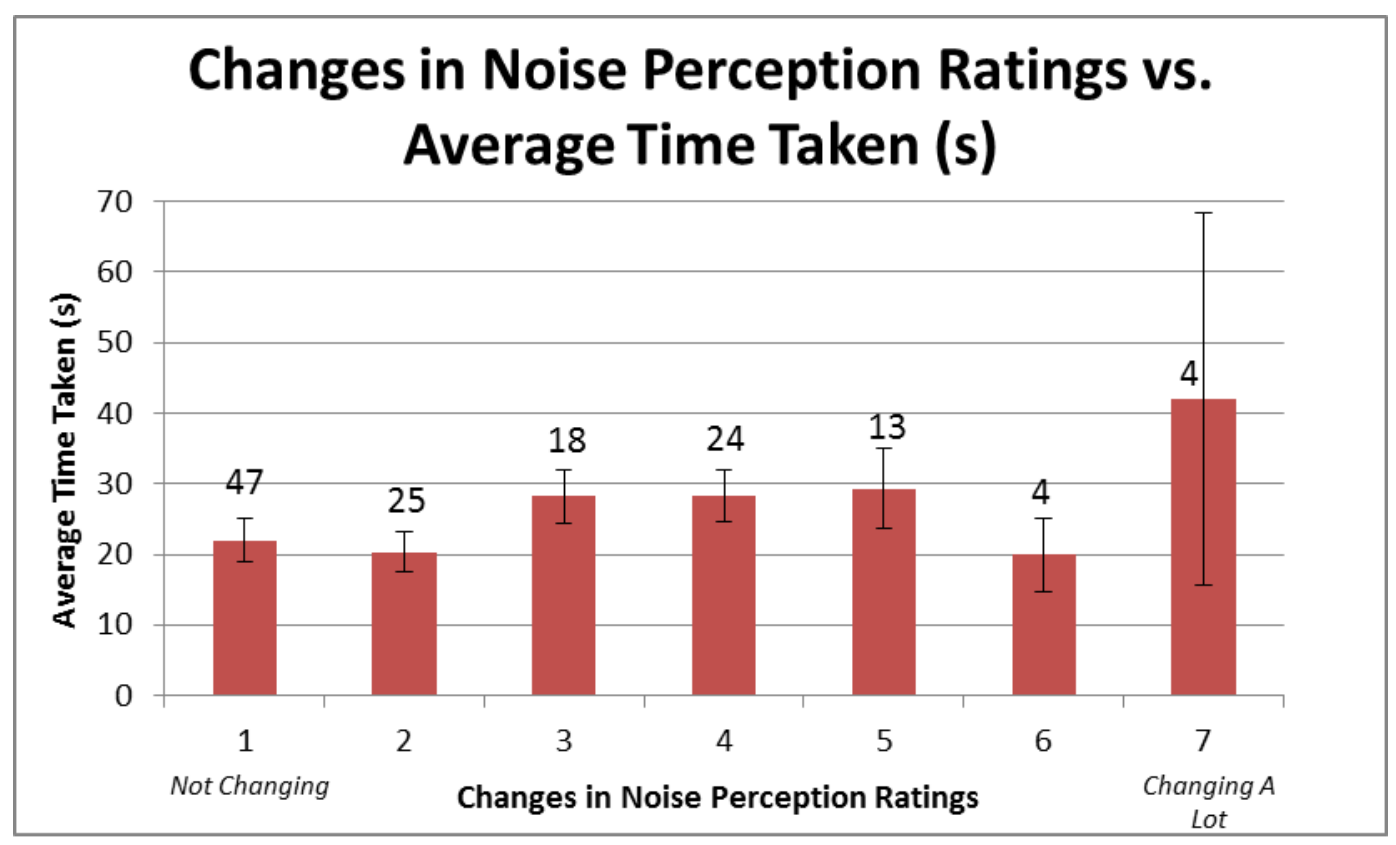

Fig. 4.19. Results of the perception ratings of changes in noise and the corresponding average time taken to solve task problems in a given session. Error bars represent the standard error of the mean. Numbers represent the sample size for each response. 


\subsection{Subjective Perception Results}

\subsubsection{Subjective Perception Results across Noise Conditions}

For each session participants were asked to rate their perception of the loudness of noise, change in noise over time, rumble of noise, annoyance to noise, and noise distractions (see Section 3.2.3.2). These ratings were compared across the five noise conditions previously mentioned. All results exhibited a non-normal distribution, as concluded by a KolmogorovSmirnov test. Therefore the Friedman ANOVA, a non-parametric test, was used to analyze these relationships. Wilcoxon tests were used to further analyze the relationships between each noise condition. A Bonferroni correction was applied and all effects are reported at a 0.005 level of significance.

Additionally, repeated measures ANOVA was still used to further strengthen the results even though it is a parametric test. The observed power, as reported by SPSS with $\alpha=0.05$, is reported for each repeated measures ANOVA test. Further results of the repeated measures ANOVA from SPSS, including sum of squares, mean square, and degrees of freedom are reported in Section 4.4.3.

\subsubsection{Loudness of Noise across Noise Conditions}

The loudness of noise ratings were significantly affected by the different noise conditions, $\chi^{2}(4)=55.95, p<0.05$. As the noise level increased, so did the ratings of loudness of noise. The average perception ratings for loudness of noise in each noise condition are shown in Figure 4.20. The results of the Wilcoxon test are shown in Table 4.4. 


\section{Table 4.4}

Wilcoxon Results between Noise Condition and Loudness of Noise. A Bonferroni correction was applied and all effects denoted with $* *$ are significant at a 0.005 level of significance.

\begin{tabular}{|c|c|c|c|c|c|}
\hline \multicolumn{6}{|c|}{ Loudness ratings between sessions } \\
\hline & & Impulse "50" & Impulse "60" & Impulse "70" & Impulse "80" \\
\hline \multirow{3}{*}{ Ambient BNL } & $\mathrm{T}$ & 84.00 & 21.50 & 15.50 & 3.00 \\
\hline & sig & $n s$ & $n s$ & $* *$ & $* *$ \\
\hline & effect size & -0.11 & -0.36 & -0.44 & -0.61 \\
\hline \multirow{3}{*}{ Impulse "50" } & $\mathrm{T}$ & & 30.00 & 41.00 & 4.00 \\
\hline & sig & & $n s$ & $* *$ & $* *$ \\
\hline & effect size & & -0.30 & -0.41 & -0.58 \\
\hline \multirow{3}{*}{ Impulse "60" } & $\mathrm{T}$ & & & 28.00 & 4.00 \\
\hline & sig & & & $n s$ & $* *$ \\
\hline & effect size & & & -0.25 & -0.60 \\
\hline \multirow{3}{*}{ Impulse "70" } & $\mathrm{T}$ & & & & 35.00 \\
\hline & sig & & & & $* *$ \\
\hline & effect size & & & & -0.45 \\
\hline
\end{tabular}

$*^{*}=$ Indicates the mean ranks between noise conditions is significant, $\mathrm{p}<0.005, \mathrm{~ns}=$ not significant.

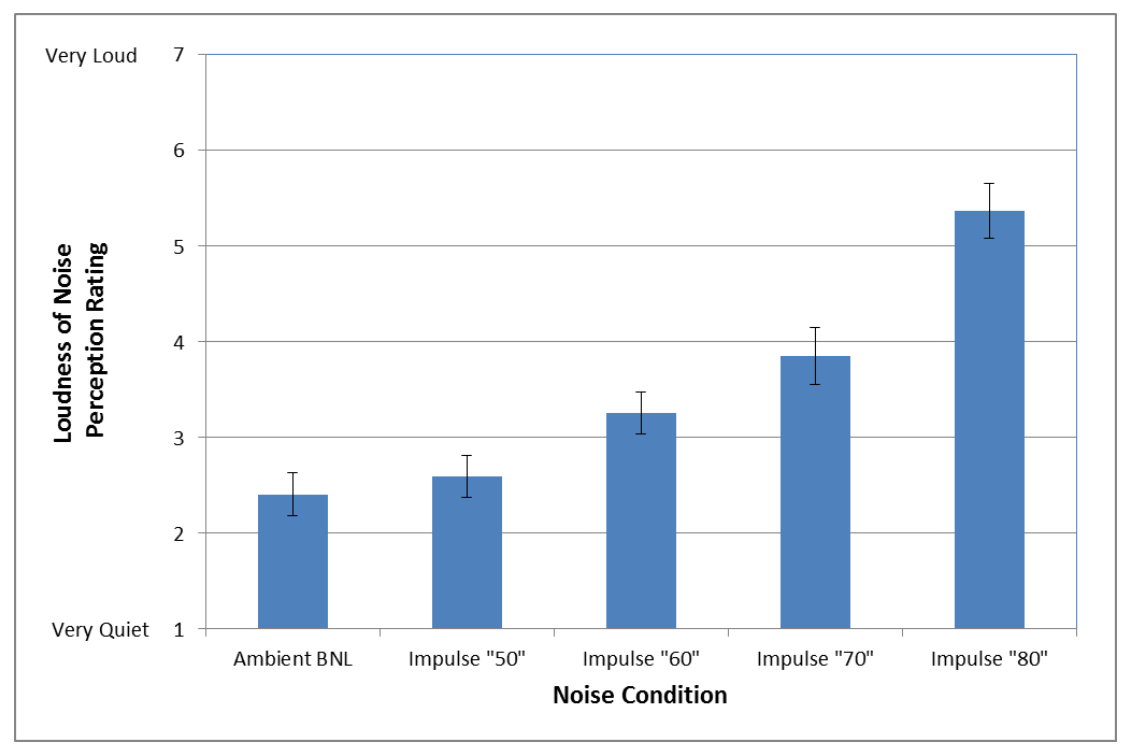

Fig. 4.20. Results of the average perception ratings of loudness of noise across each noise condition. Error bars represent the standard error of the mean. 
A repeated measures ANOVA was additionally used for comparison. For ANOVA testing, Mauchly's sphericity was violated $\left(\chi^{2}(9)=17.24, \mathrm{p}<0.05\right)$. Huynh-Feldt estimates of sphericity were used to correct the degrees of freedom and still displayed a significant effect with a large effect size, $\mathrm{F}(3.56,92.65)=30.54, \mathrm{p}<0.001, \mathrm{r}=0.72$. The observed power for this test was 1.000 , or $100 \%$, according to the results reported by SPSS with $\alpha=0.05$. This is not to suggest that there is a $100 \%$ chance that these results are exhibiting a genuine effect, but just that the probability is very good. Bonferroni post hoc tests found significant relationships as shown in Table 4.5. These significant relationships matched those found in the Wilcoxon test.

\section{$\underline{\text { Table } 4.5}$}

Bonferroni Post Hoc Tests for Loudness of Noise Ratings across Noise Conditions.

\begin{tabular}{|l|l|l|l|l|}
\hline \multicolumn{5}{|c|}{ Loudness ratings between sessions } \\
\hline & Impulse "50" & Impulse "60" & Impulse "70" & Impulse "80" \\
\hline Ambient BNL & & & ** & ** \\
\hline Impulse "50" & & ** & ** \\
\hline Impulse "60" & & & ** \\
\hline Impulse "70" & & & $* *$ \\
\hline
\end{tabular}

**Indicates the mean difference between noise conditions is significant, $p<0.05$

Test results show that loudness ratings were significantly higher for the loudest impulse session, "Impulse 80", compared to every other session including the control (ambient noise only) session. The loudness ratings for the second loudest session, "Impulse 70", were also significantly higher than the control session, which is of interest. Sessions that included the two loudest impulses resulted in a significantly different subjective loudness rating compared to a session without impulses.

\subsubsection{Change in Noise over Time across Noise Conditions}

The changes in noise over time ratings were significantly affected by the different noise conditions, $\chi^{2}(4)=43.54, p<0.05$. As the noise level increases, so does the perception ratings. 
The average perception ratings for changes in noise over time in each noise condition are shown in Figure 4.21. The results of the Wilcoxon test are shown in Table 4.6.

\section{Table 4.6}

Wilcoxon Results between Noise Condition and Change of Noise over Time. A Bonferroni correction was applied and all effects denoted with ** are significant at a 0.005 level of significance.

\begin{tabular}{|c|c|c|c|c|c|}
\hline \multicolumn{6}{|c|}{ Change in noise ratings between sessions } \\
\hline & & Impulse "50" & Impulse "60" & Impulse "70" & Impulse "80" \\
\hline \multirow{3}{*}{ Ambient BNL } & $\mathrm{T}$ & 6.00 & 0.00 & 4.50 & 2.50 \\
\hline & sig & $* *$ & $* *$ & $* *$ & $* *$ \\
\hline & effect size & -0.48 & -0.53 & -0.53 & -0.52 \\
\hline \multirow{3}{*}{ Impulse "50" } & $T$ & & 32.50 & 24.00 & 8.50 \\
\hline & sig & & $n s$ & $n s$ & $* *$ \\
\hline & effect size & & -0.18 & -0.37 & -0.44 \\
\hline \multirow{3}{*}{ Impulse "60" } & $\mathrm{T}$ & & & 46.00 & 54.00 \\
\hline & sig & & & ns & ns \\
\hline & effect size & & & -0.20 & -0.32 \\
\hline \multirow{3}{*}{ Impulse "70" } & $\mathrm{T}$ & & & & 45.50 \\
\hline & sig & & & & $n s$ \\
\hline & effect size & & & & -0.20 \\
\hline
\end{tabular}

$* *=$ Indicates the mean ranks between noise conditions is significant, $\mathrm{p}<0.005, \mathrm{~ns}=$ not significant.

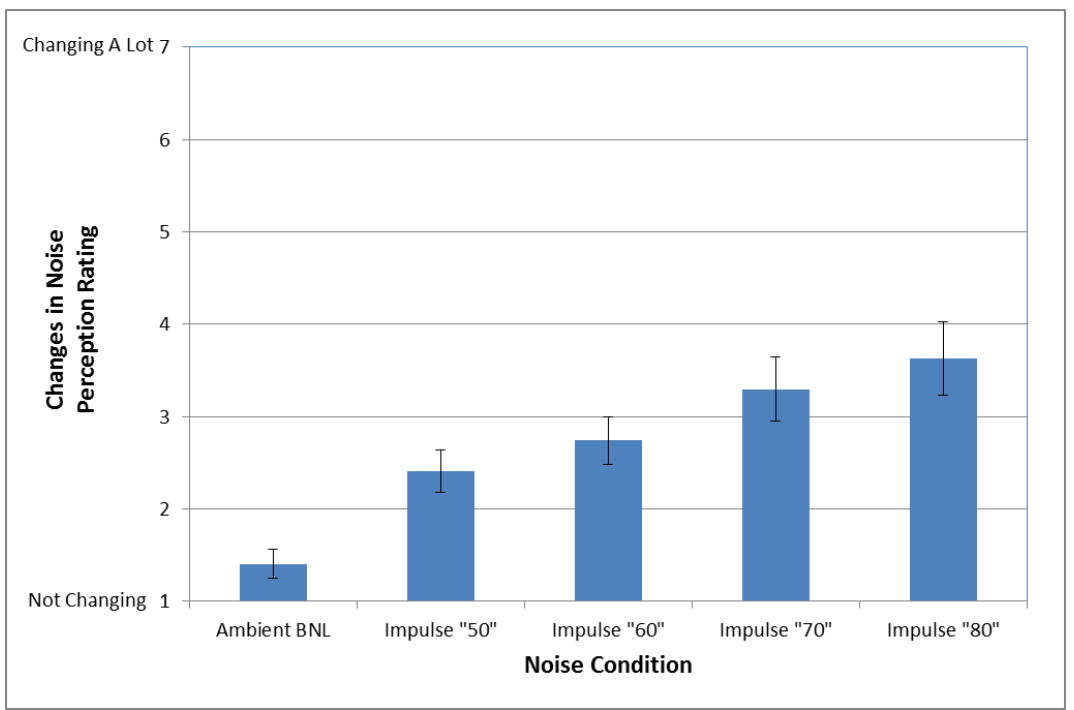

Fig. 4.21. Results of the average perception ratings of changes in noise over time across each noise condition. Error bars represent the standard error of the mean. 
A repeated measures ANOVA was additionally used for comparison. For ANOVA testing, Mauchly’s sphericity was violated $\left(\chi^{2}(9)=22.29, \mathrm{p}<0.01\right)$. Greenhouse-Geisser estimates of sphericity were used to correct the degrees of freedom and still displayed a significant effect with a large effect size, $\mathrm{F}(2.82,73.63)=14.318, \mathrm{p}<0.001, \mathrm{r}=0.57$. The observed power for this test was 1.000 , or $100 \%$, according to the results reported by SPSS with $\alpha=0.05$. This is not to suggest that there is a $100 \%$ chance that these results are exhibiting a genuine effect, but just that the probability is very good. Bonferroni post hoc tests found significant relationships as shown in Table 4.7. These significant relationships matched those found in the Wilcoxon test.

\section{$\underline{\text { Table } 4.7}$}

Bonferroni Post Hoc Tests for Changes in Noise over Time Ratings across Noise Conditions.

\begin{tabular}{|l|l|l|l|l|}
\hline \multicolumn{5}{|c|}{ Change in noise ratings between sessions } \\
\hline & Impulse "50" & Impulse "60" & Impulse "70" & Impulse "80" \\
\hline Ambient BNL & ** & ** & ** & ** \\
\hline Impulse "50" & & & ** \\
\hline Impulse "60" & & & \\
\hline Impulse "70" & & & \\
\hline
\end{tabular}

${ }^{* *}$ Indicates the mean difference between noise conditions is significant, $p<0.05$

Test results show that ratings of changes in noise over time were significantly higher at each impulse session compared to the control session. However, there was not much difference between the impulse sessions. It is concluded that any session that included an impulse resulted in a significantly different subjective change in noise over time rating compared to a session without impulses.

\subsubsection{Rumble of Noise across Noise Conditions}

The rumble of noise ratings were significantly affected by the different noise conditions, $\chi^{2}(4)=40.83, \mathrm{p}<0.05$. As the noise level increases, so does the perception ratings. The average 
perception ratings for rumble of noise over time in each noise condition are shown in Figure

4.22. The results of the Wilcoxon test are shown in Table 4.8.

\section{Table 4.8}

Wilcoxon Results between Noise Condition and Rumble of Noise. A Bonferroni correction was applied and all effects denoted with $* *$ are significant at a 0.005 level of significance.

\begin{tabular}{|c|c|c|c|c|c|}
\hline \multicolumn{6}{|c|}{ Rumble ratings between sessions } \\
\hline & & Impulse "50" & Impulse "60" & Impulse "70" & Impulse "80" \\
\hline \multirow{3}{*}{ Ambient BNL } & $\mathrm{T}$ & 68.50 & 31.00 & 23.50 & 3.50 \\
\hline & sig & $n s$ & $n s$ & $* *$ & $* *$ \\
\hline & effect size & -0.05 & -0.36 & -0.42 & -0.55 \\
\hline \multirow{3}{*}{ Impulse "50" } & $\mathrm{T}$ & & 27.50 & 18.00 & 0.00 \\
\hline & sig & & $n s$ & $* *$ & $* *$ \\
\hline & effect size & & -0.38 & -0.45 & -0.55 \\
\hline \multirow{3}{*}{ Impulse "60" } & $\mathrm{T}$ & & & 55.50 & 38.50 \\
\hline & sig & & & $n s$ & $* *$ \\
\hline & effect size & & & -0.09 & -0.46 \\
\hline \multirow{3}{*}{ Impulse "70" } & $T$ & & & & 22.00 \\
\hline & sig & & & & $* *$ \\
\hline & effect size & & & & -0.45 \\
\hline
\end{tabular}

${ }^{* *}=$ Indicates the mean ranks between noise conditions is significant, $\mathrm{p}<0.005, \mathrm{~ns}=$ not significant.

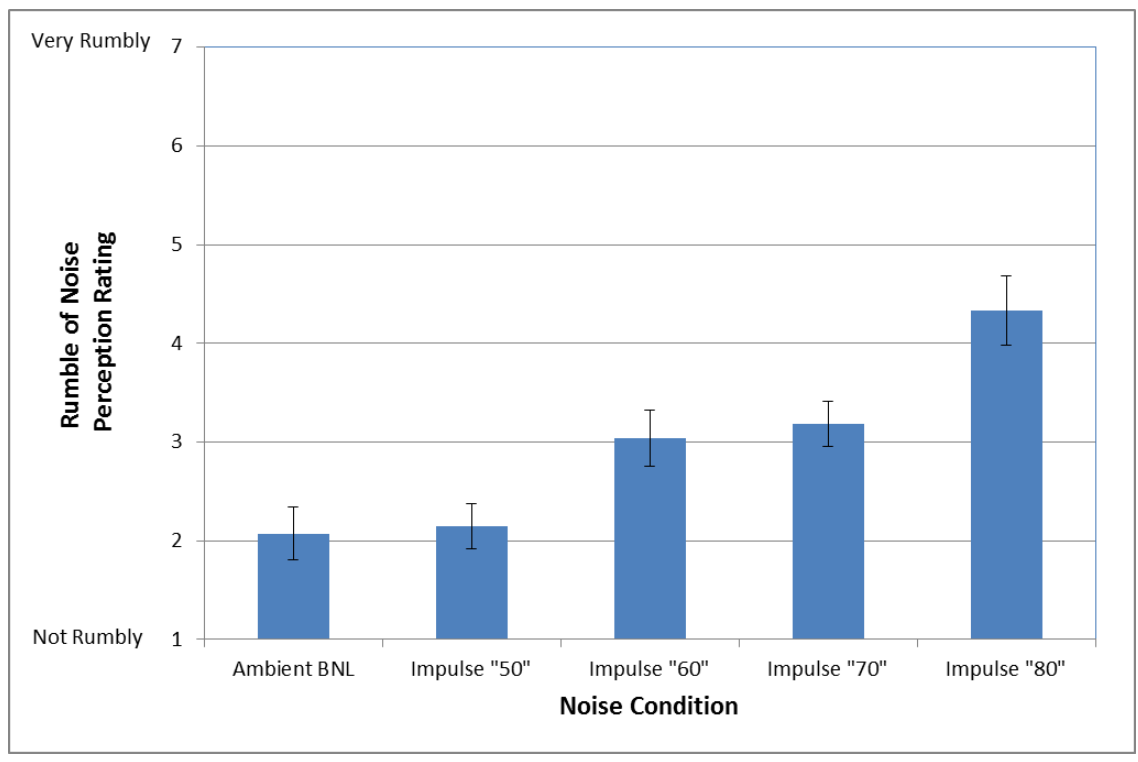

Fig. 4.22. Results of the average perception ratings of rumble of noise across each noise condition. Error bars represent the standard error of the mean. 
A repeated measures ANOVA was additionally used for comparison. For ANOVA testing, Mauchly's sphericity was not violated so sphericity was assumed, $\mathrm{F}(4,104)=18.15$, $\mathrm{p}<0.001, \mathrm{r}=0.62$. The effect size is considered large. The observed power for this test was 1.000 , or $100 \%$, according to the results reported by SPSS with $\alpha=0.05$. This is not to suggest that there is a $100 \%$ chance that these results are exhibiting a genuine effect, but just that the probability is very good. Bonferroni post hoc tests found significant relationships as shown in Table 4.9. These significant relationships matched those found in the Wilcoxon test, except that there was one additional significant relationship between the "Impulse 50" and "Impulse 60" noise conditions. Since the data had a non-normal distribution, the non-parametric test results are more likely to represent the accurate effects. Therefore the significant relationship between the "Impulse 50" and "Impulse 60" noise conditions is presented with caution.

\section{Table 4.9}

Bonferroni Post Hoc Tests for Rumble of Noise Ratings across Noise Conditions.

\begin{tabular}{|l|l|l|l|l|}
\hline \multicolumn{5}{|c|}{ Rumble ratings between sessions } \\
\hline & Impulse "50" & Impulse "60" & Impulse "70" & Impulse "80" \\
\hline Ambient BNL & & & $* *$ & $* *$ \\
\hline Impulse "50" & $* *$ & $* *$ & $* *$ \\
\hline Impulse "60" & & $* *$ \\
\hline Impulse "70" & & $* *$ \\
\hline
\end{tabular}

Test results show that rumble ratings, like loudness ratings, were significantly higher for the loudest impulse session, "Impulse 80", compared to every other session including the control (ambient noise only) session. Also like loudness ratings, rumble ratings for the second loudest session, "Impulse 70", were also significantly higher than the control session. Sessions that included the two loudest impulses resulted in significantly different subjective rumble ratings compared to a session without impulses. 


\subsubsection{Annoyance to Noise across Noise Conditions}

The annoyance to noise ratings were significantly affected by the different noise conditions, $\chi^{2}(4)=62.18, p<0.05$. As the noise level increases, so does the perception ratings. The average perception ratings for annoyance to noise over time in each noise condition are shown in Figure 4.23. The results of the Wilcoxon test are shown in Table 4.10.

\section{Table 4.10}

Wilcoxon Results between Noise Condition and Annoyance to Noise. A Bonferroni correction was applied and all effects denoted with $* *$ are significant at a 0.005 level of significance.

\begin{tabular}{|c|c|c|c|c|c|}
\hline \multicolumn{6}{|c|}{ Annoyance ratings between sessions } \\
\hline & & Impulse "50" & Impulse "60" & Impulse "70" & Impulse "80" \\
\hline \multirow{3}{*}{ Ambient BNL } & $\mathrm{T}$ & 70.00 & 26.50 & 28.00 & 2.00 \\
\hline & sig & $n s$ & $n s$ & $* *$ & $* *$ \\
\hline & effect size & -0.14 & -0.33 & -0.42 & -0.60 \\
\hline \multirow{3}{*}{ Impulse "50" } & $\mathrm{T}$ & & 34.00 & 23.50 & 0.00 \\
\hline & sig & & $n s$ & $* *$ & $* *$ \\
\hline & effect size & & -0.20 & -0.42 & -0.61 \\
\hline \multirow{3}{*}{ Impulse "60" } & $\mathrm{T}$ & & & 37.00 & 1.50 \\
\hline & sig & & & $n s$ & $* *$ \\
\hline & effect size & & & -0.26 & -0.58 \\
\hline \multirow{3}{*}{ Impulse "70" } & $\mathrm{T}$ & & & & 9.00 \\
\hline & sig & & & & $* *$ \\
\hline & effect size & & & & -0.54 \\
\hline
\end{tabular}

$*^{*}=$ Indicates the mean ranks between noise conditions is significant, $\mathrm{p}<0.005, \mathrm{~ns}=$ not significant. 


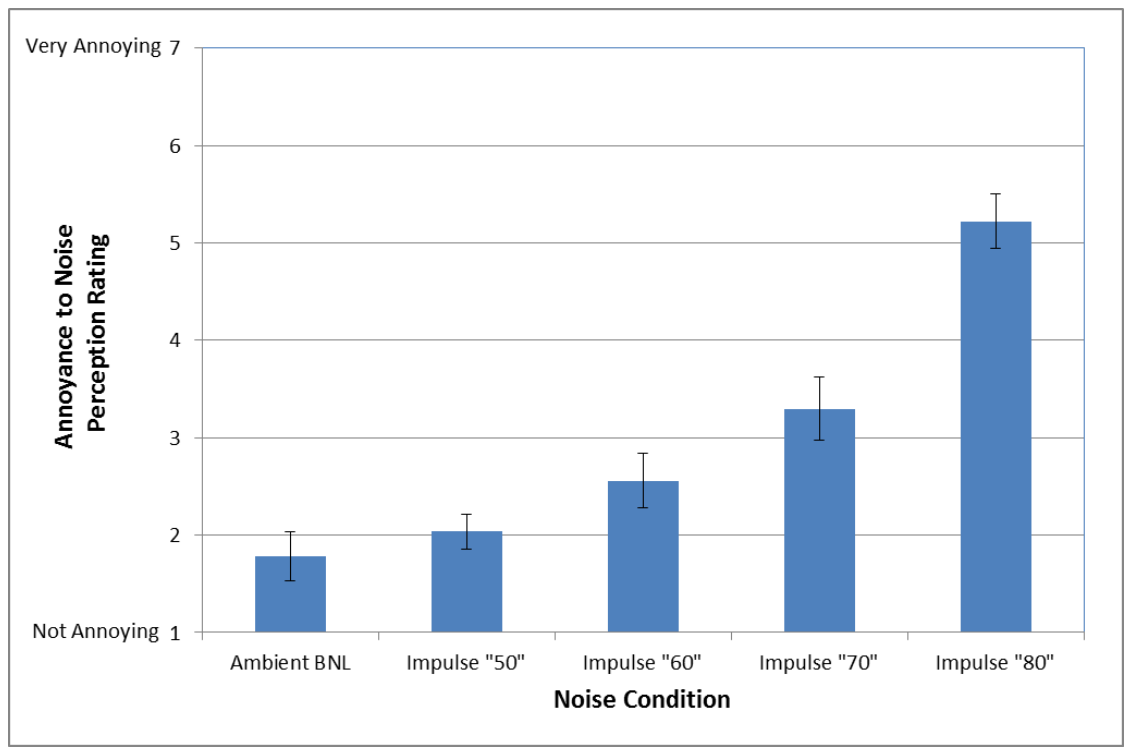

Fig. 4.23. Results of the average perception ratings of annoyance to noise across each noise condition. Error bars represent the standard error of the mean.

A repeated measures ANOVA was additionally used for comparison. For ANOVA testing, Mauchly’s sphericity was not violated so sphericity was assumed, $\mathrm{F}(4,104)=35.752$, $\mathrm{p}<0.001, \mathrm{r}=0.75$. The effect size is considered large. The observed power for this test was 1.000 , or $100 \%$, according to the results reported by SPSS with $\alpha=0.05$. This is not to suggest that there is a $100 \%$ chance that these results are exhibiting a genuine effect, but just that the probability is very good. Bonferroni post hoc tests found significant relationships as shown in Table 4.11. These significant relationships matched those found in the Wilcoxon test.

\section{$\underline{\text { Table 4.11 }}$}

Bonferroni Post Hoc Tests for Annoyance to Noise Ratings across Noise Conditions.

\begin{tabular}{|l|l|l|l|l|}
\hline \multicolumn{5}{|c|}{ Annoyance ratings between sessions } \\
\hline & Impulse "50" & Impulse "60" & Impulse "70" & Impulse "80" \\
\hline Ambient BNL & & & ** & ** \\
\hline Impulse "50" & & $* *$ & $* *$ \\
\hline Impulse "60" & & & $* *$ \\
\hline Impulse "70" & & & $* *$ \\
\hline
\end{tabular}

**Indicates the mean difference between noise conditions is significant, $p<0.05$ 
Test results show that annoyance ratings were also significantly higher for the loudest impulse session, "Impulse 80", compared to every other session including the control (ambient noise only) session. Also like loudness and rumble ratings, annoyance ratings for the second loudest session, "Impulse 70", were also significantly higher than the control session. Sessions that included the two loudest impulses resulted in significantly different subjective annoyance ratings compared to a session without impulses.

\subsubsection{Distraction to Noise across Noise Conditions}

The distraction to noise ratings were significantly affected by the different noise conditions, $\chi^{2}(4)=66.51, p<0.05$. As the noise level increases, so does the perception ratings. The average perception ratings for distraction to noise over time in each noise condition are shown in Figure 4.24. The results of the Wilcoxon test are shown in Table 4.12.

\section{Table 4.12}

Wilcoxon Results between Noise Condition and Distraction to Noise. A Bonferroni correction was applied and all effects denoted with $* *$ are significant at a 0.005 level of significance.

\begin{tabular}{|c|c|c|c|c|c|}
\hline \multicolumn{6}{|c|}{ Distraction ratings between sessions } \\
\hline & & Impulse "50" & Impulse "60" & Impulse "70" & Impulse "80" \\
\hline \multirow{3}{*}{ Ambient BNL } & $\mathrm{T}$ & 28.00 & 20.50 & 11.50 & 0.00 \\
\hline & sig & $n s$ & $* *$ & $* *$ & $* *$ \\
\hline & effect size & -0.22 & -0.46 & -0.52 & -0.61 \\
\hline \multirow{3}{*}{ Impulse "50" } & $\mathrm{T}$ & & 37.50 & 0.00 & 0.00 \\
\hline & sig & & ns & $* *$ & $* *$ \\
\hline & effect size & & -0.29 & -0.53 & -0.60 \\
\hline \multirow{3}{*}{ Impulse "60" } & $\mathrm{T}$ & & & 64.50 & 10.50 \\
\hline & sig & & & $n s$ & $* *$ \\
\hline & effect size & & & -0.21 & -0.55 \\
\hline \multirow{3}{*}{ Impulse "70" } & $\mathrm{T}$ & & & & 11.00 \\
\hline & sig & & & & $* *$ \\
\hline & effect size & & & & -0.52 \\
\hline
\end{tabular}

${ }^{* *}=$ Indicates the mean ranks between noise conditions is significant, $\mathrm{p}<0.005, \mathrm{~ns}=$ not significant. 


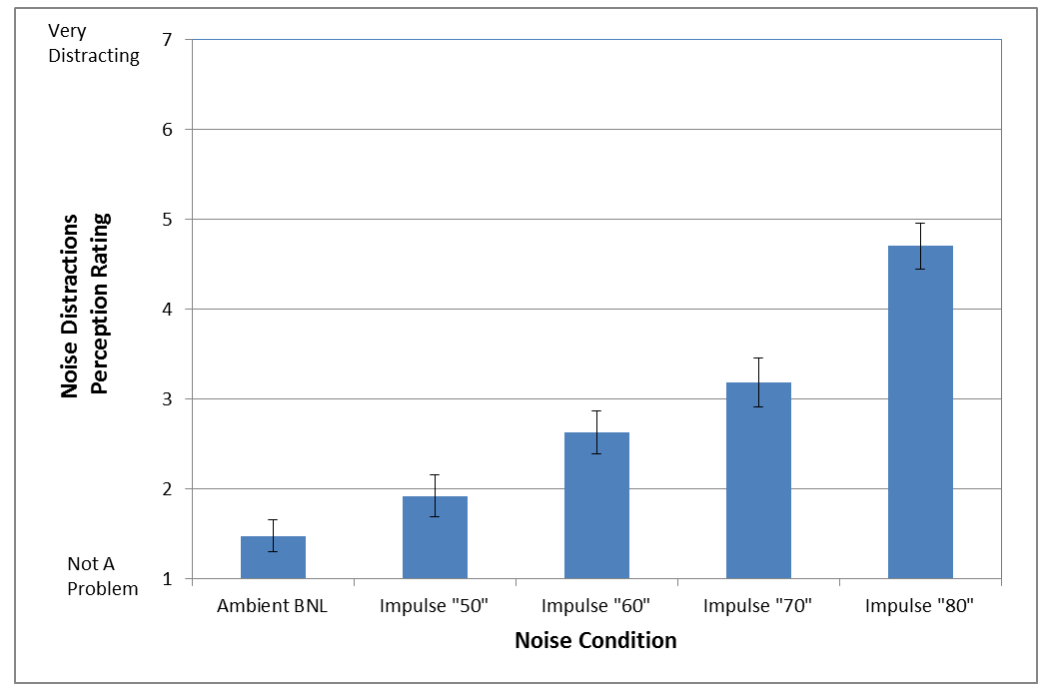

Fig. 4.24. Results of the average perception ratings of distraction to noise across each noise condition. Error bars represent the standard error of the mean.

A repeated measures ANOVA was additionally used for comparison. For ANOVA testing, Mauchly's sphericity was not violated so sphericity was assumed, $F(4,104)=36.44$, $\mathrm{p}<0.001, \mathrm{r}=0.75$. The effect size is considered large. The observed power for this test was 1.000 , or $100 \%$, according to the results reported by SPSS with $\alpha=0.05$. This is not to suggest that there is a $100 \%$ chance that these results are exhibiting a genuine effect, but just that the probability is very good. Bonferroni post hoc tests found significant relationships as shown in Table 4.13. These significant relationships matched those found in the Wilcoxon test.

\section{$\underline{\text { Table } 4.13}$}

Bonferroni Post Hoc Tests for Distraction to Noise Ratings across Noise Conditions.

\begin{tabular}{|l|l|l|l|l|}
\hline \multicolumn{5}{|c|}{ Distraction ratings between sessions } \\
\hline & Impulse "50" & Impulse "60" & Impulse "70" & Impulse "80" \\
\hline Ambient BNL & & $* *$ & $* *$ & $* *$ \\
\hline Impulse "50" & & $* *$ & $* *$ \\
\hline Impulse "60" & & $* *$ \\
\hline Impulse "70" & & $* *$ \\
\hline$* *$ Indicates the mean difference between noise conditions is \\
significant, $\mathrm{p}<0.05$
\end{tabular}


Test results show that distraction ratings were also significantly higher for the loudest impulse session, "Impulse 80", compared to every other session including the control session. Distraction ratings for the "Impulse 60" and "Impulse 70" session were also significantly higher than the control session. Sessions that included the "Impulse 60", "Impulse 70", or "Impulse 80" resulted in significantly different subjective distraction ratings compared to a session without impulses.

\subsubsection{Discussion of Subjective Perception Results across Noise Conditions}

For all results of subjective perception ratings across noise conditions, the two loudest noise bursts were always significantly different compared to the control (ambient noise only) session. This suggests that the "Impulse 70 " (67 dBA, $\left.\mathrm{L}_{\mathrm{Apk}}\right)$ may be a general level at which the noise burst level compared to the background noise becomes significantly different to a condition with the same background noise level where no noise bursts are present. This issue was stated as a goal in Section 1.1.

Additionally, it is interesting that the session including the loudest noise burst, "Impulse 80" (77 dBA, $\mathrm{L}_{\mathrm{Apk}}$ ), was significantly different than all other noise burst sessions for subjective perception ratings of loudness, rumble, annoyance, and distraction. These results may suggest that this level of noise burst is unacceptable.

For comparison, Thackray et al. suggested that boom levels need to be lower than 71 dBA to avoid measurable startle response, as was discussed in section 2.1.4 (Thackray 1975). Woodhead concluded that noise bursts at $90 \mathrm{~dB}$ appeared to be a critical level on another performance task, the Mackworth multichannel task as discussed in section 2.1.3.

Subjects provided comments on the questionnaires at the end of each test session regarding their reactions to the bursts of noise. Eleven subjects noted in some capacity that 
generally the bursts of noise were startling, distracting, and/or caused anxiety during the test sessions. Two of those eleven subjects noted that the quieter impulses were less distracting.

Other subjects had different reactions to the impulses. Three subjects mentioned that their first exposure to the bursts was the most distracting, but that they were able to adapt to some degree after that. Three other subjects did not believe the impulses affected them in any capacity. Two subjects actually found the impulses to be stimulating to some degree.

\subsubsection{Relationships of Subjective Perception Results to Noise Metrics}

Subjective perception results were compared to the different noise metric results for each impulse to find any correlations between task performance and each noise metric, including each time interval associated with each metric. A Pearson Product Correlation Coefficient, Spearman Coefficient, and a linear mixed model analysis were analyzed for each relationship. Tables for all results are shown in Appendix A.

All factors of subjective perception were significantly correlated to each noise metric, $\mathrm{p}<$ 0.01. It is difficult to make any conclusions from this data which is not a surprise considering the noise source. The source stimulus was essentially the same .wav file presented at different levels. Because of this, all of the noise metrics were highly correlated. This was confirmed with both Pearson and Spearman coefficients, which found all noise metrics to be significantly correlated to each other, $\mathrm{p}<0.01$. The main point is that each subjective parameter had a significant relationship to each impulse as measured by each noise metric even across each different time interval of analysis. 


\subsubsection{Relationships of Subjective Perception Results across Noise Conditions with Gender, Age, and Noise Sensitivity as Covariates}

There were many significant relationships found between subjective perception results and noise conditions as shown in section 4.4.1. However, there are additional independent variables that need to be addressed to fully explore these relationships. Gender, age, and noise sensitivity are additional independent variables that were collected in this study. It is important to factor in these variables to the analysis of variance to analyze their effects on the relationships between the subjective perception ratings to the five noise conditions previously mentioned.

Unfortunately, additional independent variables are difficult to include in a nonparametric test such as the Friedman's ANOVA. However repeated measures ANOVA with covariates may be still be analyzed to study these relationships with multiple independent variables. Because of the non-normal distributions of the subjective perception ratings, these results are presented with caution. Additionally, the observed power, as reported by SPSS with $\alpha$ $=0.05$, is reported for each repeated measures ANOVA test.

The SPSS outputs for each subjective perception rating with each covariate combination are shown in Tables 4.14 to 4.18. The significance of each test is the first column to note in each table. There are multiple cases in which the test results are still significant even when including one or two covariates. When gender is the only covariate, all relationships are still significant. When all three covariates are included in the model, all of the relationships are no longer significant, $\mathrm{p}<0.05$, however change in noise, rumble, and annoyance are not far off with $\mathrm{p}$ values less than 0.1 . For example, the results of the average perception ratings of annoyance to noise across each noise condition with gender splits are shown in Figure 4.25. 
The observed power is the next column to note when analyzing these results. Notice that as the number of independent variables increases, the observed power generally decreases, as expected. Observed power depends on the number of independent variables and the sample size. In all cases with all three covariates, the results are not significant, $\mathrm{p}<0.05$, but the observed power is also below the recommended 0.8 . A larger sample size would have been desired to increase the observed power and therefore the probability that these tests are showing a genuine effect (Field and Hole 2003). Therefore these results are presented with caution.

Additionally, Bonferroni Post Hoc Tests were still analyzed for all tests with all three covariates using the Pairwise Comparisons from the SPSS output. All of these results matched the significant relationships, $\mathrm{p}<0.01$, across all noise conditions for each subjective perception ratings found by Friedman's ANOVA in section 4.4.1. These results increase the confidence that the relationships between noise conditions previously discussed may in fact be genuine.

\section{Table 4.14}

Analysis of variance for loudness to noise ratings across noise conditions with each combination of gender, age, and noise sensitivity as covariates. All results assume for sphericity except when stated otherwise.

\begin{tabular}{|c|c|c|c|c|c|c|c|c|c|}
\hline Covariates & $\begin{array}{c}\text { Within-Subjects } \\
\text { Variable }\end{array}$ & $\begin{array}{c}\text { Type III Sum } \\
\text { of Squares }\end{array}$ & df & $\begin{array}{l}\text { Mean } \\
\text { Square }\end{array}$ & $\mathrm{F}$ & Sig. & $\begin{array}{c}\text { Partial Eta } \\
\text { Squared }\end{array}$ & $\begin{array}{l}\text { Noncent. } \\
\text { Parameter }\end{array}$ & $\begin{array}{c}\text { Observed } \\
\text { Power }^{\mathrm{a}}\end{array}$ \\
\hline none & \multirow{8}{*}{$\begin{array}{l}\text { Loudness to } \\
\text { Noise Ratings } \\
\text { across Noise } \\
\text { Conditions }\end{array}$} & 153.822 & $3.564^{\mathrm{b}}$ & 43.166 & 30.535 & 0.000 & 0.540 & 108.811 & 1.000 \\
\hline Gender & & 19.939 & $3.634^{\mathrm{b}}$ & 5.486 & 3.876 & 0.008 & 0.134 & 14.085 & 0.861 \\
\hline Age & & 15.092 & 4.000 & 3.773 & 3.057 & 0.020 & 0.109 & 12.228 & 0.790 \\
\hline Noise Sensitivity & & 15.300 & 4.000 & 3.825 & 2.938 & 0.024 & 0.105 & 11.752 & 0.771 \\
\hline Gender and Noise Sensitivity & & 9.587 & $3.817^{\mathrm{b}}$ & 2.512 & 1.800 & 0.139 & 0.070 & 6.871 & 0.516 \\
\hline Gender and Age & & 12.724 & 4.000 & 3.181 & 2.539 & 0.045 & 0.096 & 10.158 & 0.699 \\
\hline Age and Noise Sensitivity & & 10.345 & 4.000 & 2.586 & 2.032 & 0.096 & 0.078 & 8.127 & 0.588 \\
\hline Gender, Age, and Noise Sensitivity & & 10.040 & 4.000 & 2.510 & 1.941 & 0.110 & 0.078 & 7.764 & 0.565 \\
\hline
\end{tabular}




\section{$\underline{\text { Table 4.15 }}$}

Analysis of variance for change in noise over time ratings across noise conditions with each combination of gender, age, and noise sensitivity as covariates. All results assume for sphericity except when stated otherwise.

\begin{tabular}{|c|c|c|c|c|c|c|c|c|c|}
\hline Covariates & $\begin{array}{c}\text { Within-Subjects } \\
\text { Variable }\end{array}$ & $\begin{array}{c}\text { Type III Sum } \\
\text { of Squares }\end{array}$ & df & $\begin{array}{l}\text { Mean } \\
\text { Square }\end{array}$ & $\mathrm{F}$ & Sig. & $\begin{array}{c}\text { Partial Eta } \\
\text { Squared }\end{array}$ & $\begin{array}{l}\text { Noncent. } \\
\text { Parameter }\end{array}$ & $\begin{array}{c}\text { Observed } \\
\text { Power }^{\mathrm{a}}\end{array}$ \\
\hline none & \multirow{8}{*}{$\begin{array}{l}\text { Change in } \\
\text { Noise over } \\
\text { Time Ratings } \\
\text { across Noise } \\
\text { Conditions }\end{array}$} & 80.400 & $2.832^{\mathrm{b}}$ & 28.392 & 14.318 & 0.000 & 0.355 & 40.545 & 1.000 \\
\hline Gender & & 18.863 & $2.876^{\mathrm{b}}$ & 6.559 & 3.339 & 0.026 & 0.118 & 9.604 & 0.724 \\
\hline Age & & 11.656 & $2.702^{\mathrm{b}}$ & 4.315 & 2.184 & 0.104 & 0.080 & 5.900 & 0.504 \\
\hline Noise Sensitivity & & 6.446 & $2.809^{\mathrm{b}}$ & 2.295 & 1.152 & 0.333 & 0.044 & 3.237 & 0.288 \\
\hline Gender and Noise Sensitivity & & 5.194 & $2.849^{\mathrm{b}}$ & 1.824 & 0.924 & 0.430 & 0.037 & 2.631 & 0.237 \\
\hline Gender and Age & & 15.467 & $2.755^{\mathrm{b}}$ & 5.615 & 2.932 & 0.044 & 0.109 & 8.077 & 0.646 \\
\hline Age and Noise Sensitivity & & 10.885 & $2.696^{\mathrm{b}}$ & 4.038 & 2.042 & 0.123 & 0.078 & 5.505 & 0.474 \\
\hline Gender, Age, and Noise Sensitivity & & 13.351 & $2.759^{\mathrm{b}}$ & 4.839 & 2.543 & 0.069 & 0.100 & 7.017 & 0.577 \\
\hline
\end{tabular}

${ }^{\mathrm{a}}$ Computed using alpha $=.05,{ }^{\mathrm{b}}$ Greenhouse-Geisser correction used

$\underline{\text { Table } 4.16}$

Analysis of variance for rumble of noise ratings across noise conditions with each combination

of gender, age, and noise sensitivity as covariates. All results assume for sphericity.

\begin{tabular}{|c|c|c|c|c|c|c|c|c|c|}
\hline Covariates & $\begin{array}{c}\text { Within-Subjects } \\
\text { Variable }\end{array}$ & \begin{tabular}{|c} 
Type III Sum \\
of Squares
\end{tabular} & df & $\begin{array}{c}\text { Mean } \\
\text { Square }\end{array}$ & $\mathrm{F}$ & Sig. & $\begin{array}{c}\text { Partial Eta } \\
\text { Squared }\end{array}$ & $\begin{array}{l}\text { Noncent. } \\
\text { Parameter }\end{array}$ & $\begin{array}{c}\text { Observed } \\
\text { Power }^{\mathrm{a}}\end{array}$ \\
\hline none & \multirow{8}{*}{$\begin{array}{c}\text { Rumble of } \\
\text { Noise Ratings } \\
\text { across Noise } \\
\text { Conditions }\end{array}$} & 91.437 & 4.000 & 22.859 & 18.153 & 0.000 & 0.411 & 72.612 & 1.000 \\
\hline Gender & & 26.331 & 4.000 & 6.583 & 5.247 & 0.001 & 0.173 & 20.990 & 0.964 \\
\hline Age & & 2.817 & 4.000 & 0.704 & 0.540 & 0.707 & 0.021 & 2.160 & 0.176 \\
\hline Noise Sensitivity & & 28.882 & 4.000 & 7.221 & 5.808 & 0.000 & 0.189 & 23.231 & 0.978 \\
\hline Gender and Noise Sensitivity & & 27.170 & 4.000 & 6.792 & 5.484 & 0.001 & 0.186 & 21.936 & 0.971 \\
\hline Gender and Age & & 8.310 & 4.000 & 2.078 & 1.606 & 0.179 & 0.063 & 6.423 & 0.478 \\
\hline Age and Noise Sensitivity & & 5.596 & 4.000 & 1.399 & 1.087 & 0.368 & 0.043 & 4.347 & 0.331 \\
\hline Gender, Age, and Noise Sensitivity & & 10.585 & 4.000 & 2.646 & 2.068 & 0.091 & 0.082 & 8.271 & 0.596 \\
\hline
\end{tabular}

${ }^{\mathrm{a} C}$ Computed using alpha $=.05$ 


\section{$\underline{\text { Table 4.17 }}$}

Analysis of variance for annoyance to noise ratings across noise conditions with each

combination of gender, age, and noise sensitivity as covariates. All results assume for sphericity.

\begin{tabular}{|c|c|c|c|c|c|c|c|c|c|}
\hline Covariates & $\begin{array}{c}\text { Within-Subjects } \\
\text { Variable }\end{array}$ & $\begin{array}{c}\text { Type III Sum } \\
\text { of Squares }\end{array}$ & df & $\begin{array}{c}\text { Mean } \\
\text { Square }\end{array}$ & $\mathrm{F}$ & Sig. & $\begin{array}{c}\text { Partial Eta } \\
\text { Squared }\end{array}$ & $\begin{array}{l}\text { Noncent. } \\
\text { Parameter }\end{array}$ & $\begin{array}{c}\text { Observed } \\
\text { Power }^{\mathrm{a}}\end{array}$ \\
\hline none & \multirow{8}{*}{$\begin{array}{c}\text { Annoyance to } \\
\text { Noise Ratings } \\
\text { across Noise } \\
\text { Conditions }\end{array}$} & 206.341 & 4.000 & 51.585 & 35.752 & 0.000 & 0.579 & 143.006 & 1.000 \\
\hline Gender & & 51.157 & 4.000 & 12.789 & 9.233 & 0.000 & 0.270 & 36.933 & 0.999 \\
\hline Age & & 4.764 & 4.000 & 1.191 & 0.798 & 0.529 & 0.031 & 3.193 & 0.248 \\
\hline Noise Sensitivity & & 37.968 & 4.000 & 9.492 & 6.497 & 0.000 & 0.206 & 25.986 & 0.989 \\
\hline Gender and Noise Sensitivity & & 32.894 & 4.000 & 8.224 & 5.870 & 0.000 & 0.197 & 23.480 & 0.979 \\
\hline Gender and Age & & 13.751 & 4.000 & 3.438 & 2.414 & 0.054 & 0.091 & 9.656 & 0.674 \\
\hline Age and Noise Sensitivity & & 5.541 & 4.000 & 1.385 & 0.918 & 0.457 & 0.037 & 3.672 & 0.282 \\
\hline Gender, Age, and Noise Sensitivity & & 12.147 & 4.000 & 3.037 & 2.115 & 0.085 & 0.084 & 8.461 & 0.607 \\
\hline
\end{tabular}

${ }^{\mathrm{a}}$ Computed using alpha $=.05$

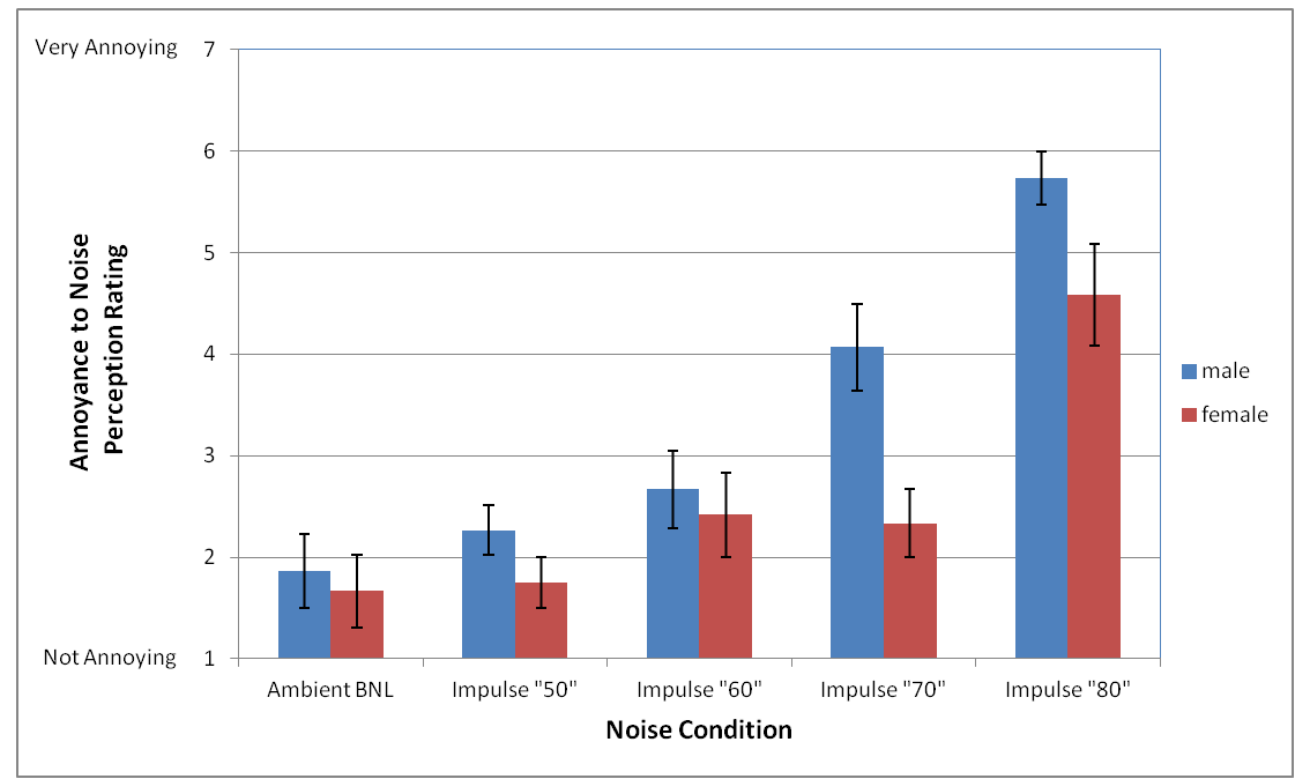

Fig. 4.25. Results of the average perception ratings of annoyance to noise across each noise condition with gender splits. Error bars represent the standard error of the mean. 
Table 4.18

Analysis of variance for distraction to noise ratings across noise conditions with each

combination of gender, age, and noise sensitivity as covariates. All results assume for sphericity.

\begin{tabular}{|c|c|c|c|c|c|c|c|c|c|}
\hline Covariates & $\begin{array}{c}\text { Within-Subjects } \\
\text { Variable }\end{array}$ & $\begin{array}{c}\text { Type III Sum } \\
\text { of Squares }\end{array}$ & df & $\begin{array}{c}\text { Mean } \\
\text { Square }\end{array}$ & $\mathrm{F}$ & Sig. & $\begin{array}{c}\text { Partial Eta } \\
\text { Squared }\end{array}$ & $\begin{array}{c}\text { Noncent. } \\
\text { Parameter }\end{array}$ & $\begin{array}{c}\text { Observed } \\
\text { Power }^{\mathrm{a}} \\
\end{array}$ \\
\hline none & \multirow{8}{*}{$\begin{array}{l}\text { Distraction to } \\
\text { Noise Ratings } \\
\text { across Noise } \\
\text { Conditions }\end{array}$} & 170.178 & 4.000 & 42.544 & 36.440 & 0.000 & 0.584 & 145.760 & 1.000 \\
\hline Gender & & 34.606 & 4.000 & 8.652 & 7.386 & 0.000 & 0.228 & 29.544 & 0.995 \\
\hline Age & & 3.554 & 4.000 & 0.888 & 0.754 & 0.558 & 0.029 & 3.017 & 0.235 \\
\hline Noise Sensitivity & & 23.435 & 4.000 & 5.859 & 4.842 & 0.001 & 0.162 & 19.369 & 0.949 \\
\hline Gender and Noise Sensitivity & & 20.880 & 4.000 & 5.220 & 4.294 & 0.003 & 0.152 & 17.177 & 0.918 \\
\hline Gender and Age & & 7.978 & 4.000 & 1.995 & 1.694 & 0.158 & 0.066 & 6.776 & 0.502 \\
\hline Age and Noise Sensitivity & & 2.975 & 4.000 & 0.744 & 0.609 & 0.657 & 0.025 & 2.437 & 0.194 \\
\hline Gender, Age, and Noise Sensitivity & & 7.073 & 4.000 & 1.768 & 1.448 & 0.225 & 0.059 & 5.791 & 0.434 \\
\hline
\end{tabular}

${ }^{\mathrm{a} C}$ Computed using alpha $=.05$ 


\section{Chapter 5: Conclusions}

This study examined the effect of varying levels of broadband noise bursts on human performance and perception. This work implemented bursts of noise ranging from peak Aweighted sound pressure levels ( $\mathrm{L}_{\mathrm{Apk}}$ ) of 47 to $77 \mathrm{dBA}$ presented over a $\mathrm{L}_{\mathrm{Apk}}$ ambient background noise level $37 \mathrm{~dB} \mathrm{~L}_{\mathrm{eq}}$ measured over 2 minutes. The ambient background noise matched a room criteria rating of $\mathrm{RC}-29(\mathrm{H})$ based on a 2-minute log average of the sound pressure level data. Twenty-seven subjects were exposed to bursts of noise a number of times in a randomized yet controlled fashion across four sessions and a fifth session with no impulses as a control. The session order for each subject was determined with use of a Latin square design to help avoid bias in the results.

For each session, participants participated in an arithmetic task that involved a version of a digit span task and then completed a subjective questionnaire. Task performance was measured and analyzed by total percentage of correct answers and average time taken to complete each question for each session. Subjective perception was measured and analyzed from results of the subjective questionnaires. Additionally, each sound stimulus was analyzed using a number of noise metrics. Statistical analyses were applied to the results to further study the relationships.

Results show significant relationships, $\mathrm{p}<0.05$, between each noise condition and subjective perception qualities for both parametric and non-parametric statistical analyses. Few significant relationships were found in relation to task performance, although there are still some general trends worth reporting. 


\subsection{Task Performance}

Woodhead found that when presenting loud bursts of noise during the arithmetic task a significant detriment in performance was found when the burst was presented during the presentation of the first number, or the memorization period, compared to both a control session or a session when the burst was presented during the presentation of the second number, of the calculation period (1964). One major difference between that arithmetic task and the one used for this study was that the previous study presented the burst of noise for every question during the session. This study only presented the burst two to five times in a twenty minute session. Therefore performance was analyzed across all test questions in a given session as well as across all test questions presented with an impulse in a given session.

For performance across all test questions, there were no significant relationships compared to other noise conditions or the control session. This suggests that the presentation of a few impulses over a time period around 20-30 minutes may not have an effect on one's overall performance during that time period. More research would be needed to determine if the effect would change over a longer session: for example, an 8-hour workday.

The only significant relationship, $\mathrm{p}<0.05$, to overall performance was to the order of test sessions as presented to each participant. This exhibits a practice effect for this test. This is why a Latin square model was established for this study. The design helped to limit the practice effect by balancing the presentation order of each noise condition across all subjects.

For performance across test questions presented during an impulse, there were some general trends worth reporting. The overall percentage of correct impulse test questions decreased as the level of each impulse increased. Additionally, when the same questions were presented during other sessions with no impulse present, the overall percentages of correct 
answers were always greater when the test question was presented without an impulse for all levels of impulse. Both of these trends did not exhibit any statistical significant relationships but they are still of interest to report.

\subsection{Subjective Perception}

Subjective perception results were collected from subjective questionnaire ratings on various qualities of noise: loudness of noise, changes in noise over time, rumble of noise, annoyance to noise, and distraction to noise. There were significant relationships, $\mathrm{p}<0.05$, between noise conditions and subjective perception qualities. The overall relationships were no longer significant when accounting for additional independent variables: gender, age, and noise sensitivity. However, the observed power for these tests were low and it is recommended that future tests use a larger sample size to fully account for these additional variables. Additionally, the same significant relationships between each noise condition and subjective perception qualities were found throughout almost every parametric and non-parametric test, even with additional independent variables. Because of this, the relationships found have a good chance of being genuine effects.

For all qualities of subjective perception tested, there was a significant difference, $\mathrm{p}<0.05$, in the ratings of test sessions that included the two loudest noise bursts compared to the session with no noise bursts. Additionally, for ratings of loudness, rumble, annoyance, and distraction, there was a significant difference, $\mathrm{p}<0.05$, in the ratings of test sessions that included the loudest noise burst compared to all other sessions with noise bursts. This may suggest that the loudest noise burst $\left(77 \mathrm{dBA}, \mathrm{L}_{\mathrm{Apk}}\right)$ is not acceptable where the level of the second loudest noise burst ( $67 \mathrm{dBA}, \mathrm{L}_{\mathrm{Apk}}$ ) may be near the lowest level for bursts of noise that may be considered unacceptable in an otherwise normal background noise level condition, in this case 
RC-29(H). These results are in line with previous work that found boom levels need to be lower than $71 \mathrm{dBA}$ measured inside to avoid a measurable startle response (Thackray 1975).

\subsection{Noise Metrics}

All sound stimuli were analyzed using a number of noise metrics: Equivalent-Continuous Sound Level ( $\left.\mathrm{L}_{\mathrm{eq}}\right), \mathrm{L}_{1}-\mathrm{L}_{99}$, Sound Exposure Level (ASEL/CSEL), Perceived Level (PL), and Perceived Noise Level (PNL). Since the impulses were essentially the same broadband noise burst presented at different levels, there is not much information in this study to discuss the differences between each metric in relation to the sound sources. The results of all metrics for each impulse are significantly correlated, $\mathrm{p}<0.01$, as reported by a Pearson Product Correlation Coefficient, Spearman Correlation Coefficient, and a linear mixed model analysis.

Much like the general noise condition, each metric had a significant relationship, $p<0.05$, to each subjective perception quality but no significant relationships to task performance. Due to the similar correlations between metrics, it is difficult to make any further conclusions other than that all metrics have a significant relationship to each subjective quality. It would be wise to use a variety of signals that prove to be not as well correlated across all metrics for any future studies that want to test these relationships.

For those metrics that have been previously used for analysis of sonic booms (ASEL, CSEL, PL, and PNL), there appears to be no significant difference between the final values when different analysis intervals are selected around the burst of noise for the two loudest impulses (67-77 dBA, $\mathrm{L}_{\mathrm{Apk}}$ ) when presented over a background noise resembling an RC-29(H). This is beneficial to work done with louder noise bursts such as sonic booms when the overpressures are above these values. However, caution should be taken when analyzing bursts of noise at lower levels compared to the background noise. 


\subsection{Future Research}

This thesis found that there is a noticeable change in most qualities of subjective perception for a test session with broadband noise bursts at $\mathrm{L}_{\mathrm{Apk}}$ values of $67 \mathrm{dBA}$ and above compared to a test session with no bursts with a background noise level resembling an RC29(H). Although no significant results were found in regards to noise condition and task performance, there are general trends that show a decrease in performance of specific test questions of a memorization/arithmetic task when a burst of noise is present.

Broadband noise bursts were used for this experiment, but it will be interesting to see what effect, if any, noise with different characteristics may have on human performance and perception. Although some work has focused on sonic booms (Sullivan 2010, Marshall and Davies 2010, Marshall and Davies 2011, Rathsam et al. 2012) it may be important to see how people would react to disruptions or noise impulses that take place in office or hospital settings. No matter the sound stimulus selected, previous research has shown that is just as important to at least report the background noise or test across different background noise levels (Teichner et al.1963, Lim 2008).

Although age was not found to be a significant factor in this study, it should be noted that the overall range of ages (19 to 38 ) was relatively small compared to the entire community. It may be wise to widen the age range for future tests if possible.

For future research involving a version of the arithmetic test used in this study, it is recommended to further review the order of test questions presented to each subject. In retrospect it would have been wise to find a way to randomize the order of test questions, and therefore presentation of noise bursts in a respective session, between subjects. Although the difficulty of each test question in the main test was comparable, it is possible that the specific 
order of test questions had an additional effect on the performance of the task outside of the variables that were tested. 


\section{References}

Baddeley, A. (1997). The role of memory in cognition: Working memory. Human memory: Theory and practice (pp. 49)

Baker, M. A., \& Holding, D. H. (1993). The effects of noise and speech on cognitive task performance. The Journal of General Psychology, 120(3), 339-355.

Belojevic, G., Slepcevic, V., \& Jakovljevic, B. (2001). Mental performance in noise: The role of introversion. Journal of Environmental Psychology, 21(2), 209-213.

Beranek, L. L., \& Vér, I., L. (Eds.). (1992). Noise and vibration control engineering: Principles and applications John Wiley \& Sons, Inc.

Berlyne, D. E., Borsa, D. M., Hamacher, J. H., \& Koenig, I. D. V. (1966). (1966) pairedassociate learning and the timing of arousal. Journal of Experimental Psychology, 72(1), 1.

Broadbent, D. E. (1957). Effects of noises of high and low frequency on behaviour. Ergonomics, 1(1), 21-29. doi: 10.1080/00140135708964568

Broadbent, D. E. (1958). Effect of noise on an "intellectual" task. The Journal of the Acoustical Society of America, 30(9), 824. doi: 10.1121/1.1909779

Dittrich, K., \& Oberfeld, D. (2009). A comparison of the temporal weighting of annoyance and loudness. The Journal of the Acoustical Society of America, 126(6), 3168. doi:

$10.1121 / 1.3238233$ 
Field, A., \& Hole, G. (2003). How to design and report experiments. London: Sage Publications.

Frankenhaeuser, M., \& Lundberg, U. (1977). The influence of cognitive set on performance and arousal under different noise loads. Motivation and Emotion, 1(2), 139-149. doi:

10.1007/BF00998516

Gee, K. L., Swift, S. H., Sparrow, V. W., Plotkin, K. J., \& Downing, J. M. (2007). On the potential limitations of conventional sound metrics in quantifying perception of nonlinearly propagated noise. The Journal of the Acoustical Society of America, 121(1), EL1-EL7.

Harris, C. M. (Ed.). (1998). Handbook of acoustical measurements and noise control (Third ed.) Acoustical Society of America.

Hreinsson, G. (1993). Aircraft noise. (Unpublished Undergraduate). Virginia Polytechnic Institute and State University,

Jackson, G. M., \& Leventhall, H. G. (1972). Calculation of the perceived level of noise (PLdB) using Stevens' method (mark VII). Applied Acoustics, 6(1), 23-34.

Johnson, D. R., \& Robinson, D. W. (1967). The subjective evaluation of sonic bangs. Acustica, $18(5), 241-258$.

Johnson, D. R., \& Robinson, D. W. (1969). Procedure for calculating the loudness of sonic bangs. Acustica, 21(6), 307-318. 
Lim, C., Kim, J., Hong, J., \& Lee, S. (2008). Effect of background noise levels on community annoyance from aircraft noise. The Journal of the Acoustical Society of America, 123(2), 766-771.

Marshall, A., \& Davies, P. (2010). A paired comparison experiment to examine startle evoked by low level sonic booms and other transients. Proceedings of 20th International Congress on Acoustics, ICA 2010, Sydney, Australia.

Marshall, A., \& Davies, P. (2011). Metrics including time-varying loudness models to assess the impact of sonic booms and other transient sounds. Noise Control Engineering Journal, 59(6), 681-697.

Miller, D. M. (2011). Human response to low-amplitude sonic booms. (Unpublished Ph.D.). The Pennsylvania State University,

Moorhouse, A. T., Waddington, D. C., \& Adams, M. D. (2007). The effect of fluctuations on the perception of low frequency sound. Low Frequency Noise, Vibration and Active Control, 26(2), 81-89.

Persson Waye, K., Bengtsson, J., Kjellberg, A., \& Benton, S. (2001). Low frequency noise "pollution" interferes with performance. Noise \& Health, 4(13), 33-49.

Rathsam, J., Loubeau, A., \& Klos, J. (2012). A study in a new test facility on indoor annoyance caused by sonic booms. (Tech. Rep. No. NASA/TM-2012-217332). NASA Langley Research Center: 
SanMiguel, I., Linden, D., \& Escera, C. (2010). Attention capture by novel sounds: Distraction versus facilitation. European Journal of Cognitive Psychology, 22(4), 481-515.

Schutte, M., Marks, A., Wenning, E., \& Griefahn, B. (2007). The development of the noise sensitivity questionnaire. Noise \& Health, 9(34), 15-24.

Shepherd, K. P., \& Sullivan, B. M. (1991). A loudness calculation procedure applied to shaped sonic booms. (Technical Paper No. NASA TP-3134).

Stevens, S. S. (1972). Perceived level of noise by mark VII and decibels (E). The Journal of the Acoustical Society of America, 51(2), 575-601.

Sullivan, B. M., Klos, J., Buehrle, R. D., McCurdy, D. A., \& Haering Jr., E. A. (2010). Human response to low-intensity sonic booms heard indoors and outdoors. (Technical Memorandum No. NASA/TM-20).

Tafalla, R. J., \& Evans, G. W. (1997). Noise, physiology, and human performance: The potential role of effort. Journal of Occupational Health Psychology, 2(2), 148-155. doi: $10.1037 / 1076-8998.2 .2 .148$

Teichner, W. H., Arees, E., \& Reilly, R. (1963). Noise and human performance, A psychophysiological approach. Ergonomics, 6(1), 83-97.

Thackray, R. I. (1972). Sonic boom exposure effects II.3:Startle responses. Journal of Sound \& Vibration, 20, 519-526. doi: 10.1016/0022-460X(72)90675-X 
Thackray, R. I., Touchstone, R. M., \& Bailey, J. P. (1974). A comparison of the startle effects resulting from exposure to two levels of simulated sonic booms. Journal of Sound \& Vibration, 33(4), 379-389.

Thackray, R. I., Touchstone, R. M., \& Bailey, J. P. (1975). Reactions to sonic booms- A report of two studies and a general evaluation of startle effects. Aviation, Space, and Environmental Medicine, 46, 369-376.

Walker, E. L., \& Tarte, R. D. (1963). Memory storage as a function of arousal and time with homogeneous and heterogeneous lists. Journal of Verbal Learning and Verbal Behavior, 2(1), 113-119.

Wang, L. M., \& Novak, C. C. (2010). Human performance and perception-based evaluations of indoor noise criteria for rating mechanical system noise with time-varying fluctuations. ASHRAE Transactions, 116, 553-568.

Weiner, B., \& Walker, E. L. (1966). Motivational factors in short-term retention. Journal of Experimental Psychology, 71(2), 190-193. doi: 10.1037/h0022848

Woodhead, M. M. (1958). Effects of bursts of loud noise on a continuous visual task. British Journal of Industrial Medicine, 15(2), 120-125.

Woodhead, M. M. (1959). Effect of brief loud noise on decision making. The Journal of the Acoustical Society of America, 31(10), 1329-1331.

Woodhead, M. M. (1964). The effect of bursts of noise on an arithmetic task. The American Journal of Psychology, 77(4), 627-633. 
Zimmer, K., Ghani, J., \& Ellermeier, W. (2008). The role of task interference and exposure duration in judging noise annoyance. Journal of Sound and Vibration, 311(3-5), 1039-1051. 


\section{Appendix A: Additional Statistical Analyses Results}

\section{$\underline{\text { Table A.1. }}$}

Results of repeated measures ANOVA from SPSS analyzing task performance across noise conditions.

\begin{tabular}{|c|c|c|c|c|c|c|c|c|}
\hline $\begin{array}{c}\text { Within-Subjects } \\
\text { Variable }\end{array}$ & $\begin{array}{l}\text { Type III Sum } \\
\text { of Squares }\end{array}$ & $d f$ & $\begin{array}{l}\text { Mean } \\
\text { Square }\end{array}$ & $F$ & Sig. & $\begin{array}{c}\text { Partial Eta } \\
\text { Squared }\end{array}$ & $\begin{array}{c}\text { Noncent. } \\
\text { Parameter }\end{array}$ & $\begin{array}{c}\text { Observed } \\
\text { Power }^{a}\end{array}$ \\
\hline $\begin{array}{l}\text { Total percent correct } \\
\text { of all test questions } \\
\text { across noise } \\
\text { conditions }\end{array}$ & .042 & 4 & .011 & .759 & .554 & .028 & 3.035 & .237 \\
\hline $\begin{array}{c}\text { Total average time } \\
\text { taken for all test } \\
\text { questions across } \\
\text { noise conditions }\end{array}$ & 651.948 & 2.883 & 226.141 & .836 & .475 & .031 & 2.409 & .219 \\
\hline $\begin{array}{l}\text { Total percent correct } \\
\text { of impulse-present } \\
\text { questions across } \\
\text { noise conditions }\end{array}$ & .109 & 3 & .036 & .972 & .410 & .036 & 2.917 & .256 \\
\hline $\begin{array}{l}\text { Total average time } \\
\text { taken for impulse- } \\
\text { present questions } \\
\text { across noise } \\
\text { conditions }\end{array}$ & 1289.974 & 2.449 & 526.716 & 3.266 & .035 & .112 & 7.998 & .661 \\
\hline
\end{tabular}

a. Computed using alpha $=.05$

\section{Table A.2.}

Results of repeated measures ANOVA from SPSS analyzing task performance across test session order.

\begin{tabular}{|c|c|c|c|c|c|c|c|c|}
\hline $\begin{array}{c}\text { Within-Subjects } \\
\text { Variable }\end{array}$ & $\begin{array}{c}\text { Type III Sum } \\
\text { of Squares }\end{array}$ & $\mathrm{df}$ & $\begin{array}{c}\text { Mean } \\
\text { Square }\end{array}$ & $\mathrm{F}$ & Sig. & $\begin{array}{c}\text { Partial Eta } \\
\text { Squared }\end{array}$ & $\begin{array}{c}\text { Noncent. } \\
\text { Parameter }\end{array}$ & $\begin{array}{c}\text { Observed } \\
\text { Power }^{\mathrm{a}}\end{array}$ \\
\hline $\begin{array}{c}\text { Total percent correct } \\
\text { of all test questions } \\
\text { across session order }\end{array}$ & .481 & 3.230 & .149 & 12.388 & .000 & .323 & 40.009 & 1.000 \\
\hline $\begin{array}{c}\text { Total average time } \\
\text { taken for all test } \\
\text { questions across } \\
\text { session order }\end{array}$ & 8448.585 & 1.123 & 7525.149 & 17.592 & .000 & .404 & 19.750 & .988 \\
\hline
\end{tabular}

a. Computed using alpha $=.05$ 


\section{Table A.3.}

Results of Pearson Product Correlation Coefficient, Spearman Coefficient, and a linear mixed model analysis for relations of subjective perception ratings to total peak sound pressure level $\left(\mathrm{L}_{\mathrm{pk}}\right)$. All results denoted with $* *$ are significant at $\mathrm{p}<0.01$.

\begin{tabular}{|c|c|c|}
\hline Subject Questionnaire Results & Statistical Measure & Lpk (dB) \\
\hline \multirow{3}{*}{ Loudness to noise } & $\mathrm{F}_{1,134}$ & $87.69 * *$ \\
\hline & $\begin{array}{l}\text { Pearson Correlation Coefficient } \\
\text { ( } \mathrm{r} \text { ) }\end{array}$ & $.630 * *$ \\
\hline & $\begin{array}{l}\text { Spearman Correlation } \\
\text { Coefficient }(\mathrm{r})\end{array}$ & $.594 * *$ \\
\hline \multirow{3}{*}{ Change in noise over time } & $\mathrm{F}_{1,134}$ & $31.42 * *$ \\
\hline & $\begin{array}{l}\text { Pearson Correlation Coefficient } \\
\text { ( } \mathrm{r} \text { ) }\end{array}$ & $.437 * *$ \\
\hline & $\begin{array}{l}\text { Spearman Correlation } \\
\text { Coefficient }(r)\end{array}$ & $.429 * *$ \\
\hline \multirow{3}{*}{ Rumble of noise } & $\mathrm{F}_{1,134}$ & $42.85 * *$ \\
\hline & $\begin{array}{l}\text { Pearson Correlation Coefficient } \\
\text { ( r ) }\end{array}$ & $.494 * *$ \\
\hline & $\begin{array}{c}\text { Spearman Correlation } \\
\text { Coefficient }(\mathrm{r})\end{array}$ & $.481 * *$ \\
\hline \multirow{3}{*}{ Annoyance to noise } & $\mathrm{F}_{1,134}$ & $98.78 * *$ \\
\hline & $\begin{array}{l}\text { Pearson Correlation Coefficient } \\
\text { ( } \mathrm{r} \text { ) }\end{array}$ & $.653 * *$ \\
\hline & $\begin{array}{l}\text { Spearman Correlation } \\
\text { Coefficient }(r)\end{array}$ & $.616^{* *}$ \\
\hline \multirow{3}{*}{ Distraction to noise } & $\mathrm{F}_{1,134}$ & $111.61 * *$ \\
\hline & $\begin{array}{l}\text { Pearson Correlation Coefficient } \\
\text { ( } \mathrm{r} \text { ) }\end{array}$ & $.675^{* *}$ \\
\hline & $\begin{array}{l}\text { Spearman Correlation } \\
\text { Coefficient }(r)\end{array}$ & $.672 * *$ \\
\hline
\end{tabular}


Table A.4.

Results of Pearson Product Correlation Coefficient, Spearman Coefficient, and a linear mixed model analysis for relations of subjective perception ratings to equivalent-continuous sound level $\left(\mathrm{L}_{\mathrm{eq}}\right)$. All results denoted with $* *$ are significant at $\mathrm{p}<0.01$.

\begin{tabular}{|c|c|c|c|c|c|c|c|}
\hline \multirow{2}{*}{ Subject Questionnaire Results } & \multirow{2}{*}{ Statistical Measure } & \multicolumn{6}{|c|}{ Leq $(\mathrm{dB})$} \\
\hline & & $2 \min$ & $1 \mathrm{~min}$ & $30 \mathrm{sec}$ & $10 \mathrm{sec}$ & $5 \mathrm{sec}$ & $1 \mathrm{sec}$ \\
\hline \multirow{3}{*}{ Loudness to noise } & $\mathrm{F}_{1,134}$ & $85.30 * *$ & $88.16^{* *}$ & $90.18 * *$ & $91.36 * *$ & $90.88 * *$ & $87.45 * *$ \\
\hline & $\begin{array}{l}\text { Pearson Correlation Coefficient } \\
(\mathrm{r})\end{array}$ & $.625^{* *}$ & $.631 * *$ & $.636 * *$ & $.638 * *$ & $.637 * *$ & $.630 * *$ \\
\hline & $\begin{array}{l}\text { Spearman Correlation } \\
\text { Coefficient }(r)\end{array}$ & $.594 * *$ & $.594 * *$ & $.594 * *$ & $.594 * *$ & $.594 * *$ & $.594 * *$ \\
\hline \multirow{3}{*}{ Change in noise over time } & $\mathrm{F}_{1,134}$ & $20.27 * *$ & $22.14 * *$ & $24.04 * *$ & $26.86 * *$ & $28.41 * *$ & $31.47 * *$ \\
\hline & $\begin{array}{l}\text { Pearson Correlation Coefficient } \\
(\mathrm{r})\end{array}$ & $.364 * *$ & $.378 * *$ & $.391 * *$ & $.410 * *$ & $.420 * *$ & $.437 * *$ \\
\hline & $\begin{array}{c}\text { Spearman Correlation } \\
\text { Coefficient }(r)\end{array}$ & $.429 * *$ & $.429 * *$ & $.429 * *$ & $.429 * *$ & $.429 * *$ & $.429 * *$ \\
\hline \multirow{3}{*}{ Rumble of noise } & $\mathrm{F}_{1,134}$ & $38.13 * *$ & $39.65 * *$ & $41.02 * *$ & $42.62 * *$ & $43.08 * *$ & $42.72 * *$ \\
\hline & $\begin{array}{l}\text { Pearson Correlation Coefficient } \\
(\mathrm{r})\end{array}$ & $.472 * *$ & $.479 * *$ & $.485 * *$ & $.493 * *$ & $.495 * *$ & $.493 * *$ \\
\hline & $\begin{array}{c}\text { Spearman Correlation } \\
\text { Coefficient }(r) \\
\end{array}$ & $.481 * *$ & $.481 * *$ & $.481 * *$ & $.481 * *$ & $.481 * *$ & $.481 * *$ \\
\hline \multirow{3}{*}{ Annoyance to noise } & $\mathrm{F}_{1,134}$ & $104.83 * *$ & $106.79 * *$ & $107.53 * *$ & $106.29 * *$ & $104.35 * *$ & $98.35 * *$ \\
\hline & $\begin{array}{l}\text { Pearson Correlation Coefficient } \\
(\mathrm{r})\end{array}$ & $.664 * *$ & $.667 * *$ & $.669 * *$ & $.666^{* *}$ & $.663 * *$ & $.652 * *$ \\
\hline & $\begin{array}{l}\text { Spearman Correlation } \\
\text { Coefficient }(r)\end{array}$ & $.616^{* *}$ & $.616^{* *}$ & $.616^{* *}$ & $.616^{* *}$ & $.616^{* *}$ & $.616^{* *}$ \\
\hline \multirow{3}{*}{ Distraction to noise } & $\mathrm{F}_{1,134}$ & $98.72 * *$ & $103.30 * *$ & $107.18 * *$ & $111.20 * *$ & $112.18 * *$ & $111.22 * *$ \\
\hline & $\begin{array}{l}\text { Pearson Correlation Coefficient } \\
(\mathrm{r})\end{array}$ & $.653 * *$ & $.661 * *$ & $.668 * *$ & $.675^{* *}$ & $.676^{* *}$ & $.675 * *$ \\
\hline & $\begin{array}{l}\text { Spearman Correlation } \\
\text { Coefficient }(\mathrm{r})\end{array}$ & $.672 * *$ & $.672 * *$ & $.672 * *$ & $.672 * *$ & $.672 * *$ & $.672 * *$ \\
\hline
\end{tabular}




\section{Table A.5.}

Results of Pearson Product Correlation Coefficient, Spearman Coefficient, and a linear mixed model analysis for relations of subjective perception ratings to $\mathrm{L}_{1}-\mathrm{L}_{99}$. All results denoted with $* *$ are significant at $\mathrm{p}<0.01$.

\begin{tabular}{|c|c|c|c|c|c|c|c|}
\hline \multirow{2}{*}{ Subject Questionnaire Results } & \multirow{2}{*}{ Statistical Measure } & \multicolumn{6}{|c|}{ L1-L99 (dB) } \\
\hline & & $2 \mathrm{~min}$ & $1 \mathrm{~min}$ & $30 \mathrm{sec}$ & $10 \mathrm{sec}$ & $5 \mathrm{sec}$ & $1 \mathrm{sec}$ \\
\hline \multirow{3}{*}{ Loudness to noise } & $\mathrm{F}_{1,134}$ & $85.46 * *$ & $88.19 * *$ & $88.76^{* *}$ & $86.09 * *$ & $86.32 * *$ & $58.70 * *$ \\
\hline & $\begin{array}{c}\text { Pearson Correlation Coefficient } \\
(\mathrm{r})\end{array}$ & $.625 * *$ & $.631 * *$ & $.633 * *$ & $.627 * *$ & $.627 * *$ & $.553 * *$ \\
\hline & $\begin{array}{c}\text { Spearman Correlation } \\
\text { Coefficient }(r)\end{array}$ & $.594 * *$ & $.594 * *$ & $.594 * *$ & $.594 * *$ & $.594 * *$ & $.594 * *$ \\
\hline \multirow{3}{*}{ Change in noise over time } & $\mathrm{F}_{1,134}$ & $21.73 * *$ & $29.13 * *$ & $30.54 * *$ & $32.17 * *$ & $32.08 * *$ & $34.36 * *$ \\
\hline & $\begin{array}{l}\text { Pearson Correlation Coefficient } \\
(\mathrm{r})\end{array}$ & $.375^{* *}$ & $.424 * *$ & $.432 * *$ & $.441 * *$ & $.441 * *$ & $.453 * *$ \\
\hline & $\begin{array}{c}\text { Spearman Correlation } \\
\text { Coefficient }(r)\end{array}$ & $.429 * *$ & $.429 * *$ & $.429 * *$ & $.429 * *$ & $.429 * *$ & $.429 * *$ \\
\hline \multirow{3}{*}{ Rumble of noise } & $\mathrm{F}_{1,134}$ & $37.68 * *$ & $41.79 * *$ & $43.18 * *$ & $42.33 * *$ & $42.42 * *$ & $34.31 * *$ \\
\hline & $\begin{array}{c}\text { Pearson Correlation Coefficient } \\
(\mathrm{r})\end{array}$ & $.470 * *$ & $.489 * *$ & $.495 * *$ & $.491 * *$ & $.492 * *$ & $.453 * *$ \\
\hline & $\begin{array}{c}\text { Spearman Correlation } \\
\text { Coefficient }(r) \\
\end{array}$ & $.481 * *$ & $.481 * *$ & $.481 * *$ & $.481 * *$ & $.481 * *$ & $.481 * *$ \\
\hline \multirow{3}{*}{ Annoyance to noise } & $\mathrm{F}_{1,134}$ & $104.17 * *$ & $100.20 * *$ & $100.08 * *$ & $96.46 * *$ & $97.46 * *$ & $59.95^{* *}$ \\
\hline & $\begin{array}{c}\text { Pearson Correlation Coefficient } \\
(\mathrm{r}) \\
\end{array}$ & $.663 * *$ & $.655^{* *}$ & $.655 * *$ & $.648 * *$ & $.650 * *$ & $.557 * *$ \\
\hline & $\begin{array}{c}\text { Spearman Correlation } \\
\text { Coefficient }(\mathrm{r}) \\
\end{array}$ & $.616^{* *}$ & $.616^{* *}$ & $.616^{* *}$ & $.616^{* *}$ & $.616^{* *}$ & $.616^{* *}$ \\
\hline \multirow{3}{*}{ Distraction to noise } & $\mathrm{F}_{1,134}$ & $99.34 * *$ & $108.87 * *$ & $111.87 * *$ & $110.29 * *$ & $111.09 * *$ & $79.50 * *$ \\
\hline & $\begin{array}{c}\text { Pearson Correlation Coefficient } \\
(\mathrm{r})\end{array}$ & $.654 * *$ & $.671 * *$ & $.676 * *$ & $.673 * *$ & $.675^{* *}$ & $.612 * *$ \\
\hline & $\begin{array}{l}\text { Spearman Correlation } \\
\text { Coefficient }(r)\end{array}$ & $.672 * *$ & $.672 * *$ & $.672 * *$ & $.672 * *$ & $.672 * *$ & $.672 * *$ \\
\hline
\end{tabular}


Table A.6.

Results of Pearson Product Correlation Coefficient, Spearman Coefficient, and a linear mixed model analysis for relations of subjective perception ratings to A-weighted sound exposure level (ASEL). All results denoted with $* *$ are significant at $\mathrm{p}<0.01$.

\begin{tabular}{|c|c|c|c|c|c|c|c|}
\hline \multirow{2}{*}{ Subject Questionnaire Results } & \multirow{2}{*}{ Statistical Measure } & \multicolumn{6}{|c|}{ ASEL (dB) } \\
\hline & & $2 \min$ & $1 \mathrm{~min}$ & $30 \mathrm{sec}$ & $10 \mathrm{sec}$ & $5 \mathrm{sec}$ & $1 \mathrm{sec}$ \\
\hline \multirow{3}{*}{ Loudness to noise } & $\mathrm{F}_{1,134}$ & $85.67 * *$ & $87.62 * *$ & $88.86 * *$ & $89.31 * *$ & $88.57 * *$ & $84.12 * *$ \\
\hline & $\begin{array}{l}\text { Pearson Correlation Coefficient } \\
\text { ( } \mathrm{r} \text { ) }\end{array}$ & $.626 * *$ & $.630 * *$ & $.633 * *$ & $.634 * *$ & $.632 * *$ & $.622 * *$ \\
\hline & $\begin{array}{c}\text { Spearman Correlation } \\
\text { Coefficient }(\mathrm{r})\end{array}$ & $.594 * *$ & $.594 * *$ & $.594 * *$ & $.594 * *$ & $.594 * *$ & $.594 * *$ \\
\hline \multirow{3}{*}{ Change in noise over time } & $\mathrm{F}_{1,134}$ & $20.84 * *$ & $22.63 * *$ & $24.40 * *$ & $27.16^{* *}$ & $28.63 * *$ & $32.15^{* *}$ \\
\hline & $\begin{array}{l}\text { Pearson Correlation Coefficient } \\
\qquad(\mathrm{r})\end{array}$ & $.368 * *$ & $.381 * *$ & $.394 * *$ & $.412 * *$ & $.421 * *$ & $.441 * *$ \\
\hline & $\begin{array}{c}\text { Spearman Correlation } \\
\text { Coefficient }(r)\end{array}$ & $.429 * *$ & $.429 * *$ & $.429 * *$ & $.429 * *$ & $.429 * *$ & $.429 * *$ \\
\hline \multirow{3}{*}{ Rumble of noise } & $\mathrm{F}_{1,134}$ & $38.06 * *$ & $39.16^{* *}$ & $40.22 * *$ & $41.63 * *$ & $42.10 * *$ & $41.69 * *$ \\
\hline & $\begin{array}{l}\text { Pearson Correlation Coefficient } \\
(\mathrm{r})\end{array}$ & $.472 * *$ & $.477 * *$ & $.482 * *$ & $.488 * *$ & $.490 * *$ & $.488 * *$ \\
\hline & $\begin{array}{l}\text { Spearman Correlation } \\
\text { Coefficient }(\mathrm{r})\end{array}$ & $.481 * *$ & $.481 * *$ & $.481 * *$ & $.481 * *$ & $.481 * *$ & $.481 * *$ \\
\hline \multirow{3}{*}{ Annoyance to noise } & $\mathrm{F}_{1,134}$ & $104.79 * *$ & $105.54 * *$ & $105.22 * *$ & $102.88 * *$ & $100.51 * *$ & $92.96 * *$ \\
\hline & $\begin{array}{l}\text { Pearson Correlation Coefficient } \\
\text { ( } \mathrm{r})\end{array}$ & $.664 * *$ & $.665 * *$ & $.665 * *$ & $.660 * *$ & $.656 * *$ & $.641 * *$ \\
\hline & $\begin{array}{c}\text { Spearman Correlation } \\
\text { Coefficient }(\mathrm{r})\end{array}$ & $.616^{* *}$ & $.616^{* *}$ & $.616^{* *}$ & $.616^{* *}$ & $.616^{* *}$ & $.616^{* *}$ \\
\hline \multirow{3}{*}{ Distraction to noise } & $\mathrm{F}_{1,134}$ & $99.16^{* *}$ & $102.53 * *$ & $105.32 * *$ & $108.31 * *$ & $108.89 * *$ & $107.17 * *$ \\
\hline & $\begin{array}{l}\text { Pearson Correlation Coefficient } \\
\text { ( } \mathrm{r})\end{array}$ & $.654 * *$ & $.660 * *$ & $.665 * *$ & $.670 * *$ & $.671 * *$ & $.668 * *$ \\
\hline & $\begin{array}{c}\text { Spearman Correlation } \\
\text { Coefficient }(\mathrm{r})\end{array}$ & $.672 * *$ & $.672 * *$ & $.672 * *$ & $.672 * *$ & $.672 * *$ & $.672 * *$ \\
\hline
\end{tabular}




\section{Table A.7.}

Results of Pearson Product Correlation Coefficient, Spearman Coefficient, and a linear mixed model analysis for relations of subjective perception ratings to $\mathrm{C}$-weighted sound exposure level (CSEL). All results denoted with $* *$ are significant at $\mathrm{p}<0.01$.

\begin{tabular}{|c|c|c|c|c|c|c|c|}
\hline \multirow{2}{*}{ Subject Questionnaire Results } & \multirow{2}{*}{ Statistical Measure } & \multicolumn{6}{|c|}{ CSEL (dB) } \\
\hline & & $2 \mathrm{~min}$ & $1 \mathrm{~min}$ & $30 \mathrm{sec}$ & $10 \mathrm{sec}$ & $5 \mathrm{sec}$ & $1 \mathrm{sec}$ \\
\hline \multirow{3}{*}{ Loudness to noise } & $\mathrm{F}_{1,134}$ & $81.69 * *$ & $85.03 * *$ & $87.66^{* *}$ & $90.39 * *$ & $90.86 * *$ & $89.56 * *$ \\
\hline & $\begin{array}{l}\text { Pearson Correlation Coefficient } \\
(\mathrm{r})\end{array}$ & $.617 * *$ & $.624 * *$ & $.630 * *$ & $.636^{* *}$ & $.637 * *$ & $.634 * *$ \\
\hline & $\begin{array}{c}\text { Spearman Correlation } \\
\text { Coefficient }(\mathrm{r}) \\
\end{array}$ & $.594 * *$ & $.594 * *$ & $.594 * *$ & $.594 * *$ & $.594 * *$ & $.594 * *$ \\
\hline \multirow{3}{*}{ Change in noise over time } & $\mathrm{F}_{1,134}$ & $18.41 * *$ & $20.25 * *$ & $22.14 * *$ & $24.93 * *$ & $26.48 * *$ & $29.64 * *$ \\
\hline & $\begin{array}{l}\text { Pearson Correlation Coefficient } \\
(\mathrm{r})\end{array}$ & $.349 * *$ & $.363 * *$ & $.378 * *$ & $.397 * *$ & $.407 * *$ & $.427 * *$ \\
\hline & $\begin{array}{c}\text { Spearman Correlation } \\
\text { Coefficient }(\mathrm{r}) \\
\end{array}$ & $.429 * *$ & $.429 * *$ & $.429 * *$ & $.429 * *$ & $.429 * *$ & $.429 * *$ \\
\hline \multirow{3}{*}{ Rumble of noise } & $\mathrm{F}_{1,134}$ & $36.48 * *$ & $37.89 * *$ & $39.21 * *$ & $41.24 * *$ & $41.96 * *$ & $43.01 * *$ \\
\hline & $\begin{array}{l}\text { Pearson Correlation Coefficient } \\
(\mathrm{r})\end{array}$ & $.464 * *$ & $.471 * *$ & $.477 * *$ & $.486 * *$ & $.490 * *$ & $.494 * *$ \\
\hline & $\begin{array}{c}\text { Spearman Correlation } \\
\text { Coefficient }(r) \\
\end{array}$ & $.481^{* *}$ & $.481 * *$ & $.481 * *$ & $.481 * *$ & $.481 * *$ & $.481 * *$ \\
\hline \multirow{3}{*}{ Annoyance to noise } & $\mathrm{F}_{1,134}$ & $101.62 * *$ & $104.59 * *$ & $106.38 * *$ & $107.02 * *$ & $106.25 * *$ & $101.63 * *$ \\
\hline & $\begin{array}{l}\text { Pearson Correlation Coefficient } \\
(\mathrm{r})\end{array}$ & $.658 * *$ & $.663 * *$ & $.667 * *$ & $.668 * *$ & $.666^{* *}$ & $.658 * *$ \\
\hline & $\begin{array}{c}\text { Spearman Correlation } \\
\text { Coefficient }(\mathrm{r}) \\
\end{array}$ & $.616^{* *}$ & $.616 * *$ & $.616 * *$ & $.616^{* *}$ & $.616 * *$ & $.616 * *$ \\
\hline \multirow{3}{*}{ Distraction to noise } & $\mathrm{F}_{1,134}$ & $93.43 * *$ & $98.31 * *$ & $102.62 * *$ & $108.06 * *$ & $110.04 * *$ & $111.69 * *$ \\
\hline & $\begin{array}{l}\text { Pearson Correlation Coefficient } \\
\qquad(\mathrm{r})\end{array}$ & $.642 * *$ & $.652 * *$ & $.660 * *$ & $.670 * *$ & $.673 * *$ & $.676^{* *}$ \\
\hline & $\begin{array}{c}\text { Spearman Correlation } \\
\text { Coefficient }(\mathrm{r})\end{array}$ & $.672 * *$ & $.672 * *$ & $.672 * *$ & $.672 * *$ & $.672 * *$ & $.672 * *$ \\
\hline
\end{tabular}




\section{Table A.8.}

Results of Pearson Product Correlation Coefficient, Spearman Coefficient, and a linear mixed model analysis for relations of subjective perception ratings to perceived level (PL). All results denoted with $* *$ are significant at $\mathrm{p}<0.01$.

\begin{tabular}{|c|c|c|c|c|c|c|c|}
\hline \multirow{2}{*}{ Subject Questionnaire Results } & \multirow{2}{*}{ Statistical Measure } & \multicolumn{6}{|c|}{$\mathrm{PL}(\mathrm{dB})$} \\
\hline & & $2 \mathrm{~min}$ & $1 \mathrm{~min}$ & $30 \mathrm{sec}$ & $10 \mathrm{sec}$ & $5 \mathrm{sec}$ & $1 \mathrm{sec}$ \\
\hline \multirow{3}{*}{ Loudness to noise } & $\mathrm{F}_{1,134}$ & $85.03 * *$ & $86.63 * *$ & $88.31 * *$ & $89.32 * *$ & $88.29 * *$ & $79.43 * *$ \\
\hline & $\begin{array}{c}\text { Pearson Correlation Coefficient } \\
(\mathrm{r})\end{array}$ & $.628 * *$ & $.632 * *$ & $.635 * *$ & $.634 * *$ & $.630 * *$ & $.608 * *$ \\
\hline & $\begin{array}{c}\text { Spearman Correlation } \\
\text { Coefficient }(\mathrm{r})\end{array}$ & $.594 * *$ & $.594 * *$ & $.594 * *$ & $.594 * *$ & $.594 * *$ & $.594 * *$ \\
\hline \multirow{3}{*}{ Change in noise over time } & $\mathrm{F}_{1,134}$ & $20.41 * *$ & $21.46 * *$ & $22.60 * *$ & $26.35 * *$ & $28.51 * *$ & $33.71 * *$ \\
\hline & $\begin{array}{l}\text { Pearson Correlation Coefficient } \\
(\mathrm{r})\end{array}$ & $.372 * *$ & $.385^{* *}$ & $.398 * *$ & $.418^{* *}$ & $.428 * *$ & $.452 * *$ \\
\hline & $\begin{array}{c}\text { Spearman Correlation } \\
\text { Coefficient }(\mathrm{r})\end{array}$ & $.429 * *$ & $.429 * *$ & $.429 * *$ & $.429 * *$ & $.429 * *$ & $.429 * *$ \\
\hline \multirow{3}{*}{ Rumble of noise } & $\mathrm{F}_{1,134}$ & $38.01 * *$ & $38.74 * *$ & $39.64 * *$ & $40.79 * *$ & $41.77 * *$ & $40.46^{* *}$ \\
\hline & $\begin{array}{c}\text { Pearson Correlation Coefficient } \\
(\mathrm{r})\end{array}$ & $.474 * *$ & $.480 * *$ & $.485^{* *}$ & $.491 * *$ & $.492 * *$ & $.481 * *$ \\
\hline & $\begin{array}{c}\text { Spearman Correlation } \\
\text { Coefficient }(r) \\
\end{array}$ & $.481 * *$ & $.481 * *$ & $.481 * *$ & $.481 * *$ & $.481 * *$ & $.481 * *$ \\
\hline \multirow{3}{*}{ Annoyance to noise } & $\mathrm{F}_{1,134}$ & $104.80 * *$ & $106.07 * *$ & $107.05 * *$ & $104.63 * *$ & $100.38 * *$ & $86.41 * *$ \\
\hline & $\begin{array}{c}\text { Pearson Correlation Coefficient } \\
(\mathrm{r})\end{array}$ & $.665^{* *}$ & $.666 * *$ & $.665 * *$ & $.659 * *$ & $.652 * *$ & $.623 * *$ \\
\hline & $\begin{array}{c}\text { Spearman Correlation } \\
\text { Coefficient }(\mathrm{r}) \\
\end{array}$ & $.616^{* *}$ & $.616^{* *}$ & $.616^{* *}$ & $.616^{* *}$ & $.616^{* *}$ & $.616 * *$ \\
\hline \multirow{3}{*}{ Distraction to noise } & $\mathrm{F}_{1,134}$ & $98.80 * *$ & $101.33 * *$ & $103.97 * *$ & $107.64 * *$ & $108.32 * *$ & $103.01 * *$ \\
\hline & $\begin{array}{c}\text { Pearson Correlation Coefficient } \\
(\mathrm{r})\end{array}$ & $.656^{* *}$ & $.663 * *$ & $.668 * *$ & $.672 * *$ & $.671 * *$ & $.658 * *$ \\
\hline & $\begin{array}{c}\text { Spearman Correlation } \\
\text { Coefficient }(\mathrm{r})\end{array}$ & $.672 * *$ & $.672 * *$ & $.672 * *$ & $.672 * *$ & $.672 * *$ & $.672 * *$ \\
\hline
\end{tabular}


Table A.9.

Results of Pearson Product Correlation Coefficient, Spearman Coefficient, and a linear mixed model analysis for relations of subjective perception ratings to perceived noise level (PNL). All results denoted with $* *$ are significant at $\mathrm{p}<0.01$.

\begin{tabular}{|c|c|c|c|c|c|c|c|}
\hline \multirow{2}{*}{ Subject Questionnaire Results } & \multirow{2}{*}{ Statistical Measure } & \multicolumn{6}{|c|}{ PNL (dB) } \\
\hline & & $2 \mathrm{~min}$ & $1 \mathrm{~min}$ & $30 \mathrm{sec}$ & $10 \mathrm{sec}$ & $5 \mathrm{sec}$ & $1 \mathrm{sec}$ \\
\hline \multirow{3}{*}{ Loudness to noise } & $\mathrm{F}_{1,134}$ & $85.79 * *$ & $87.01 * *$ & $88.21 * *$ & $90.41^{* *}$ & $90.57 * *$ & $85.69^{* * *}$ \\
\hline & $\begin{array}{l}\text { Pearson Correlation Coefficient } \\
\qquad(\mathrm{r})\end{array}$ & $.623 * *$ & $.629 * *$ & $.634 * *$ & $.637 * *$ & $.637 * *$ & $.625 * *$ \\
\hline & $\begin{array}{c}\text { Spearman Correlation } \\
\text { Coefficient }(\mathrm{r})\end{array}$ & $.594 * *$ & $.594 * *$ & $.594 * *$ & $.594 * *$ & $.594 * *$ & $.594 * *$ \\
\hline \multirow{3}{*}{ Change in noise over time } & $\mathrm{F}_{1,134}$ & $20.90 * *$ & $21.66^{* *}$ & $22.47 * *$ & $25.65^{* *}$ & $26.83 * *$ & $32.01 * *$ \\
\hline & $\begin{array}{l}\text { Pearson Correlation Coefficient } \\
\text { ( } \mathrm{r} \text { ) }\end{array}$ & $.359 * *$ & $.373 * *$ & $.387 * *$ & $.408 * *$ & $.418 * *$ & $.443 * *$ \\
\hline & $\begin{array}{l}\text { Spearman Correlation } \\
\text { Coefficient }(\mathrm{r})\end{array}$ & $.429 * *$ & $.429 * *$ & $.429 * *$ & $.429 * *$ & $.429 * *$ & $.429 * *$ \\
\hline \multirow{3}{*}{ Rumble of noise } & $\mathrm{F}_{1,134}$ & $38.54 * *$ & $38.96^{* *}$ & $39.61 * *$ & $41.29^{* *}$ & $42.04 * *$ & $42.03 * *$ \\
\hline & $\begin{array}{l}\text { Pearson Correlation Coefficient } \\
\text { ( } \mathrm{r} \text { ) }\end{array}$ & $.470 * *$ & $.477 * *$ & $.482 * *$ & $.491 * *$ & $.494 * *$ & $.491 * *$ \\
\hline & $\begin{array}{c}\text { Spearman Correlation } \\
\text { Coefficient }(\mathrm{r}) \\
\end{array}$ & $.481 * *$ & $.481 * *$ & $.481 * *$ & $.481 * *$ & $.481 * *$ & $.481 * *$ \\
\hline \multirow{3}{*}{ Annoyance to noise } & $\mathrm{F}_{1,134}$ & $105.50^{* *}$ & $106.34 * *$ & $107.05^{* *}$ & $106.69^{* *}$ & $105.26 * *$ & $95.64 * *$ \\
\hline & $\begin{array}{l}\text { Pearson Correlation Coefficient } \\
\text { ( } \mathrm{r} \text { ) }\end{array}$ & $.662 * *$ & $.666^{* *}$ & $.668 * *$ & $.666^{* *}$ & $.662 * *$ & $.645^{* *}$ \\
\hline & $\begin{array}{l}\text { Spearman Correlation } \\
\text { Coefficient }(\mathrm{r}) \\
\end{array}$ & $.616^{* *}$ & $.616^{* *}$ & $.616^{* *}$ & $.616^{* *}$ & $.616^{* *}$ & $.616 * *$ \\
\hline \multirow{3}{*}{ Distraction to noise } & $\mathrm{F}_{1,134}$ & $100.29 * *$ & $101.91 * *$ & $103.81 * *$ & $108.70^{* *}$ & $109.88 * *$ & $109.19 * *$ \\
\hline & $\begin{array}{l}\text { Pearson Correlation Coefficient } \\
\text { ( } \mathrm{r} \text { ) }\end{array}$ & $.650 * *$ & $.658 * *$ & $.665 * *$ & $.674 * *$ & $.675 * *$ & $.671 * *$ \\
\hline & $\begin{array}{l}\text { Spearman Correlation } \\
\text { Coefficient }(r)\end{array}$ & $.672 * *$ & $.672 * *$ & $.672 * *$ & $.672 * *$ & $.672 * *$ & $.672 * *$ \\
\hline
\end{tabular}

